\title{
Optimization of a brushless permanent magnet linear alternator for use with a linear internal combustion engine
}

\author{
William Robert Cawthorne \\ West Virginia University
}

Follow this and additional works at: https://researchrepository.wvu.edu/etd

\section{Recommended Citation}

Cawthorne, William Robert, "Optimization of a brushless permanent magnet linear alternator for use with a linear internal combustion engine" (1999). Graduate Theses, Dissertations, and Problem Reports. 3160. https://researchrepository.wvu.edu/etd/3160

This Dissertation is protected by copyright and/or related rights. It has been brought to you by the The Research Repository @ WVU with permission from the rights-holder(s). You are free to use this Dissertation in any way that is permitted by the copyright and related rights legislation that applies to your use. For other uses you must obtain permission from the rights-holder(s) directly, unless additional rights are indicated by a Creative Commons license in the record and/ or on the work itself. This Dissertation has been accepted for inclusion in WVU Graduate Theses, Dissertations, and Problem Reports collection by an authorized administrator of The Research Repository @ WVU.

For more information, please contact researchrepository@mail.wvu.edu. 


\title{
Optimization of a Brushless Permanent Magnet Linear Alternator for Use With a Linear Internal Combustion Engine
}

\section{William R. Cawthorne}

\author{
Dissertation submitted to the \\ College of Engineering and Mineral Resources \\ at West Virginia University \\ in partial fulfillment of the degree of \\ Doctor of Philosophy \\ in \\ Electrical Engineering
}

Academic and Examining Committee Members:

Dr. Parviz Famouri, Chair

Dr. Muhammad Choudhry

Dr. Nigel Clark

Dr. Ronald Klein

Dr. Roy Nutter

Department of Computer Science and Electrical Engineering

Morgantown, West Virginia

1999

Keywords: Brushless Permanent Magnet Linear Alternator, Linear Internal Combustion Engine, Design, Optimization 


\section{Table of Contents}

Title Page

Table of Contents

Abstract

Dedication

Acknowledgments

i

ii

iv

$\mathrm{V}$

vi

$\begin{array}{lll}\text { Chapter } 1 & \text { Introduction } & 1\end{array}$

$1.1 \quad$ Literature Review 3

1.2 Problem with the Current Design 6

1.3 Statement of Proposed Research 7

1.4 Contribution 9

$\begin{array}{lll}\text { Chapter } 2 \text { Engine Modeling } & 10\end{array}$

$\begin{array}{lll}2.1 & \text { Engine Model } & 10\end{array}$

2.1.1 Development of Engine Model 13

2.1.2 Special Case Engine Model 23

Chapter 3 Alternator Modeling 25

3.1 Tubular Brushless Permanent Magnet Linear Alternator 26

3.2 Magnetic Model of the Linear Alternator 27

3.2.1 Finite Element Model 28

3.2.2 ANSYS Program Structure $\quad 31$

3.2.3 MATLAB Routine to Generate ANSYS Program 37

3.3 Electrical Model of the Linear Alternator 38

Chapter 4 Simulation 41

4.1 Linear Engine Simulation 41

4.2 Brushless Permanent Magnet Linear Alternator Simulation 44

$\begin{array}{lll}4.3 & \text { Model Validation } & 48\end{array}$

Chapter 5 Optimization $\quad 52$

5.1 Overview of MATLAB Constrained Optimization Routine 53

5.2 Linear Alternator and Engine Optimization Function 57 and Bound Selection

5.2.1 Optimization Function $\quad 58$

5.2.2 Limit Selection $\quad 65$

5.3 Optimization Results $\quad 66$ 
Chapter 6 Conclusion

6.1 Model Development and Simulation 71

$\begin{array}{ll}6.2 \text { Optimization } & 73\end{array}$

$\begin{array}{lll}6.3 & \text { Future Work } & 73\end{array}$

$\begin{array}{ll}\text { References } & 76\end{array}$

$\begin{array}{llr}\text { Appendix A } & \text { Program Code } & 80\end{array}$

$\begin{array}{ll}\text { Vita } & 110\end{array}$

Approval of Examining Committee 113 


\title{
ABSTRACT
}

\section{Optimization of a Brushless Permanent Magnet Linear Alternator for Use With a Linear Internal Combustion Engine}

\author{
William R. Cawthorne
}

Numerous applications require the generation of electric power without connection to the utility power system. Many industrial, commercial, and personal applications require uninterrupted electrical power in the event of a utility failure. Additionally, the nature of military field operations necessitates the ability to generate electricity in areas where connection to the utility is impractical or impossible. Generation units selected for these applications must be reliable, efficient, compact, and lightweight.

Presently, rotary internal combustion engines coupled with rotary alternators are the primary generation unit used in these applications. This research contends that a tubular brushless permanent magnet linear alternator with a linear internal combustion engine offers advantages over the traditionally used rotary system. The linear system directly utilizes the combustion force and eliminates the need for a crankshaft, which reduces the volume. Additionally, since the linear system consists of only one moving part, the reliability is increased, and the frictional losses are reduced.

Previous research at West Virginia University has demonstrated the stable operation of a linear alternator and linear internal combustion engine system. However, the design of this prototype alternator and engine was not coupled, and the interactions of the engine and the alternator were not considered.

This research will provide a design approach for the alternator which accounts for the characteristics of the engine used as the prime mover and the interactions between the engine and the alternator. First, models of the engine and the alternator will be developed. These models will then be integrated to represent the overall system. Next, the models will be simulated, and the results compared to experimental data taken from the prototype system. The validated models will be used in an optimization routine to maximize the efficiency and minimize the volume of the alternator. The results of the optimization will provide the design parameters for the alternator which best satisfies the objective of maximum efficiency and minimum volume. Finally, these optimization results will be discussed and explanations will be given. 


\section{DEDICATION}

\section{TO: $\quad$ WILLIAM PAUL CAWTHORNE}

I would like to dedicate this dissertation to my father William Paul Cawthorne who taught me all about life and to my son William Paul Cawthorne for whom I hope to do the same.

My father told me very early in my life that I could "do anything I put my mind to." This document, representing the completion of my Doctor of Philosophy degree, demonstrates that he was correct. He taught me the value of a good education and instilled in me the values that make me the person I am today. I only hope that I can be as good of a father to my children as he was to my sister and me. This one's for you Dad.

By coming into this world when he did, my son provided the final inspiration that resulted in the completion of this dissertation. Thank you, Billy, for giving me the push I needed to finish my research and write this document. 


\section{ACKNOWLEDGEMENTS}

I would first like to thank my wife Jennifer for her love and support throughout all of my graduate education. Simple word cannot express how important it has been to me to have her by my side during the time I was completing my degrees. I would also like to thank her for the hours spent proofreading and correcting my many mistakes.

My parents, Jackie and the late William Cawthorne, also deserve more thanks than I can give. They were my first teachers and instilled in me the importance of education. Mom and Dad, I am forever indebted to you for all that you have done for me throughout my life.

I must also thank my sister Yvonne. It is the job of an older brother to try to set a good example for his sister. However, my sister has always done so well in everything that she forced me to work harder and harder to set that good example. Thanks, Yvonne, for keeping me at my best.

I would also like to acknowledge Dr. Muhammad Choudhry, Dr. Nigel Clark, Dr. Parviz Famouri, Dr. Ronald Klein, and Dr. Roy Nutter for serving on my committee and providing me with valuable suggestions to improve this work. I would especially like to thank Dr. Famouri for serving as my advisor during my graduate education and for providing the facilities for conducting this research. I would also like to thank the Department of Defense for providing the grant which funded this research. 
CHAPTER
ONE

\section{INTRODUCTION}

The dependence on a continuous supply of electric power in industrial, commercial, military, and personal applications requires the ability to maintain electric service in the event of a failure on the utility grid and the ability to generate electricity for areas or applications where utility service is not available. Standby or emergency generators are often used as backup power supplies for buildings, industrial facilities, and power plants in the event of a loss of utility power from a utility failure or an emergency [1]-[2]. Generation sets are also used in applications in which connection to the utility grid is not possible, such as hybrid electric vehicles (HEV), or in remote locations where utility service is not available, such as military field exercises.

In emergency situations, the backup power generation systems can be used to provide necessary lighting for evacuation, to power communication systems, and to power elevators for use either by firefighters or in non-fire related emergencies [3]. In hospitals and other health care facilities, the continuous supply of electrical power is critical for maintaining the health of patients, such as those on life support systems or those in surgery where a loss of power could prove life threatening. In addition, many patients in a health care facility may not be able to evacuate themselves in the 
event of an emergency, thereby increasing the importance of backup power for lighting and for elevator function for those who cannot negotiate stairs [3].

Standby generation capabilities utilized in the event of a disruption in the utility service can allow businesses to remain operational. In fact, in many businesses and industries, the use of standby generators has become necessary to maintain operations and protect equipment in the event of a utility failure and also to provide additional electric power in times of peak demand without increasing the facility electric bill [4]-[5]. The telecommunications industry, for example, utiliz es standby power generation systems to backup satellite communication earth stations in the event of power loss to maintain reliable communications [6].

In addition to these applications, generation systems are also employed in applications where utility power is not available, such as hybrid electric vehicles. The quest for environmentally friendly and highly efficient automotive drive systems has stimulated investigation of alternative vehicle propulsion systems. Electric propulsion systems offer a highly efficient, zero emissions alternative to traditional fossil fuel based vehicle power systems. However, the present state of battery technology severely limits the range of pure electric vehicles. Until significant advances in battery technology are made, hybrid propulsion systems provide an interim solution. The hybrid vehicle is typically powered from both on-board energy storage devices, which are usually batteries, and an auxiliary power generation unit (APU), which is often an internal combustion engine.

Generation units selected for standby and emergency systems must be extremely reliable [7]-[8]. In addition, power generation sets for military, industrial, 
and personal use require a reliable, compact, and lightweight unit. The APU for HEV applications must also be compact and lightweight with high reliability.

This research contends that use of a tubular brushless permanent magnet linear alternator in conjunction with a linear internal combustion engine offers a number of advantages over the conventionally used rotary systems for electrical power generation. In a rotary configuration, the linear force imparted to the piston rod by the engine must be converted to a rotary torque through a crankshaft mechanism. This rotary energy is then transmitted to a conventional rotary generator. The linear system is capable of directly utilizing the linear piston force without the need for the additional mechanical components necessary in a rotary configuration. The result is more compact due to the absence of a crank housing and more reliable since the linear configuration has only one moving part. Additionally, the linear system should prove to be more efficient as the frictional losses associated with the crank and rod bearings are eliminated. However, the natural frequency of the linear internal combustion engine used as the prime mover in these generation sets operates at a frequency that is significantly lower than the frequency of rotary engines. The lower frequency may result in a lower power to volume ratio for the linear configuration.

\subsection{Literature Review}

The development and investigation of linear electric machines have been ongoing for a number of years. Much of the existing research focuses on the linear 
machine in the motoring mode of operation, while some work has examined the linear machine from the generating standpoint. Additionally, a number of publications examine linear alternator and engine combinations, but most of these works examine a Stirling engine as the prime mover for the system rather than the internal combustion engine.

Boldea and Nasar [9] present an analysis of the permanent linear alternator in which the fundamental differential equations describing the system are developed for both single phase and three phase machines. In a subsequent paper, Boldea and Nasar [10] outline a basic design approach for a tubular linear alternator. Their approach provides the basic geometric dimensions of the machine, including the diameter of the magnets and of the windings for a specified power output. A baseline for determining the number of coils necessary to produce the desired voltage and power level was also provided. They do not, however, examine the machine geometry from a design standpoint. In [11], Nasar and Chen present a method for obtaining an optimal design of a tubular permanent magnet linear alternator by specifying a set of machine dimensions and related constraints and allowing the computer to minimize a certain objective function.

A number of papers have been published which examine a combined linear alternator and engine system; however, most of these works are concerned with the coupling of a linear alternator and a Stirling engine with the primary focus on the engine. Holliday, Howell, and Richter [12] describe a 10kW solar powered Stirling engine combined with a linear alternator. In [13], Dochat summarizes the development of Stirling engines for applications, including electric power generation 
from solar energy. In [14], Dochar, Moynihan, and Dahr demonstrate the reliability and potential of a power generation system based on a Stirling engine and linear alternator system by presenting the results of testing on a $1 \mathrm{~kW}$ system. Shaltens and Schreiber [15] discuss the preliminary designs for their Advanced Stirling Conversion System which incorporates a free-piston Stirling engine with either a linear alternator or an hydraulic pump coupled with an induction generator to provide a nominal 25 $\mathrm{kW}$ to the utility grid.

While many of the published works that deal with li near engine and alternator combinations focus on either the alternator or the engine, several papers have been published in recent years which examine the system more holistically. Benvenuto [16] investigated the interactions between a Stirling engine, a linear alternator, and the electrical load, by formulating a mathematical model which describes the combination as a single system. The developed model is based on idealized models for the engine and the alternator and does not investigate the design aspects of either subsystem. Ulusoy and McCaughan [17] have also examined the system as a whole by coupling the dynamic model of a Stirling engine with the electrical model of a linear alternator.

Kankam, Rauch and Santiago [18] have formulated a mathematical model of a free piston Stirling engine and linear alternator combination by coupling the mechanical and thermodynamic properties of the engine with the electrical equations of the linear alternator and the electrical load. They then examine the changes in the dynamic system response to variations in system parameters. As an apparent continuation of this work, Kankam and Rauch [19] present the results of testing 
performed on a free piston Stirling engine coupled with a linear alternator. These tests were performed using a resistive load and a small induction motor load to examine the interaction and performance of the system. Fu, Nasar and Rosswurm [20] examine the stability of a free-piston Stirling engine power generation system using frequency domain analysis and Bode plot techniques to determine the stable operating regions for varying power output levels.

\subsection{Problem with the Current Design}

Previous research at West Virginia University has demonstrated the stable operation of a spark ignited, gasoline fueled linear engine and linear alternator system [21]. At no load, the existing system operates at an oscillatory frequency of $25 \mathrm{~Hz}$ and generates an open circuit voltage of $132 \mathrm{~V}$. At full load, a maximum output power of $316 \mathrm{~W}$ is produced at $79 \mathrm{~V}$.

A major problem with the present prototype design is that the engine and the alternator were designed independently with the only link between the design of the two systems being the stroke length and the estimated speed of oscillation. The present alternator was designed with only these parameters as guidelines, and the interactions between the engine and the alternator were not considered. Experimental results indicate that an inverse relationship exists between the speed of the engine and the mass of the translator. So, as the mass of the translator increases, the oscillatory speed of the machine decreases. This effect was not considered in the design of the

prototype alternator, and the magnets for the prototype alternator were selected to 
optimize the alternator performance for a given speed; however, the mass of the magnets selected resulted in a reduction in the engine speed and therefore a lower output power.

\subsection{Statement of Proposed Research}

The objective of this research is to provide a design methodology for selection of a linear alternator for a predefined linear internal combustion engine. The design method will include an optimization that will maximize the efficiency and minimize the volume of the alternator while providing the desired output power and output voltage. Figure 1.3-1 illustrates an overview diagram of the proposed work.

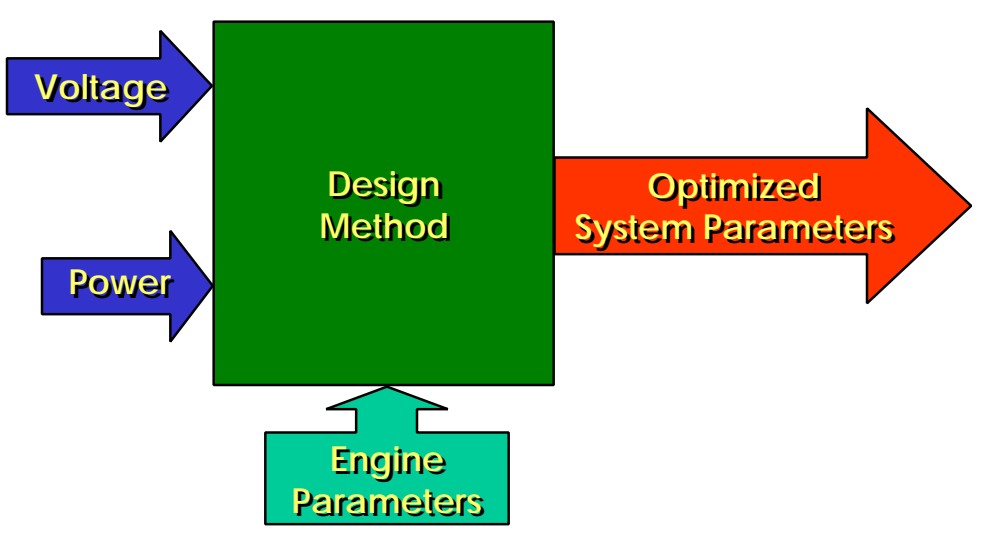

Figure 1.3-1: Overview Diagram of Proposed Work

To accomplish this goal, a basic model of a linear, internal combustion engine will be developed and analyzed. Next, models for the alternator portion of the system will be developed. These models for the engine and the alternator will be integrated to provide a single comprehensive model representing the entire engine and alternator 
system. This combined model will be verified by comparing the result of the model simulation to data taken from the existing linear engine at West Virginia University. Table 1.3-1 shows the parameters that will be examined in this study.

TABLE 1.3-1: Parameters to be examined in study of combined linear alternator and engine system

\begin{tabular}{|l|l|l|}
\hline \multicolumn{3}{|c|}{ PARAMETERS TO BE EXAMINED } \\
\hline \multicolumn{1}{|c|}{ ALTERNATOR } & ENGINE & \multicolumn{1}{c|}{ COMMON } \\
\hline Pole Pitch & Bore & Stroke Length \\
\hline Magnet Fraction & & Speed \\
\hline Magnet Height & & Translator Mass \\
\hline Slot Fraction & & \\
\hline Slot Depth & & \\
\hline Shaft Diameter & & \\
\hline Backiron Height & & \\
\hline Number of Windings & & \\
\hline Wire Size & & \\
\hline Number of Parallel Paths & & \\
\hline
\end{tabular}

Once the system model is fully developed, an optimization routine will then be applied to the model to select the system parameters. The goal will be to maximize the efficiency and minimize the volume for a desired output voltage and power. This algorithm will generate alternator parameters which will satisfy this goal. The resultant alternator will then be analyzed to verify that the designed system produces the desired output. 


\subsection{Contribution}

In the literature, a number of investigators have examined similar engine and alternator configurations as single systems, but these all use a free piston Stirling engine as the prime mover for the generator set rather than an internal combustion engine. In addition, the body of work in this area is more focused on the analysis of the systems and not the design. Instead, the system models are generated from idealized dynamic system equations with little attention paid to the magnetic design of the alternator. The contribution of this research is the integration of the brushless permanent magnet linear alternator model with a basic model of the linear internal combustion engine and the development of a design methodology for selecting the optimum alternator parameters for use with a specific engine. 


\section{CHAPTER \\ TWO}

\section{ENG INE MODEUNG}

To develop an accurate simulation of any system, a model of the system must first be developed. In this chapter, the equations that describe the operation of the engine will be developed. First, the engine will be analyzed using the standard Otto cycle of operation. Then several key assumptions will be made to simplify the model for use in the optimization routines.

\subsection{Linear Intemal Combustion Engine}

The engine will be examined using a basic model of the engine to find relationships between the bore of the engine, the mass of the translator, and the resonant frequency of oscillation. This basic model will then be used to study the effects of various magnet configurations on the oscillatory speed of the system.

In this engine, two horizontally opposed pistons are mounted on a common connecting rod which is allowed to oscillate between the two end-mounted cylinders. Each piston will move in a head that is closed on the outer end and open on the inner end. Combustion occurs alternately in each cylinder, forcing the piston assembly back and forth in an alternating fashion. Figure 2.1-1 illustrates the linear engine configuration analyzed in this section. The illustration shows the translator assembly 


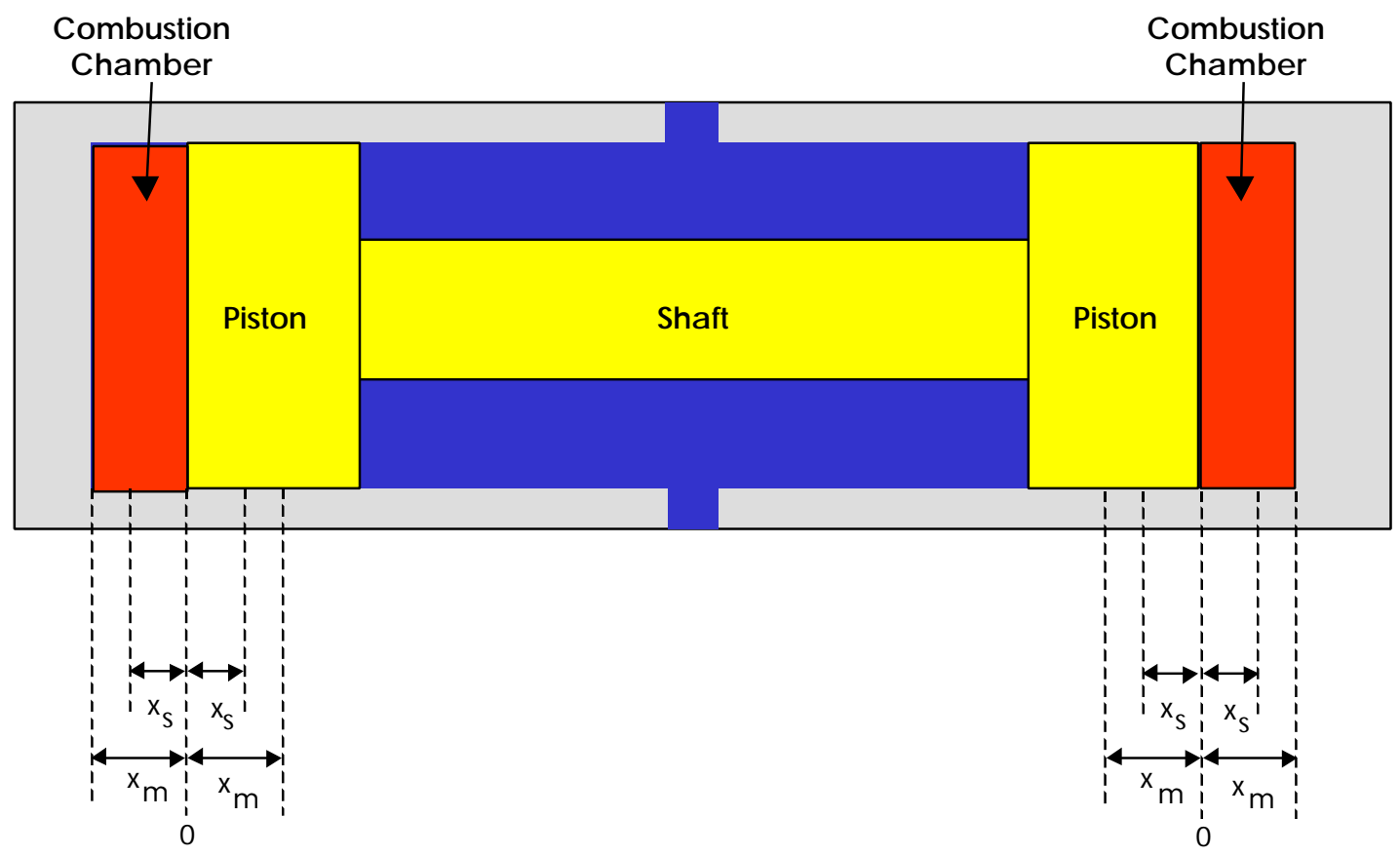

Figure 2.1-1: Simplified Cross-Sectional View of the Linear Engine

in the neutral or zero position. As the figure shows, the translator is free to move a maximum distance, $x_{m}$, in either direction from the zero position before one of the pistons contacts the head. In practice, though, the translator will only move a distance, $x_{s}$, from the zero position leaving a clearance volume in the cylinder. This distance, $x_{s}$, is the half stroke length.

As the piston assembly moves in either direction, one cylinder will undergo the expansion process while the other undergoes compression, thus functioning as a non-linear spring. The compression and expansion of each cylinder will be modeled adiabatically. The resonant frequency can then be found by setting the sum of the forces acting on the pistons due to the in-cylinder pressures and the resultant electromagnetic force of the alternator equal to the mass of the piston assembly times the acceleration of the assembly. The effect of heat addition due to combustion will 
also be examined. First, a force balance equation will be written for the system. Then, this equation will be solved for the piston assembly position from which the resonant frequency of the system can be found.

The engine operation will be modeled using the idealized Otto cycle. In the idealized Otto cycle, it is assumed that instantaneous heat addition occurs at the minimum cylinder volume and that instantaneous heat rejection occurs at the maximum volume. In addition, it is assumed that adiabatic compression occurs from maximum to minimum volume and that adiabatic expansion occurs during the transition from minimum volume to maximum volume. A pressure-volume diagram of the Otto cycle is shown in Figure 2.1-2. This diagram illustrates the relationship

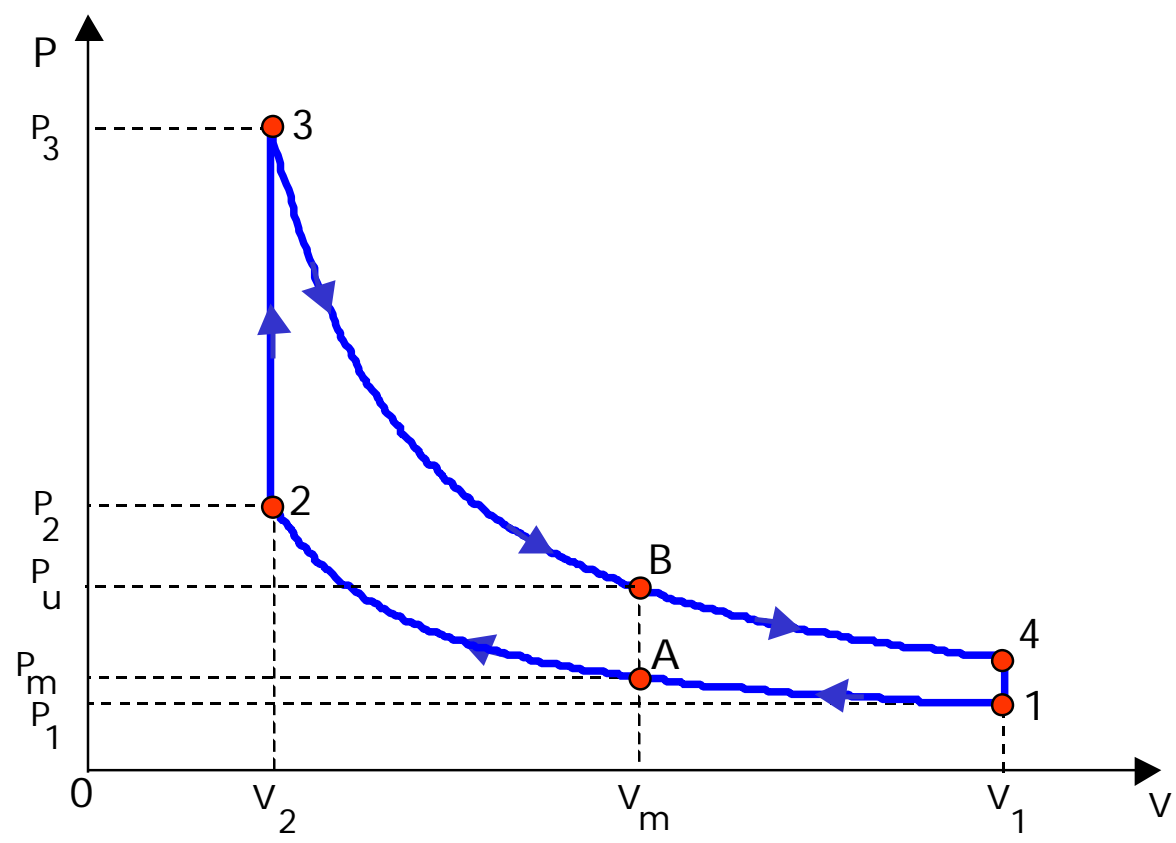

Figure 2.1-2: Pressure Volume (PV) Diagram of Id ealized Otto Cycle with Constant Volume Heat Addition and Rejection 
between the pressure in the engine cylinder with the cylinder volume. The thermodynamic operation of the engine can be understood by examining the loop presented on the PV diagram. Beginning at point 1 on the PV diagram in Figure 2.1-2, the cycle moves toward the minimum volume (the piston moves into the cylinder) in an adiabatic compression. Then, combustion occurs at point 2 . In the Otto cycle, shown in this diagram, combustion occurs at constant volume. This assumes that combustion occurs infinitely fast at the "top" of the stroke. At point 3, combustion is complete, and an adiabatic expansion of the cylinder gases begins as the piston moves out of the cylinder. When the piston reaches the "bottom" of the stroke, at point 4 of the PV diagram, the exhaust valve or port opens and allows blowdown of the cylinder gases, which reduces the in-cylinder pressure to point 1 where the cycle begins again.

\section{$\underline{\text { 2.1.1 Development of Engine Model }}$}

The basis for much of the material is this section was first developed in the thesis titled Two-Stroke Linear Engine by Subhash Nandkumar [1]. The force balance equation for the system is shown in equation 2.1.1-1.

$$
P_{L}(x) A_{B}-P_{R}(x) A_{B}-F(x)=m \ddot{x}
$$

where:

$$
\begin{array}{ll}
P_{L}(x) & \text { instantaneous pressure in left cylinder } \\
P_{R}(x) & \text { instantaneous pressure in right cylinder } \\
\mathrm{A}_{B} & \text { bore area } \\
F(x) & \text { electromagnetic and friction force } \\
m & \text { mass of translator } \\
x & \text { translator position }
\end{array}
$$


For the initial analysis, the translator will be moving from left to right in the positive $\mathrm{x}$ direction. Therefore, the right cylinder will undergo compression while the left cylinder will experience expansion.

If the midpoint pressure in the compression cylinder, $\mathrm{P}_{\mathrm{m}}$, at the point where $\mathrm{x}=0$ is known, then, using the assumption of adiabatic compression, the pressure in the right cylinder can be written as

$$
\begin{aligned}
& P_{R} V_{R}^{n}=P_{m} V_{m}^{n} \\
& P_{R}=P_{m}\left(\frac{V_{m}}{V_{R}}\right)^{n}
\end{aligned}
$$

where:

$$
\begin{array}{ll}
V_{m} & \text { cylinder volume at midpoint } \\
V_{R} & \text { right cylinder volume } \\
P_{R} & \text { right cylinder pressure } \\
n & \text { ratio of specific heats }
\end{array}
$$

The midpoint volume, $V_{m}$, can be expressed as

$$
V_{m}=A_{B} x_{m}=\left(\frac{\pi b^{2}}{4}\right) x_{m}
$$

where:

$$
b \quad \text { bore of the cylinder }
$$

Similarly, the right cylinder volume, $V_{m}$, can be written as

$$
\begin{aligned}
& V_{R}=V_{m}-\left(\frac{\pi b^{2}}{4}\right) x \\
& V_{R}=\left(\frac{\pi b^{2}}{4}\right)\left(x_{m}-x\right)
\end{aligned}
$$


Substituting equation 2.1.1-3 and 2.1.1-4 into equation 2.1.1-2 gives the expression for the pressure in the right (compression) cylinder as

$$
P_{R}=P_{m}\left(\frac{x_{m}}{x_{m}-x}\right)^{n}
$$

At this point in the development, the midpoint pressure in the left (expansion) cylinder, $P_{u}$, is unknown, but can be used to define the expansion cylinder pressure since this pressure will be determined at a later time. By similar analysis, the pressure in the left cylinder can be given as

$$
P_{L}=P_{u}\left(\frac{V_{m}}{V_{L}}\right)^{n}=P_{u}\left(\frac{x_{m}}{x_{m}+x}\right)^{n}
$$

So, the force balance equation can be rewritten by substituting equations $2.1 .1-5$ and 2.1.1-6 into 2.1.1-2 to get

$$
\left(P_{u}\left(\frac{x_{m}}{x_{m}+x}\right)^{n}-P_{m}\left(\frac{x_{m}}{x_{m}-x}\right)^{n}\right)\left(\frac{\pi b^{2}}{4}\right)-F_{E}(x)=m \ddot{x}
$$

Now, suppose the steady state half stroke of the engine is $x_{s}$. Then, the minimum volume can be given as

$$
V_{\text {min }}=V_{2}=\left(\frac{\pi b^{2}}{4}\right)\left(x_{m}-x_{s}\right)
$$


Similarly, the maximum volume is given as

$$
V_{\text {max }}=V_{1}=\left(\frac{\pi b^{2}}{4}\right)\left(x_{m}+x_{s}\right)
$$

The compression ratio is then defined as the ratio of the maximum volume to the minimum volume and can be expressed using 2.1.1-8 and 2.1.1-9 as

$$
r=\frac{x_{m}+x_{s}}{x_{m}-x_{s}}
$$

Now, the previously unknown midpoint pressure of the expansion cylinder, $P_{u}$, can be found by following the Otto cycle from the midpoint of the cylinder during compression, point A on Figure 2.1-2, through the heat addition to the midpoint of the expansion cylinder. The process of finding $P_{u}$ begins at point A in Figure 2.1-2 and follows the PV loop to the midpoint of expansion, point $\mathrm{B}$, while calculating the pressure, volume, and temperature as needed at each labeled point. From the known point $\mathrm{A}$, the pressure at point 2 is found assuming an adiabatic compression from point A to point 2. So, $P_{2}$ can be found as

$$
P_{m} V_{m}^{n}=P_{2} V_{2}^{n}
$$

So,

$$
P_{2}=P_{m}\left(\frac{V_{m}}{V_{2}}\right)^{n}
$$


Substituting equations 2.1.1-3 and 2.1.1-8 into 2.1.1-11 gives $P_{2}$ as

$$
P_{2}=P_{m}\left(\frac{x_{m}}{x_{m}-x_{s}}\right)^{n}
$$

Using the ideal gas law, the temperature at point 2 is given as

$$
\begin{gathered}
\frac{P_{m} V_{m}}{T_{m}}=\frac{P_{2} V_{2}}{T_{2}} \\
T_{2}=\frac{P_{2} V_{2} T_{m}}{P_{m} V_{m}}=\frac{P_{2}}{P_{m}} \frac{V_{2}}{V_{m}} T_{m}
\end{gathered}
$$

Substituting equations 2.1.1-3, 2.1.1-8, and 2.1.1-12 into 2.1.1-13 gives $\mathrm{T}_{2}$ as

$$
T_{2}=T_{m}\left(\frac{x_{m}}{x_{m}-x_{s}}\right)^{n-1}
$$

For constant volume adiabatic combustion, the heat added can be expressed as

$$
Q_{i n}=m c_{v}\left(T_{3}-T_{2}\right)
$$

Equation 2.1.1-15 can be applied to get the temperature at point 3 from the known temperature at point 2 .

$$
T_{3}=T_{2}+\frac{Q_{i n}}{m c_{v}}
$$


Substituting equation 2.1.1-14 into 2.1.1-16 gives

$$
T_{3}=T_{m}\left(\frac{x_{m}}{x_{m}-x_{s}}\right)^{n-1}+\frac{Q_{i n}}{m c_{v}}
$$

The pressure at point 3 can then be determined using the ideal gas law.

$$
\begin{gathered}
\frac{P_{2} V_{2}}{T_{2}}=\frac{P_{3} V_{3}}{T_{3}} \\
P_{3}=\frac{P_{2} V_{2} T_{3}}{V_{3} T_{2}}
\end{gathered}
$$

Since combustion occurs at a constant volume, $V_{3}=V_{2}$, equation 2.1.1-18 reduces to

$$
P_{3}=P_{2} \frac{T_{3}}{T_{2}}
$$

Substituting equations 2.1.1-12, 2.1.1-14, and 2.1.1-17 into equation 2.1.1-19 gives

$$
P_{3}=P_{m}\left(\frac{x_{m}}{x_{m}-x_{s}}\right)^{n}\left[\frac{T_{m}\left(\frac{x_{m}}{x_{m}-x_{s}}\right)^{n-1}+\frac{Q_{i n}}{m c_{v}}}{T_{m}\left(\frac{x_{m}}{x_{m}-x_{s}}\right)^{n-1}}\right]
$$


With the pressure and temperature at point 3 known, the pressure, $P_{u}$, can be found assuming adiabatic expansion from point 2 to point $\mathrm{B}$.

$$
P_{u} V_{u}^{n}=P_{3} V_{3}^{n}
$$

So,

$$
P_{u}=P_{3}\left(\frac{V_{3}}{V_{u}}\right)^{n}
$$

Since $V_{u}=V_{m}$ and $V_{3}=V_{2}$, equations 2.1.1-3 and 2.1.1-8 along with equation 2.1.1-20 can be substituted into equation 2.1.1-21 to get

$$
P_{3}=\left\{\left(\frac{x_{m}}{x_{m}-x_{s}}\right)^{n} P_{m}\left[\frac{T_{m}\left(\frac{x_{m}}{x_{m}-x_{s}}\right)^{n-1}+\frac{Q_{i n}}{m c_{v}}}{T_{m}\left(\frac{x_{m}}{x_{m}-x_{s}}\right)^{n-1}}\right]\right\}\left(\frac{x_{m}}{x_{m}-x_{s}}\right)^{-n}
$$

Simplifying gives

$$
P_{3}=P_{m}\left[1+\frac{Q_{i n}\left(\frac{x_{m}}{x_{m}-x_{s}}\right)^{1-n}}{m c_{v} T_{m}}\right]
$$


Now, all of the terms of equation 2.1.1-23 are known except $T_{m}$, which can be found as follows: The ratio of specific heats is given as

$$
n=\frac{C_{p}}{C_{v}}
$$

and the gas constant $R$ can be written

$$
R=C_{p}-C_{v}
$$

Combining equations 2.1.1-24 and 2.1.1-25 gives $R$ as

$$
R=(n-1) C_{v}
$$

The ideal gas law can be written as

$$
P V=m R T
$$

Substituting equation 2.1.1-26 into 2.1.1-27 gives the ideal gas law as

$$
P V=m(n-1) C_{v} T
$$

So at the midpoint of compression

$$
P_{m} V_{m}=m(n-1) C_{v} T_{m}
$$

Rearranging gives

$$
m C_{v} T_{m}=\frac{P_{m} V_{m}}{n-1}
$$


Substituting equation 2.1.1-3 and 2.1.1-30 into 2.1.1-23 gives the midpoint pressure of expansion as

$$
P_{u}=P_{m}+\frac{Q_{i n}\left(\frac{x_{m}}{x_{m}-x_{s}}\right)^{1-n}(n-1)}{A_{B} x_{m}}
$$

Now the force balance, given as equation 2.1.1-7, can be written as

$$
\left\{\left\{P_{m}+\frac{Q_{i n}\left(\frac{x_{m}}{x_{m}-x_{s}}\right)^{1-n}(n-1)}{A_{B} x_{m}}\right\}\left(\frac{x_{m}}{x_{m}+x}\right)^{n}-P_{m}\left(\frac{x_{m}}{x_{m}-x}\right)^{n}\right) A_{B}-F_{E}(x)=m \ddot{x}
$$

Simplifying gives the force balance equation which can be used to simulate the steady state operation of the linear engine as

$$
A_{B} P_{m}\left[\left(1+\frac{x}{x_{m}}\right)^{-n}-\left(1-\frac{x}{x_{m}}\right)^{-n}\right]+\frac{Q_{i n}(n-1)}{x_{m}-x_{s}}-F_{E}(x)=m \ddot{x}
$$

Equation 2.1.1-33 contains the midpoint pressure of the compressing cylinder, $P_{m}$, which may not be directly known for a given engine. However, the intake pressure at point 1 is usually known. So, the midpoint pressure, $P_{m}$, can easily be found by assuming adiabatic compression from point 1 to point $A$, which gives the pressure, $P_{m}$, as 


$$
P_{m}=P\left(\frac{V_{1}}{V_{m}}\right)^{n}
$$

Substituting equations 2.1.1-3 and 2.1.1-9 into 2.1.1-34 gives $P_{m}$, as

$$
P_{m}=P_{1}\left(\frac{x_{m}+x_{s}}{x_{m}}\right)^{n}
$$

Rearranging the expression for the compression ratio, $r$, in equation 2.1.1-10 gives

$$
x_{s}=x_{m} \frac{r-1}{r+1}
$$

Substituting equation 2.1.1-36 into equation 2.1.1-35 gives

$$
P_{m}=P_{1}\left(\frac{2 r}{r+1}\right)^{n}
$$

The force balance equation can then be written in terms of the intake pressure and the compression ratio as

$$
A_{B} P_{1}\left(\frac{2 r}{r+1}\right)^{n}\left[\left(1+\frac{x}{x_{m}}\right)^{-n}-\left(1-\frac{x}{x_{m}}\right)^{-n}\right]+\frac{Q_{i n}(n-1)}{x_{m}-x_{s}}-F_{E}(x)=m \ddot{x}
$$

The solutions to this equation will provide position and velocity information for the linear engine operating under steady state conditions. 


\subsubsection{Special Case of the Engine Model}

For this special case, the engine is assumed to be frictionless and will be operating under a no load condition. Therefore, no heat addition will be necessary to sustain the motion of the engine. The forces generated from the compressing and expanding gas in the engine cylinders will maintain the motion of the translator. Consequently, the results of this frictionless, no load case will provide the natural frequency of the engine. Nevertheless, analysis of this special case will provide information about the oscillatory speed of the engine under normal operating conditions.

Since, the engine is to be operated under no load and is to be frictionless

$$
F(x)=0
$$

and

$$
Q_{i n}=0
$$

The force balance equation, 2.1.1-38, from the previous section will be repeated here as equation 2.1.2-3

$$
A_{B} P_{1}\left(\frac{2 r}{r+1}\right)^{n}\left[\left(1+\frac{x}{x_{m}}\right)^{-n}-\left(1-\frac{x}{x_{m}}\right)^{-n}\right]+\frac{Q_{i n}(n-1)}{x_{m}-x_{s}}-F(x)=m \ddot{x}
$$

Substituting equations 2.1.2-1 and 2.1.2-2 into 2.1.2-3 give the new force balance as

$$
A_{B} P_{1}\left(\frac{2 r}{r+1}\right)^{n}\left[\left(1+\frac{x}{x_{m}}\right)^{-n}-\left(1-\frac{x}{x_{m}}\right)^{-n}\right]=m \ddot{x}
$$


Although this force balance is for the special case of a frictionless engine operating under no load, information about the normal loaded operation of the engine can be determined from this formulation. If the proper amount of heat, $Q_{i n}$, is added to the engine under normal operating conditions the $\frac{Q_{i n}(n-1)}{x_{m}-x_{s}}$ term would completely cancel the $F(x)$ term, leaving equation 2.1.2-4 as the representation of the engine under loaded operation. If the heat added is such that these terms do not cancel, it is impossible to maintain the compression ratio of the engine. If too much heat is added, the stroke length increases until the stroke reaches the maximum value where the piston would contact the head. If too little heat is added, the stroke gets shorter and shorter until the motion completely dies out.

In practice, however, the engine does not exactly follow the idealized Otto cycle resulting in operating speeds that are slightly slower than the natural frequency. As the loading increases, the engine operation deviates from the no load model. In addition, the actual engine used for this application is a two-stroke engine which would cause further deviation from the idealized model. The result is a decrease in engine speed as the loading is increased. This phenomenon is not represented with the ideal model. Nevertheless, since this speed reduction is small over the load range of the engine, the results of the ideal model provide a close approximation of the engine operation and are sufficient for use in this research. 
$\overline{\text { CHAPTER }}$
THREE

\section{ALTERNATOR MODEUNG}

The modeling technique for the alternator used in this research is based on a finite element analysis package. In an initial attempt to reduce computation time, a magnetic circuit based model of the linear alternator was investigated. However, the results from the magnetic circuit modeling were not accurate over the large range of design possibilities needed in the optimization. In fact, accurate modeling of the air core linear alternator was found to be nearly impossible due to the large leakage flux.. Consequently, the magnetic circuit approach was abandoned in favor of the more accurate and more computationally intensive finite element approach.

This chapter examines the formulation of the alternator model. First, a physical and operational description of the tubular brushless permanent magnet linear alternator is provided. Then, the basis for the finite element analysis method is discussed. Finally, an examination of the ANSYS model of the linear alternator is presented. 


\subsection{Tubular Brushless Permanent Magnet Linear Altemator}

The tubular brushless permanent magnet linear alternator consists of two main components, a stator and a translator. The stator includes the outer shell of the machine which houses the armature windings, the back iron, and the winding spacers. The translator is the moving portion of the machine that is made up of the permanent magnets and the shaft to which they are mounted. A cross sectional view of the linear alternator and engine is shown in Figure 3.1-1.

The permanent magnet linear alternator operates on the same basic physical principles as conventional rotary alternators. The principle that governs the voltage generating operation of the alternator is Faraday's Law expressed as

$$
e_{i n d}=-\frac{d \lambda}{d t}=-N \frac{d \phi}{d t}
$$

where

$\lambda$ the total flux passing through the coil

$\phi \quad$ flux passing through one turn of the coil

$N \quad$ number of turns in the coil

$e_{\text {ind }} \quad$ voltage induced on the coil

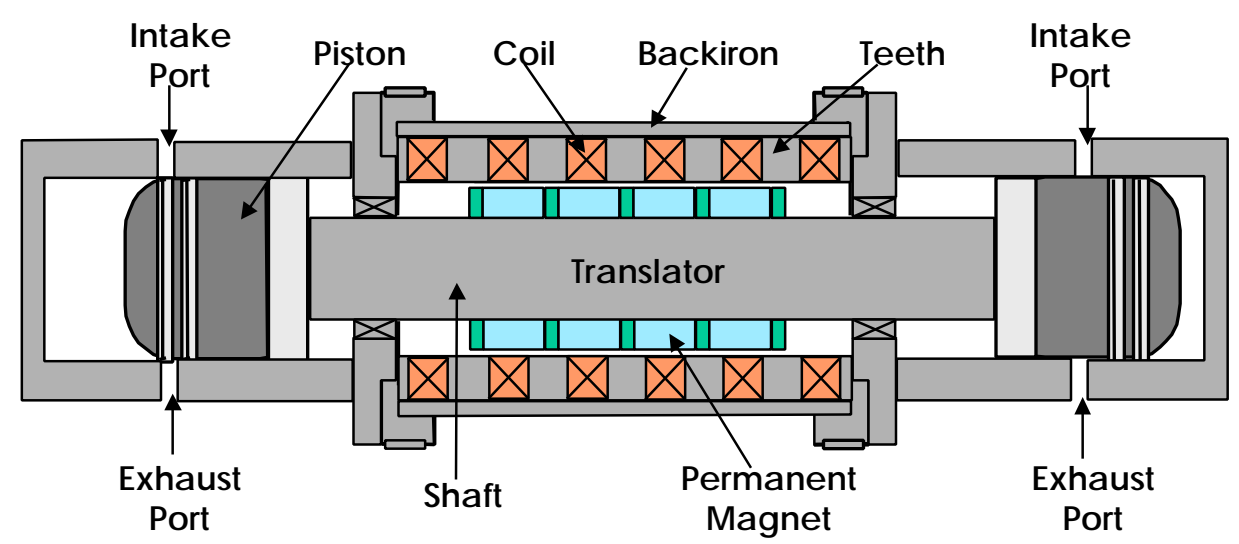

Figure 3.1-1: Cross Sectional View of Tubular Brushless Pemanent Magnet Linear Altemator 
The permanent magnets mounted on the translator creat e a magnetic field around the magnets. As the translator is moved through the stationary windings on the stator, a voltage is induced in the windings as specified by Faraday's Law. When the engine is operating, the translator of the alternator moves relative to the stationary armature coils, thereby creating a changing magnetic field. This changing magnetic field then induces a voltage on the armature coils of the machine. When a load is connected across the output terminals of the armature windings, current flows through the load and power is extracted from the alternator.

The alternator selected for use in this research is a single phase machine. The single phase alternator was chosen to maintain conformity with the existing linear alternator and engine system used for validation purposes. In addition, the pole pitch of the alternator was set equal to the stroke length of the engine to reduce the harmonic content of the output waveforms.

\subsection{Magetnic Model of the Linear Altemator}

This section examines the development of the model of a brushless permanent magnet linear alternator using the ANSYS finite element analysis package. First, the finite element method is described, and the governing equations are examined. The basic structure of an ANSYS program is then examined. Finally, a MATLAB routine for generating the ANSYS program for different machine geometries and translator positions is discussed. 


\subsubsection{Finite Element Method}

The finite element method is a numerical technique for solving eng ineering problems involving differential equations applied over regions constrained by boundary conditions. The governing equations and boundary conditions for most problems can easily be determined, but it is usually difficult or impossible to find a closed-form, analytic solution. The finite element method provides an accurate numerical solution for such problems by dividing the model into small, interconnected elements and solving the governing equations for each small element. The elements are joined by ensuring the boundaries of each element are compatible with those of its neighbors and with the overall boundary conditions of the model. The entire solution can then be found by assembling all of the individual elements [1].

In this work, the finite element method is used to find the magnetic fields in the linear alternator in a magnetostatic case. Magnetostatic analysis is governed by the following subset of Maxwell's equations [2]:

$$
\begin{aligned}
& \nabla \bullet \mathbf{B}=0 \\
& \nabla \times \mathbf{H}=\mathbf{J} \\
& \text { where } \\
& \mathbf{B} \quad \text { magnetic flux density vector } \\
& \mathbf{H} \quad \text { magnetic field intensity vector } \\
& \mathbf{J} \quad \text { total current density vector }
\end{aligned}
$$

In addition to Maxwell's equations, the constitutive relation that describes the behavior of the magnetic material is given as: 


$$
\mathbf{B}=\mu \mathbf{H}
$$

where

$\mu \quad$ magnetic permeability

For nonlinear magnetic materials, the magnetic permeability in the constitutive equation is given as a function of the field intensity, $\mathbf{H}$.

In this analysis, considerable sim plification is possible by using a potential function to represent the magnetic field density, B [3]. The magnetic vector potential, A, can be defined as

$$
\mathbf{B}=\nabla \times \mathbf{A}
$$

Use of the magnetic vector potential, A, from equation 3.2.1-4 along with the constitutive equation given in 3.2.1-3, allows equations 3.2.1-1 and 3.2.1-2 to be rewritten in terms of the magnetic vector potential as

$$
\begin{aligned}
& \nabla \bullet \nabla \times \mathbf{A}=0 \\
& \nabla \times \nabla \times \mathbf{A}=\mu \mathbf{J}
\end{aligned}
$$

To insure the uniqueness of the magnetic vector potential formulation, the Coulomb gauge, as given in equation (3.2.1-7) is employed [2].

$$
\nabla \bullet \mathbf{A}=0
$$


The Coulomb gauge coupled with the vector identity $\nabla \times \nabla \times \mathbf{A}=\nabla(\nabla \cdot \mathbf{A})-\nabla^{2} \mathbf{A}$ [3] can be applied to equation 3.2.1-6 to get

$$
\nabla^{2} \mathbf{A}=-\mu \mathbf{J}
$$

In the two dimensional analysis that will be used in this research, the model is defined in the $x-y$ plane, and the winding current flows in only the z-direction. Therefore, the applied load, $\mathbf{J}$, has only a z-component as shown in equation 3.1.1-9.

$$
\mathbf{J}=J_{Z} \hat{\mathbf{a}}_{\mathbf{z}}
$$

Since the model has translational symmetry, the magnetic vector potential, $\mathbf{A}$, has the same vector form as the applied load, as shown in equation 3.1.1-10 [1].

$$
\mathbf{A}=A_{Z}(x, y) \hat{\mathbf{a}}_{\mathrm{z}}
$$

Using equations 3.1.1-9 and 3.1.1-10, equation 3.1.1-8 can be rewritten for this special case in scalar form as [4]

$$
\frac{\partial^{2}}{\partial x^{2}} A_{Z}+\frac{\partial^{2}}{\partial y^{2}} A_{Z}=-\mu J_{Z}
$$


Equation 3.1.1-11 is the elemental differential equation which must be solved for each element of the model. These elemental differential equations are assembled into a matrix equation representing the behavior of the entire system, the boundary conditions are imposed, and the solution is generated.

\subsubsection{ANSYS Program Structure}

For this application, the ANSYS package was operated in the batch mode in which a program file is read into the ANSYS processor and the output results are written to an output file. This method is in contrast to using the graphical user interface (GUI) to enter and analyze the model. The batch mode is needed in this analysis because the optimization routines that will be employed are in the MATLAB environment. Therefore, a method is needed to generate and analyze an ANSYS program from the MATLAB environment. The batch processor in ANSYS is the ideal solution. In this system, a MATLAB routine has been created which generated an ANSYS batch file based on information about the machine geometry and the translator position. Before investigating the MATLAB routine which generates the ANSYS batch file, it is instructive to examine the structure of the ANSYS batch program.

The ANSYS environment is divided into several subsections. The /BEGIN area is used to define general parameters. The preprocessor (/PREP7) area is where the model of the magnetic system is developed. In the solution processor (/SOLU), the finite element solutions are generated. Finally, in the postprocessor (/POST1) the outputs are generated. 
The ANSYS batch files generated in this work start with the /PREP7 preprocessor section. First, the element type is selected and its parameters are defined. For this analysis, the PLANE53 element is selected. The PLANE53 element models two dimensional magnetic fields in either planar or axisymmetric configurations. The element is based on a magnetic vector potential formulation and is used for magnetostatic analysis. The element also has a nonlinear capability for modeling the B-H curves of nonlinear materials. The parameter switch is set to define these as axisymmetric elements. Since the linear alternator is symmetric about the centerline of the translator shaft, it is only necessary to model half of the geometry in ANSYS. By setting the axisymmetric property of the element, the remainder of the geometry is determined by rotating the given cross section about the axis of symmetry.

Once the element type is specified, the material properties for all of the materials used in the model are specified. In particular, the B-H curve for the electrical steel used for the alternator teeth and back iron is provided to ANSYS. Also, the relative permeability for the aluminum, copper, and air are given. Finally, the residual induction, $B_{r}$, and the coercive force, $H_{c}$, of the magnets are entered.

Next, the keypoints of the design are entered. The keypoints are the vertices of the individual areas of the design. Figure 3.2.2-1 illustrates the ANSYS model of the linear alternator with the keypoints identified by number. The keypoints are specified by supplying the keypoint number and the three dimensional coordinates of the point. Since this is an axisymmetric model, the z-coordinate is given as zero. 


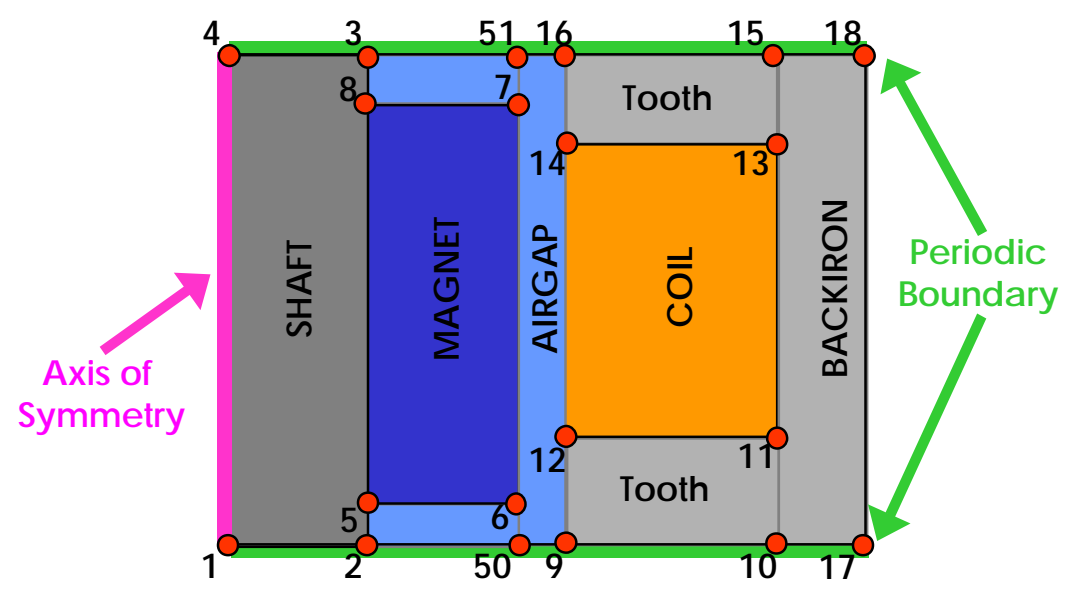

Figure 3.2.2-1: Linear Altemator for ANSYS Modeling with Keypoint Numbers Shown

This defines the two dimensional model which will be rotated around the axis of symmetry to produce the full three dimensional model.

Once the keypoints are defined, the various model areas are specified. The areas are the sections of the design which will later be assigned material types. So, each component of the machine that is a different material is defined as a separate area. The areas are defined by listing all of the keypoints which define the area. The ordering of the list is done by looping around the area in a counter clockwise fashion.

When listing the keypo ints which define an area, it is important to list all of the keypoints on the perimeter of the area, not just those at the vertexes of the particular area. If all of the keypoints on the perimeter are not included, the ANSYS processor will not recognize the interface between adjacent areas and will produce erroneous results.

The next step in the ANSYS program is creating names for each model area. Although this is not necessary for calculating the results, naming the areas makes the 
ANSYS program easier to write, read, and debug, because, from this point on, the area can be referenced by a name rather than by an area number. Once the names are created, they are used to assign the previously defined material numbers to the respective model areas.

With all of the areas defined and given material properties, the model can now be meshed. Meshing of the model involves dividing each area into the small elements which will be used for the finite element solution. The ANSYS processor provides an automated method for meshing the model in which the software chooses the meshing parameters.

Once all of the elements are created, boundary conditions must be applied to the model. For this analysis, a periodic boundary condition is used. To simplify the ANSYS modeling and reduce computation times, only a single pole pitch of the machine is modeled. Figure 3.2.2-2 illustrates a section of the linear alternator with the single pole pitch to be modeled highlighted and with all of the alternator geometry parameters labeled. The periodic boundary condition is used to simulate the existence of additional poles on either side of the modeled pole. The total number of poles in each design is accounted for later in the simulation routines.

The ANSYS software does not provide a means for defining periodic boundary conditions on axisymmetric models. Therefore, a custom macro was written to accomplish this task. The macro finds all of the nodes along one of the edges where the periodic boundary condition is to be defined. The corresponding nodes on the opposite edge are also identified. Then, a constraint equation is written for each pair of nodes such that the magnetic field at the "top" node is equal in 


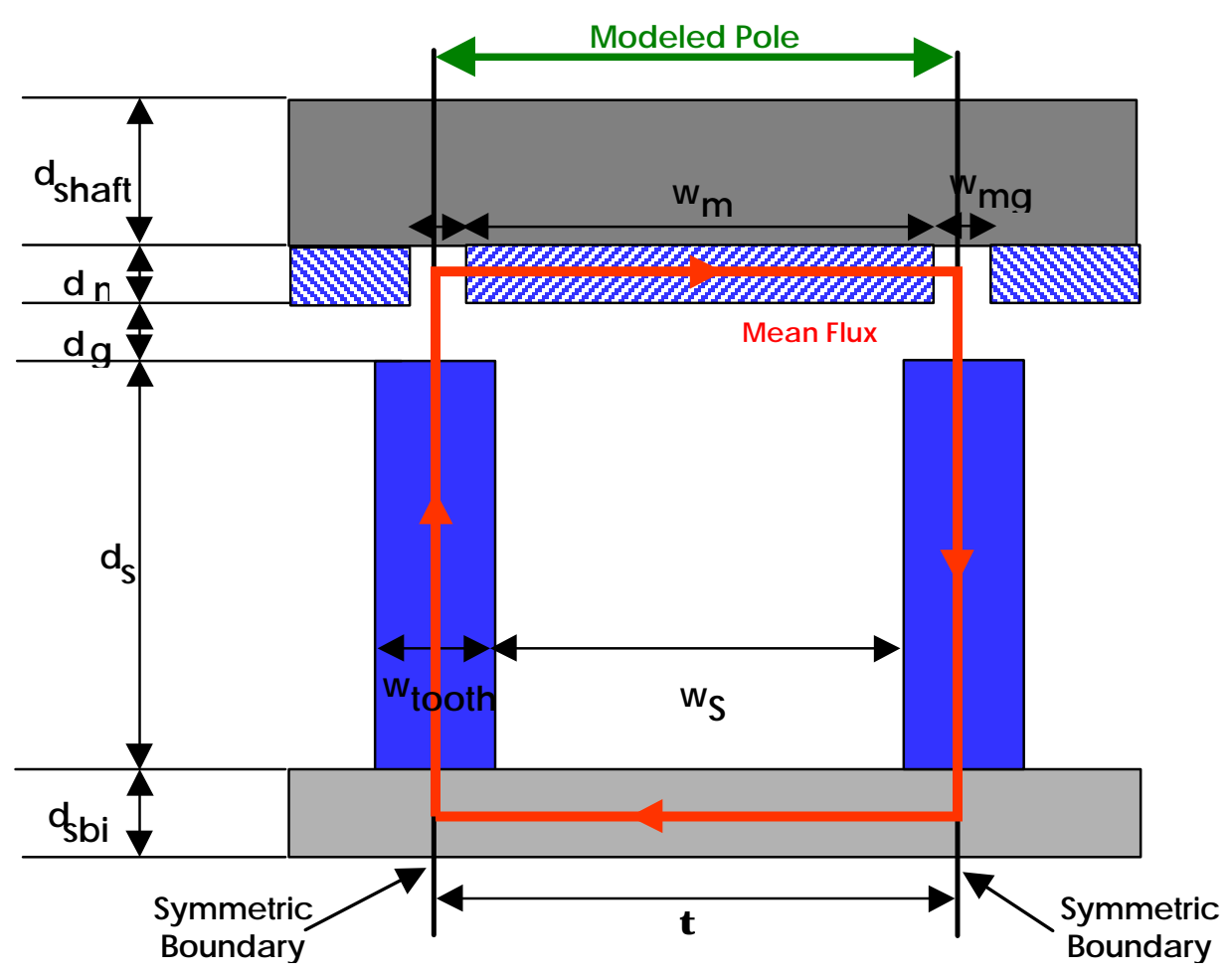

Figure 3.2.2-2: C ross Sectional View of One Pole Pitch of the Linear Altemator for Magnetic Circ uit Analysis

magnitude but opposite in direction to the corresponding "bottom" node. This negative symmetry is necessary since the magnetic field directions are in opposite directions from adjacent poles.

The boundary condition on the outer edge of the stator backiron is defined as a parallel boundary condition. With this definition, the flux at the edge of the backiron is constrained to be parallel with the edge. The result is that all of the machine flux is contained within the backiron and there is no leakage to the surrounding air. Making this boundary assumption does not sacrifice much in the accuracy of the results as the permeability of the backiron material is much larger than that of the surrounding air and there is very little leakage. However, the simplification of the model by selecting 
this boundary condition, rather than having to add another air element to the model, reduces the computation time.

Specifying the boundary conditions is the last step in defining the model in the preprocessor, so the ANSYS solution processor (/SOLU) is then selected. In the solution processor, the current flowing in the alternator is applied to the winding area, and the solution is performed.

Once the solution is found, the postprocessor (/POST1) is utilized to examine the results. For this analysis, the flux linking the winding is the most important result. Figure 3.2.2-3 illustrates the flux lines found from the ANSYS analysis for an air core linear alternator configuration with a typical geometry, and Figure 3.2.2-4 depicts the flux lines for an iron core linear alternator with the same geometry.

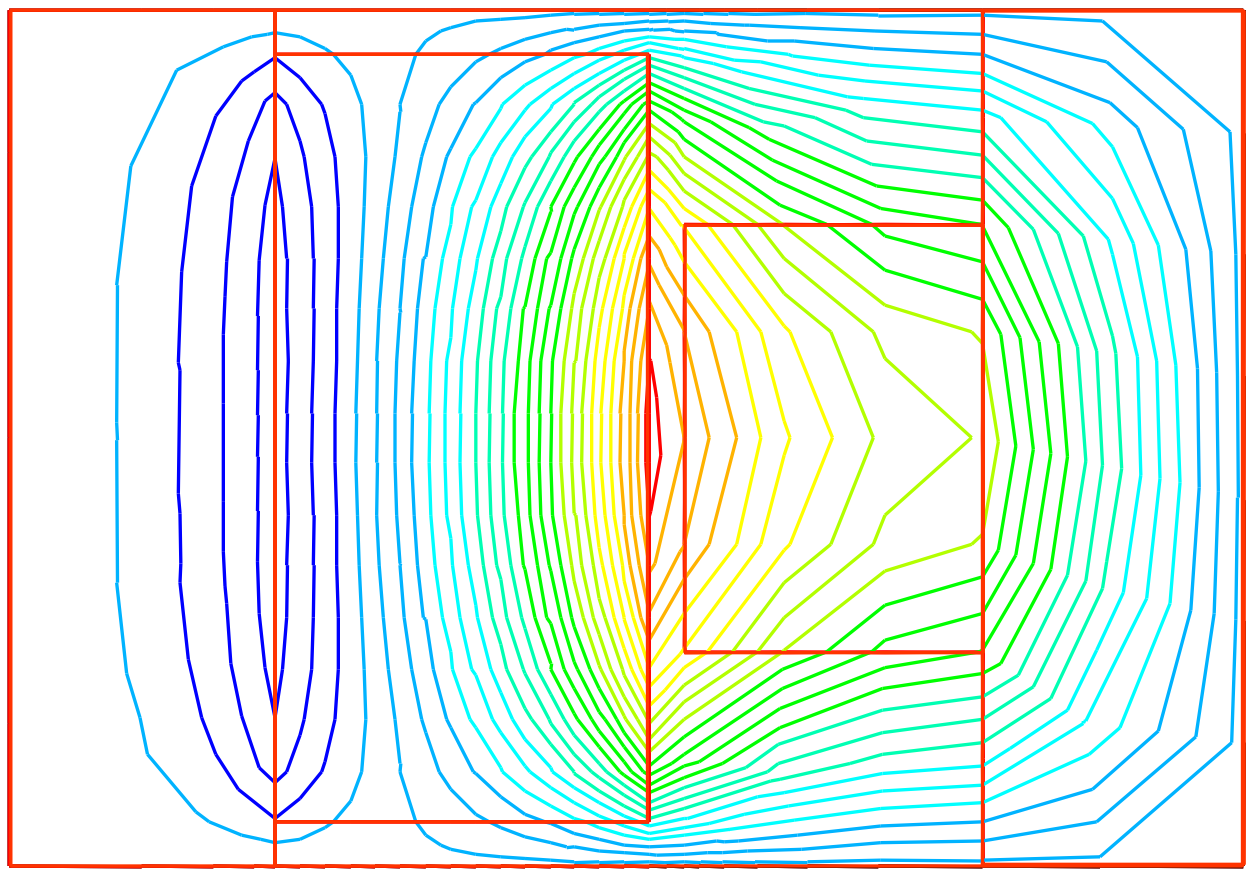

Figure 3.2.2-3: Flux lines for typic al a ir c ore linea r a ltemator 


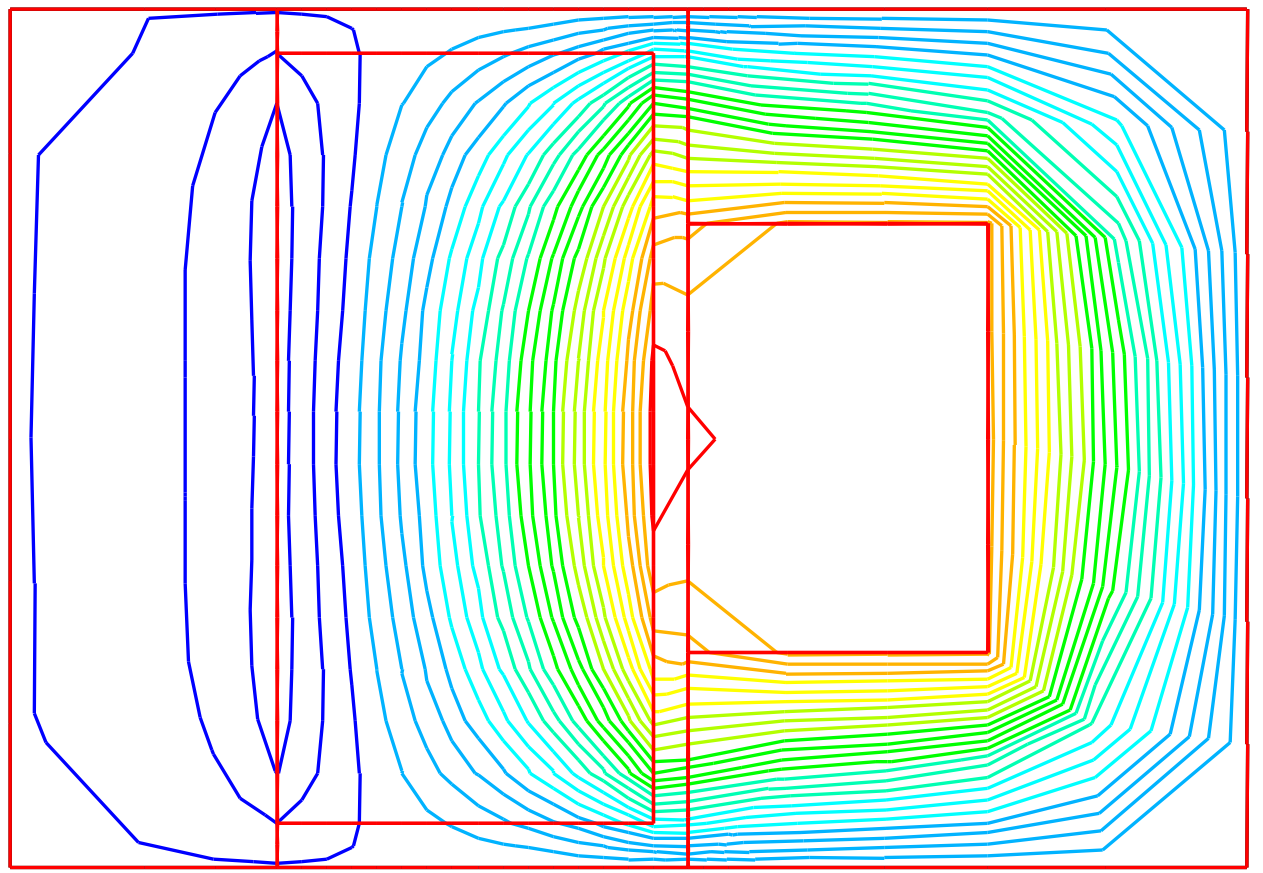

Figure 3.2.2-4: Flux lines for typic al iron core linear altemator

The flux linking the coil is found by defining a path that stretches radially across the backiron at a position in the center of the winding. The ANSYS command macro FLUXV is then used to find the flux crossing the defined path. This backiron flux value is then written to a file for use by the simulation routines. With the results exported to a file, the ANSYS batch file ends.

\subsubsection{MATLAB Routine to Generate ANSYS Program}

Since the optimization of the system will be performed $u$ sing MATLAB, it was necessary to be able to generate the ANSYS batch files from the MATLAB environment. So, two MATLAB functions were written to create the ANSYS files. Because much of the ANSYS program does not change as the machine geometry and 
translator position vary, the ANSYS file was divided into several sections. The function get_ansys_data is responsible for organizing these sections into one complete file. In the first section, the element type and material properties are specified. Since this does not change from model to model, this section is simply read from a text file and written directly to the ANSYS file. The next section is the definition of the machine geometry and material assignments. Since this section does change, the MATLAB function, generate_ansys_file, takes the machine geometry parameters as inputs and adds the keypoint definitions, the area definitions, the area names, and the material assignments to the ANSYS file.

The meshing and boundary condition commands are then read from a file and written to the ANSYS program. Next, the get_ansys_data function adds the commands for applying the currents to the windings and reads the remainder of the ANSYS program from a text file.

\subsection{Eectrical Model of the Linear Altemator}

The previous section described the magnetic model of the linear alternator. Since the goal of this research is concerned with the output voltage and power of the alternator, it is also necessary to examine the electrical model of the linear alternator. Figure 3.3-1 shows the equivalent circuit of the single phase linear alternator used in this research. 


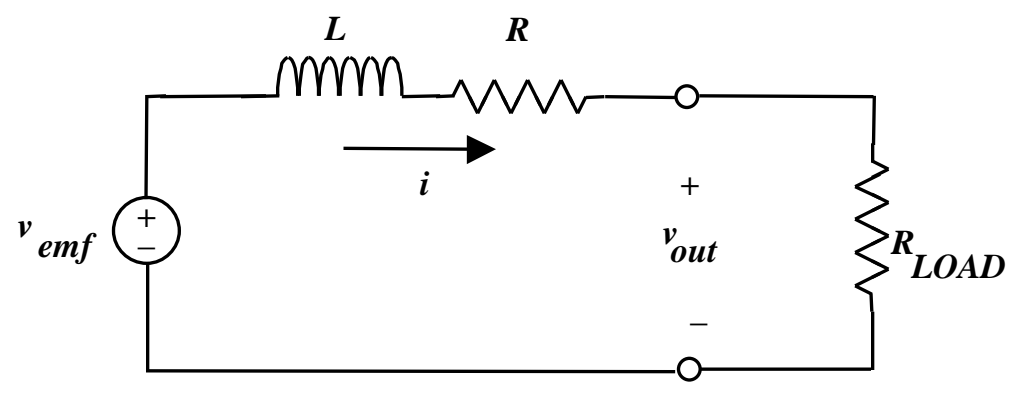

Figure 3.3-1: Equiva lent Circ uit of the Single Phase Linear Altemator

The voltage equation for this machine can then be written as

$$
v_{\text {out }}=v_{\text {emf }}-R i-L \frac{d i}{d t}
$$

where the back emf of the machine is given as

$$
v_{e m f}=N \frac{d}{d t} \phi
$$

In these equations, the self inductance of the machine, $L$, and the linking flux, $\phi$, are determined from the finite element analysis performed on the machine.

Typically, the alternator electrical output would be found by solving the differential equations presented above. However, since in this situation the steady state characteristics of the alternator are of interest, the alternator electrical characteristic can be found using the phasor notation for these equations. Equation (3.3-2) can be used to find the magnitude of the back emf of the alternator. However, this value must be divided by the square root of two to convert the magnitude to an RMS value. This voltage is used as the reference, so the phase angle of the back emf is set to zero. Then, the current in the machine can be found as 


$$
\mathbf{I}=\frac{\frac{\mathbf{V}_{e m f}}{\sqrt{2}} \angle 0^{\circ}}{\left(R+R_{L O A D}\right)+j \omega L}
$$

The output voltage of the machine can be found from

$$
\mathbf{V}_{\text {OUT }}=R_{L O A D} \mathbf{I}
$$

Finally, the output power of the machine can be found as

$$
P=\operatorname{REAL}\left(\mathbf{V}_{\text {oUT }} \mathbf{I}^{*}\right)
$$

The electrical model, then, is based on the results from the magnetic anal ysis of the machine. The inductance and the flux linkage are found from the magnetic analysis. The flux linkage information is used to calculate the back emf of the alternator. Then, with the back emf and the impedance of the windings known, the current can be determined. Once the current is known, the output voltage and the output power can easily be determined. 
\begin{tabular}{l} 
CHAPTER \\
FOUR \\
\hline
\end{tabular}

SIMULATION

The models developed in the previous chapters for the engine and the linear alternator are only useful if they can be combined with simulation routines to determine the operation of the modeled systems. This chapter examines the formulation of the simulation routines for the models and presents the results of the simulations. Then, the results of the simulations are validated using known data.

\subsection{Linear Engine Simulation}

In this section, a simulation of the system using $\mathrm{t}$ he model developed in Chapter 2 will be examined. This simulation will be performed using the engine parameters of an existing, spark ignited, gasoline-fueled engine. Table 4.1-1 lists the engine parameters for the existing engine [1]

Table 4.1-1: Existing Engine Parameters

\begin{tabular}{|l|c|l|l|}
\hline Bore & $b$ & 36.5 & $\mathrm{~mm}$ \\
\hline Maximum Half Stroke & $x_{m}$ & 25 & $\mathrm{~mm}$ \\
\hline Intake Pressure & $P_{1}$ & 250 & $\mathrm{kPa}$ \\
\hline Compression Ratio & $r$ & 10.4 & \\
\hline
\end{tabular}


A routine to numerically integrate the force balance equation, given in equation 2.1.2-4 and repeated here as equation 4.1-1, over one complete stroke was written to perform the simulation.

$$
A_{B} P_{1}\left(\frac{2 r}{r+1}\right)^{n}\left[\left(1+\frac{x}{x_{m}}\right)^{-n}-\left(1-\frac{x}{x_{m}}\right)^{-n}\right]=m \ddot{x}
$$

To represent the coupling between the alternator in the engine in this simulation, the mass of the translator used in the force balance equation is the mass of the translator with the alternator attached. Since the engine model was developed for a frictionless, no load case, the interactions of the alternator electromagnetic force on the engine is not considered.

Both the Euler method and the improved Euler, or trapezoidal, method were employed to numerically integrate the engine force balance equation. Since the results of the two methods were within one percent of each other, the standard Euler method was selected based on the lower computation time.

Figure 4.1-1 illustrates the simulated and experimental translator position plotted against time for one cycle and shows that the engine simulation produces results which accurately describe the operation of the existing engine. The experimental result shows that the stroke length of the engine for this particular run is slightly larger than the published data used in the simulation. Since the firing points in the experimental system are manually adjusted, it is entirely expected that the stroke length would vary slightly from the published data. The experimental data also 


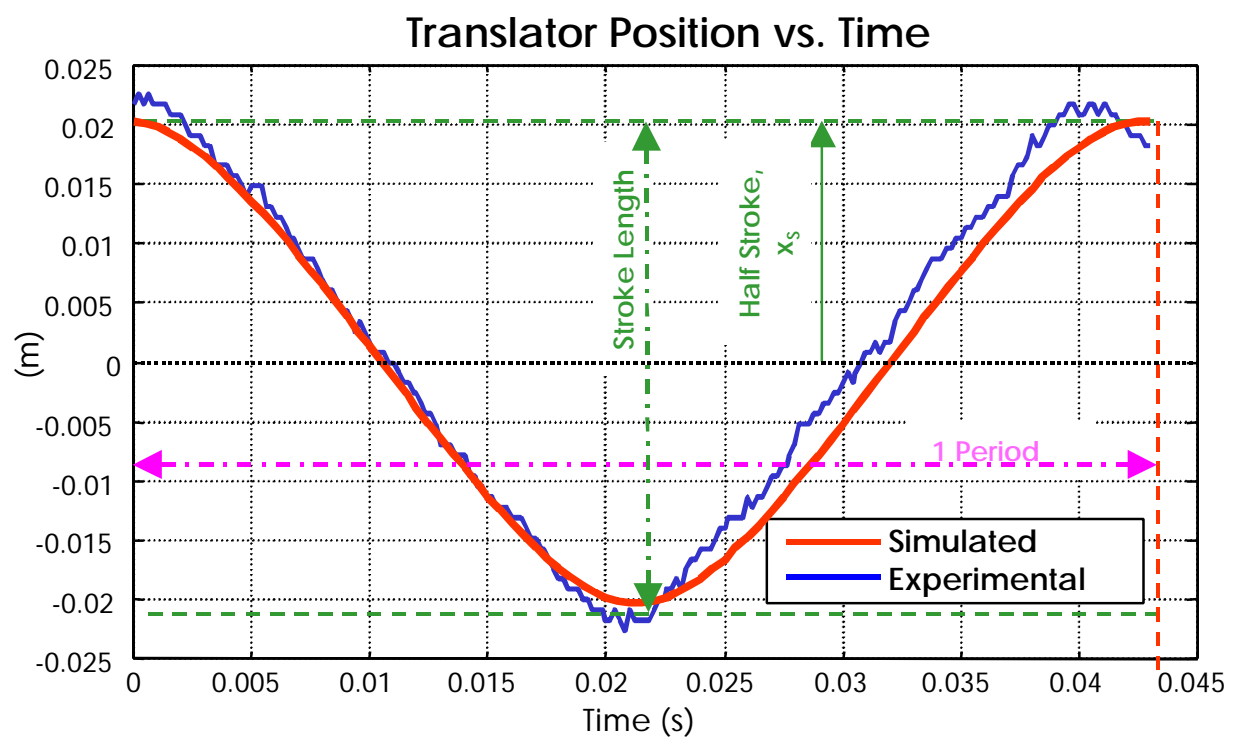

Figure 4.1-1: Plot of Transla tor Position vs. Time for one engine cycle

shows that the frequency of the engine is slightly higher than the simulation. Since the stroke length is slightly longer, the compression ratio of the engine is also higher than the simulation, which would account for the increased speed.

In addition to the position waveforms, some other plots of the engine operation are included. Figure 4.1-2 shows the translator velocity as a function of

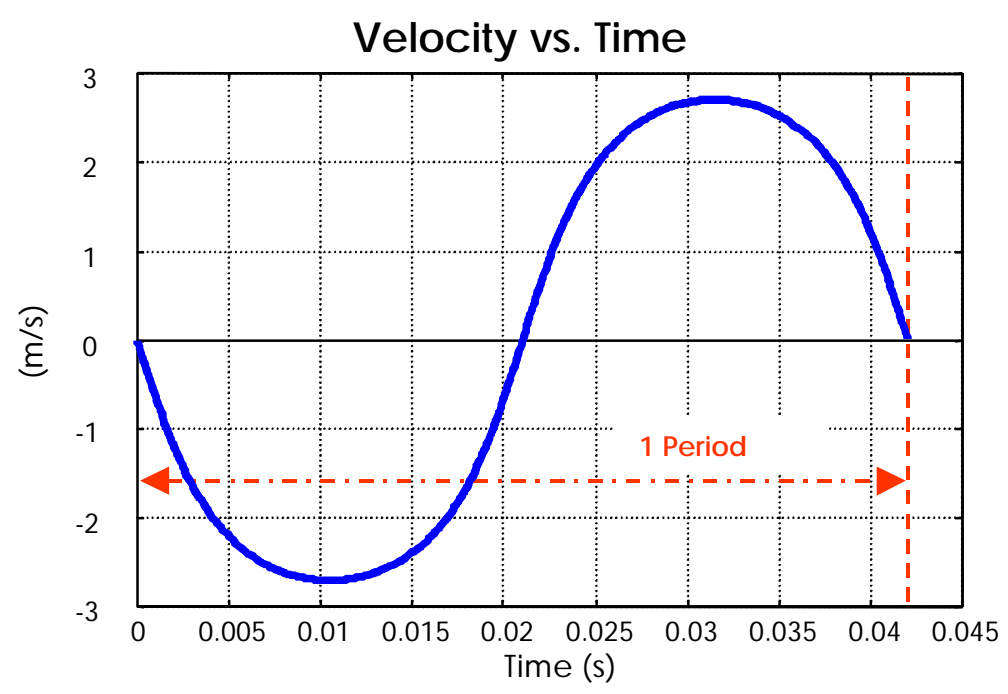

Figure 4.1-2: Plot of Translator Velocity vs. Time for one engine cycle 


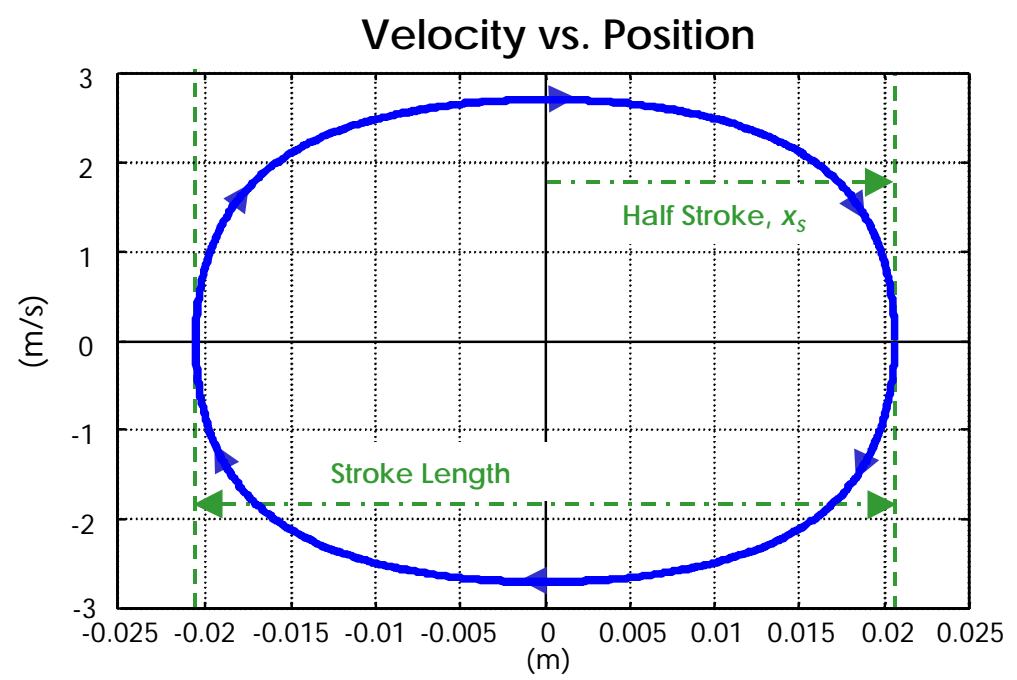

Figure 4.1-3: Plot of Translator Veloc ity vs. Translator position for one complete engine cycle

time and Figure 4.1-3 depicts the translator velocity as a function of the translator position. It should again be noted that the engine model utilized in this research represents a frictionless, no load engine. Therefore, the simulation results represent this engine operating at no load.

\subsection{Brushless Pemanent Magnet Linear Altemator Simulation}

The alternator simulation is based on the models for the linear alternator that were developed in Chapter 3. The simulation routine provides means for selecting between a full finite element analysis and a simplified finite element analysis. In the full finite element simulation, the finite element program analyzes the alternator at a number of different translator positions and formulates a flux profile based on these 
multiple positions. In the simplified version, only the peak flux is calculated using the finite element routine, and a sinusoidal flux distribution based on the calculated peak flux is assumed.

Figure 4.2-1 illustrates the flowchart of the simulation routine. This simulation begins by establishing all of the necessary alternator parameters. Then, the flux linking the coil is determined. If the simplified version is used, only the peak flux is calculated, and a sinusoidal flux distribution is assumed. With the full finite element model, the system is analyzed with the translator in a number of positions over one half of a pole pitch. The flux for the full pole pitch is found by reflecting the finite element output. The symmetry of the design allows for this reflection and saves computation time.

Once the flux vs. position data is found, a Fourier representation of the flux distribution is determined. The periodic nature of the flux distribution makes the Fourier representation an ideal candidate for representing the flux distribution. Since the computation effort associated with the finite element solutions is high, the goal was to reduce the number of finite element solutions that had to be generated. With a Fourier representation, only a few finite element solutions were necessary to generate an accurate representation of the flux distribution. The Fourier representation allowed for a much finer discretization of the flux data.

Next, the engine simulation discussed in the previous section is executed and the translator position and velocity, as well as the frequency of one cycle, are obtained from this routine. A Fourier representation of the engine position data is 
also developed. As previously discussed, the coupling between the engine and the alternator is represented in the mass of the translator used in the engine simulation.

The electrical parameters of the machine, $R$ and $L$, are found from the
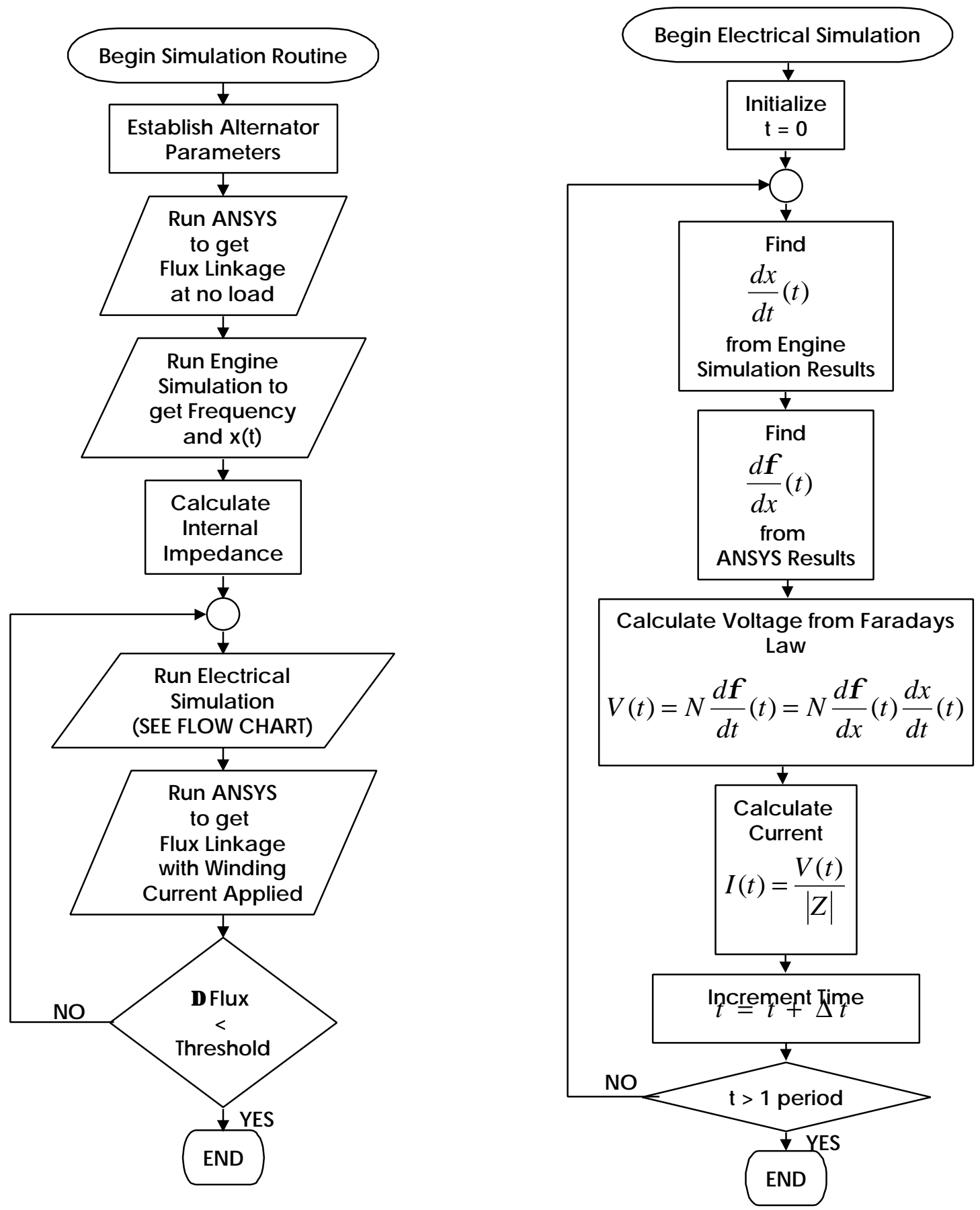

Figure 4.2-1: Flowcha rts for Simula tion Routine 
geometry of the machine, the wire size, and the number of turns. The impedance is then found using the frequency of the machine as determined by the engine simulation.

The internally generated voltage of the machine is then calculated in a loop of time through one period using the following equation at each instant of time:

$$
V(t)=N \frac{d \phi(t)}{d x} \frac{d x(t)}{d t} \bullet(\# \text { poles }-1)
$$

The magnitude of the current is then calculated

$$
I(t)=\frac{V(t)}{|Z|}
$$

Once the loop completed one period, the current waveform is phase shifted based on the angle of the impedance. The output power and the copper and core losses are then determined so the efficiency of the alternator can be calculated.

Next, the flux linking the coil is determined again. However, this time the current flowing in the windings, as determined above, is applied to the windings in the model. This allows for simulation of the armature reaction, which is a distortion of the original magnetic field due to the current in the machine windings. This newly calculated flux is compared with the original flux. If the flux change exceeds a preselected threshold, the entire process starting with the voltage calculation is repeated until the flux change falls below the desired threshold. This iterative process is necessary since the current flowing in the machine is not known until the generated voltage is known, but the voltage is not known until the machine flux is known, and the machine flux cannot be accurately found without knowing the current in the machine. So, the only way to start is to assume an initial current (in this case no load 


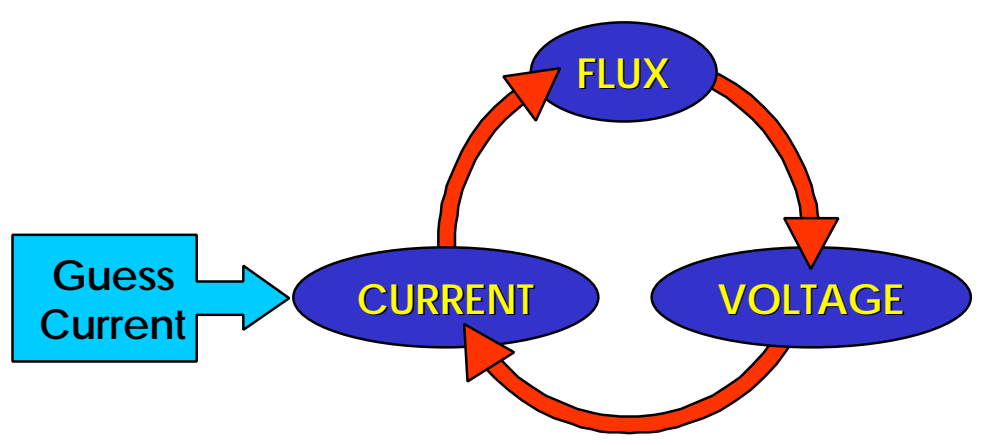

Figure 4.2-2: Illustration of problem finding Simulation Solution

or zero current is assumed), perform the simulation, and verify the assumption with a comparison on the initial flux to the flux with the current applied. Figure 4.2-2 illustrates this process.

\subsection{Model Validation}

The usefulness of any developed model and simulation can be determined by the accuracy with which they represent the actual system. To determine the usefulness of the models and simulations developed for the linear alternator and engine system in the previous sections and chapters, the results of the simulations must be validated against known data.

To validate the simulations, the finite element model was applied to the existing air core linear alternator and engine. The simulation output was then compared with experimental data obtained from the actual machine. The following figures illustrate the results of the simulation and compare these results to the existing 


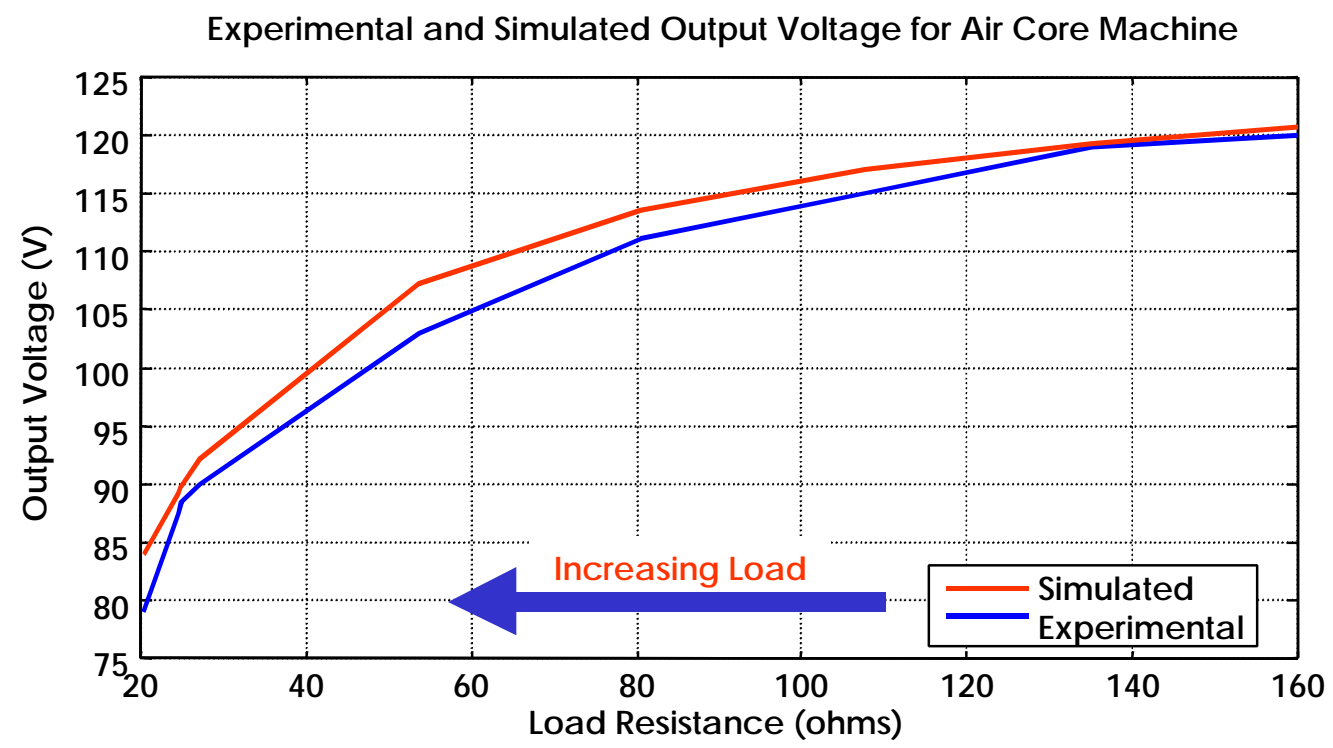

Figure 4.3-1: Experimental and Simula ted Output Voltage for the existing a ir core ma chine

machine. Figure 4.3-1 shows the simulated and experimental output voltage, while Figure 4.3-2 illustrates the simulated and experimental output power over the load range for the existing air core machine.

Figures 4.3-1 and 4.3-2 show that the simulated and the experimental results

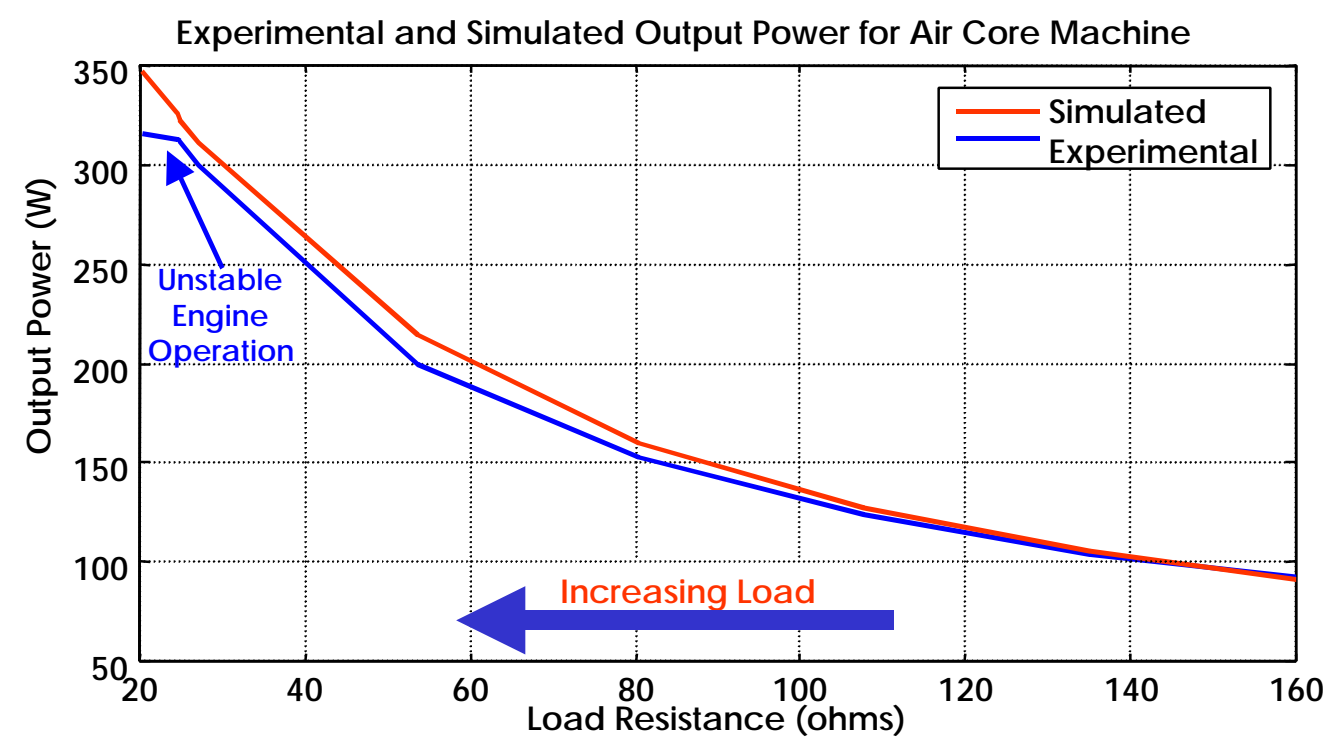

Figure 4.3-2: Experimental and Simulated Output Power for the existing a ir core ma chine 


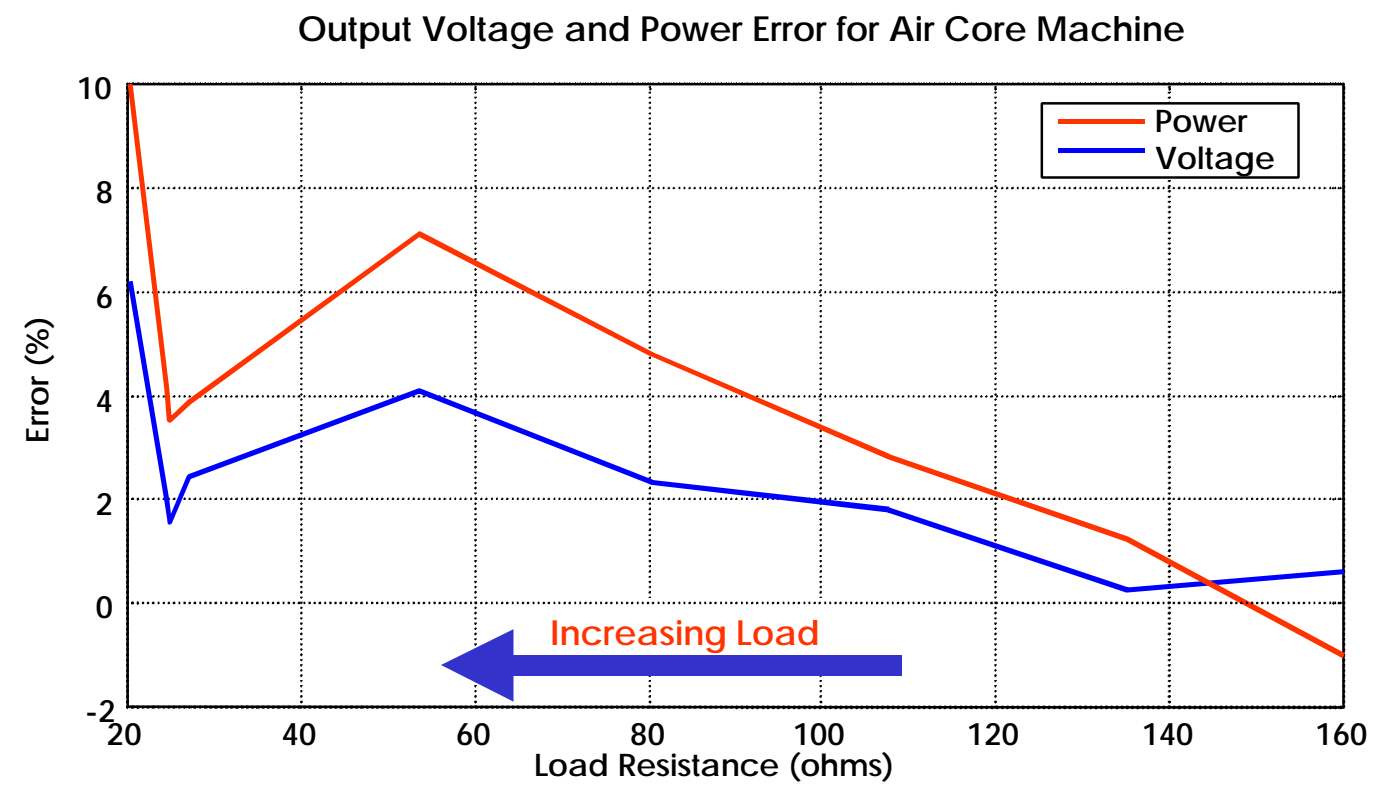

Figure 4.3-3: Error between Experimenta I and Simula ted O utput Powerand Output Voltage for the existing a ir core machine

demonstrate a strong correlation, indicating that the models used for the engine and alternator do, in fact, accurately represent the existing system. Figure 4.3-3 illustrates the error between the experimental data and the simulated data. Equation 4.3-1 was used to calculate the error between the experimental and the simulated data.

$$
\text { Error }=\frac{\text { Simulated }- \text { Experimental }}{\frac{\text { Simulated }+ \text { Experimental }}{2}} * 100
$$

This data shows that the finite element model and the simulation routine provide an accurate representation of the air core linear machine. As expected, the errors are larger at higher loads due to the simple engine model used. During the experimental data collection, it was observed that the engine frequency decreased as the load was increased. In fact, the load level was limited by the output capability of 
the engine. At the highest load used in this test, the engine operation became unstable resulting in the problem with the experiment power trace in Figure 4.3-2.

The engine model used in this simulation does not account for the engine speed decrease due to higher load. Therefore, the simulated voltage is greater than the experimental because the simulated machine moves faster. Without formulation of a much more complex engine model, this speed difference cannot accurately be determined.

With the finite element analysis model and the simulation routine validated against the experimental data for the existing machine, the finite element model was then modified for use with the iron core machine. Since the finite element model was shown to accurately model the air core machine, the slight changes necessary to convert the model to an iron core machine will not affect the accuracy of the analysis. In addition, the validation of the air core simulation indicates that not only are the models good, but also that the simulation process is also accurate. 
\begin{tabular}{l} 
CHAPTER \\
FIVE \\
\hline
\end{tabular}

\section{OPTIMIZATION}

Due to the many choices available, a number of combinations of parameters exist for the linear alternator and engine system which would meet a desired output voltage and output power. However, each of these different designs would result in a machine with a different efficiency and different volume. Since the goal of this research is to find the most efficient alternator with the smallest volume, a method must be developed for selecting this design. The optimization routines discussed in this chapter provide a method for selecting a design.

The MATLAB function for constrained minimization is used to perform the optimization. The chapter provides an overview of the techniques employed by MATLAB to determine the optimum design. Then, the function written to interact with MATLAB to optimize the linear alternator is explored. Some of the problems encountered in creating this function are examined, and the engineering choices made are discussed. An examination of the bounds selected for the optimization variables is given. Finally, the optimization is performed to select the best possible alternator for a specific linear engine, and the results of the optimization are presented and discussed. 


\subsection{Ovenview of MATLAB Constrained Optimization Routine}

The goal of an optimization is to determine the system parameters, $\mathbf{x}$, such that some system characteristic is minimized or maximized. More detailed optimizations included constraints on the system parameters and are capable of handling bounds on the parameters. In general, the optimization problem can be stated as

$$
\begin{array}{llll} 
& & \multicolumn{2}{c}{\operatorname{MINIMIZE} f(\mathbf{x})} \\
\text { subject to } & g_{i}(\mathbf{x})=0 & i=1 \ldots n & \text { equality constraint } \\
& g_{i}(\mathbf{x}) \leq 0 & i=n+1 \ldots m & \text { inequality constraint } \\
& \mathbf{x}_{\mathbf{1}} \leq \mathbf{x} \leq \mathbf{x}_{\mathbf{u}} & & \text { parameter boundaries }
\end{array}
$$

To solve this optimization problem, the MATLAB command for constrained optimizations, CONSTR, uses a Sequential Quadratic Programming (SQP) method. The SQP method involves approximating the Hessian of the Lagrangian function for each iteration. The Hessian is then used to formulate a Quadratic Programming (QP) sub-problem whose solution is used to find the search direction in a line search procedure which updates the design parameters, $\mathbf{x}$, for the next iteration [1].

Implementation of the SQP technique involves updating the Hessian matrix of the Lagrangian function given in equation 5.1-2.

$$
L(\mathbf{x}, \lambda)=f(\mathbf{x})+\sum_{i=1}^{m} \lambda_{i} g_{i}(\mathbf{x})
$$


The Hessian updates are performed based on the formulation by Broyden [2], Fletcher [3], Goldfarb [4], and Shanno [5] (BFGS) as given in (5.1-3)

$$
\mathbf{H}_{k+1}=\mathbf{H}_{k}+\frac{\mathbf{q}_{k} \mathbf{q}_{k}^{T}}{\mathbf{q}_{k}^{T} \mathbf{s}_{k}}-\frac{\mathbf{H}_{k}^{T} \mathbf{H}_{k}}{\mathbf{s}_{k}^{T} \mathbf{H}_{k} \mathbf{s}_{k}}
$$

where $\mathbf{s}_{k} \equiv \mathbf{x}_{k+1}-\mathbf{x}_{k}$

$$
\mathbf{q}_{k} \equiv \nabla f\left(\mathbf{x}_{k+1}\right)+\sum_{i=1}^{m} \lambda_{i} \nabla g_{i}(\mathbf{x})_{k+1}-\left(\nabla f\left(\mathbf{x}_{k}\right)+\sum_{i=1}^{m} \lambda_{i} \nabla g_{i}(\mathbf{x})_{k}\right)
$$

The starting Hessian matrix can be set to any positive definite, symmetric matrix, such as the identity matrix, $\mathbf{I}$.

With the Hessian updated, the QP sub-problem is formulated by performing a quadratic approximation of the Lagrangian function given in equation (5.1-2). By incorporating the parameter bounds into the inequality constraints and including the Hessian formulation, the general optimization problem can be expressed as

$$
\begin{array}{lll} 
& \text { MINIMIZE } \frac{1}{2} \mathbf{d}^{T} \mathbf{H}_{k} \mathbf{d}+\nabla f\left(\mathbf{x}_{k}\right) \mathbf{d} \\
\text { subject to } & \nabla \mathbf{g}_{i}(\mathbf{x})^{T} \mathbf{d}+\mathbf{g}_{i}(\mathbf{x})=0 & i=1 \ldots n \\
& \nabla \mathbf{g}_{i}(\mathbf{x})^{T} \mathbf{d}+\mathbf{g}_{i}(\mathbf{x}) \leq 0 & i=n+1 \ldots m
\end{array}
$$

The solution of QP problem in equation 5.1-4 can be determined by examining the general quadratic programming problem given as

$$
\begin{array}{llr} 
& \text { MINIMIZE } \frac{1}{2} \mathbf{x}^{T} \mathbf{H} \mathbf{x}+\mathbf{c}^{T} \mathbf{x} \\
\text { subject to } & \mathbf{A}_{i} \mathbf{x}=b & i=1 \ldots n \\
& \mathbf{A}_{i} \mathbf{x} \leq b & i=n+1 \ldots m
\end{array}
$$


The solution to 5.1-5 involves maintaining a set of the estimates of the active problem constraints, $\bar{A}_{k}$. A basis, $\mathbf{Z}_{\mathrm{k}}$, whose columns are orthogonal to $\bar{A}_{k}$ can be formed, as shown in equation 5.1-6, from the last $m-l$ columns of the QR decomposition of $\bar{A}_{k}$ where $l$ is the number of active constraints [1].

$$
\begin{gathered}
\mathbf{Q} \overline{\mathbf{A}}_{k}^{T}=\left[\begin{array}{c}
\mathbf{R} \\
0
\end{array}\right] \\
Z_{k i j}=Q_{i j} \quad i=1: n ; j=m-l: m
\end{gathered}
$$

The basis, $\mathbf{Z}_{\mathrm{k}}$, represents the feasible subspace for the search direction $\mathbf{d}_{\mathrm{k}}$. As long as the search direction is formed as a combination of the columns of $\mathbf{Z}_{\mathrm{k}}$, it will remain on the boundaries of the active constraints. So, if $\mathbf{p}$ is a vector of constraints, the search direction, $\mathbf{d}_{\mathrm{k}}$, can be given as

$$
\mathbf{d}_{k}=\mathbf{p} \mathbf{Z}_{k}^{T}
$$

Then, the new iterate can be found from

$$
\mathbf{x}_{k+1}=\mathbf{x}_{k}+\alpha_{k} \mathbf{d}_{k}
$$

With this definition for the new iterate, the value of the objective function in equation 5-1.5 can be expressed at iteration $k+1$ as 


$$
f(\mathbf{p})_{k+1}=\frac{1}{2}\left(\mathbf{x}_{k}+\mathbf{p} \mathbf{Z}_{k}\right)^{T} \mathbf{H}\left(\mathbf{x}_{k}+\mathbf{p} \mathbf{Z}_{k}\right)+\mathbf{c}^{T}\left(\mathbf{x}_{k}+\mathbf{p} \mathbf{Z}_{k}\right)
$$

The projected gradient of the objective function in the $\mathbf{Z}_{\mathrm{k}}$ subspace can subsequently be found by differentiating equation $5.1-9$ with respect to $\mathbf{p}$, which yields

$$
\nabla f(\mathbf{p})_{k+1}=\mathbf{Z}_{k}^{T} \mathbf{H} \mathbf{Z}_{k} \mathbf{p}+\mathbf{Z}_{k}\left(\mathbf{H} \mathbf{x}_{k}+\mathbf{c}\right)
$$

The minimum of the objective function at iteration $k+l$ is found by setting the projected gradient equal to zero. The set of constraints, $\mathbf{p}$, which minimizes the objective function at the next iterate is found by solving the system of linear equations given in equation 5.1-11.

$$
\mathbf{Z}_{k}^{T} \mathbf{H Z} \mathbf{Z}_{k} \mathbf{p}=-\mathbf{Z}_{k}\left(\mathbf{H} \mathbf{x}_{k}+\mathbf{c}\right)
$$

Once equation 5.1-11 is solved for the set of constraints, $\mathbf{p}$, which minimizes the objective function as the next iterate, the new search direction can be found as

$$
\mathbf{d}_{k+1}=\mathbf{p} \mathbf{Z}_{k}^{T}
$$

and the new iterate $\mathbf{x}_{k+1}$ can be found by adding a step in the search direction to the previous value of $\mathrm{x}$, as shown in equation 5.1-13. 


$$
\mathbf{x}_{k+1}=\mathbf{x}_{k}+\alpha_{k} \mathbf{d}_{k}
$$

The step length, $\alpha_{k}$, in equation $5.1-13$ is selected to produce a decreasing merit function. The merit function utilized has the form [1]

$$
?(\mathbf{x})=f(\mathbf{x})+\sum_{i=1}^{n} r_{i} g_{i}(\mathbf{x})+\sum_{i=n}^{m} r_{i} \max \left(0, g_{i}(\mathbf{x})\right)
$$

where penalty parameter, $r$, is defined as

$$
r_{k i}=\max \left\{\lambda_{i}, \frac{1}{2}\left(r_{(k-1) i}+\lambda_{i}\right)\right\} \quad i=1 . . m
$$

\subsection{Linear Altemator and Engine Optimization Function and Bound Selection}

The optimization in this work was written to optimize a permanent magnet brushless linear alternator with respect to the efficiency and volume of the alternator using the CONSTR command in MATLAB. This inputs for this command include a function which returns the value to be optimized and the limits on the design variables. This section examines the optimization function for the linear alternator optimization and examines the selection of the parameter bounds. 


\subsubsection{Optimization Function}

The optimization routine takes the desired output power and the desired output voltage as inputs and finds the alternator and engine configuration that minimizes the specified objective function for a given engine. Since the MATLAB optimization command is written to minimize the objective function, and part of the desire is to maximize the system conversion efficiency, the efficiency portion of the objective function must be defined as the reciprocal of efficiency as shown in equation 5.2.1-1. This part of the objective function directs the optimization routine to maximize the efficiency.

$$
\text { OBJECTIVE FUNCTION }=\frac{1}{\text { efficiency }}
$$

The system efficiency is determined by finding the ratio of the output power to the input power. In this situation, the input power is considered the power delivered to the alternator, so the efficiency of the engine is not considered. Therefore, the input power can be found by adding the core and copper losses to the electrical output power. Figure 5.2.1-1 illustrates the power flow diagram used in this calculation.

The core losses are found from data supplied by the manufacturer. This data gives core loss values for a range of induction and is developed for excitation at $60 \mathrm{~Hz}$. Therefore, a correction factor is needed to use this information at frequencies other than $60 \mathrm{~Hz}$. In [6], the core loss is shown to be proportional to the frequency of 


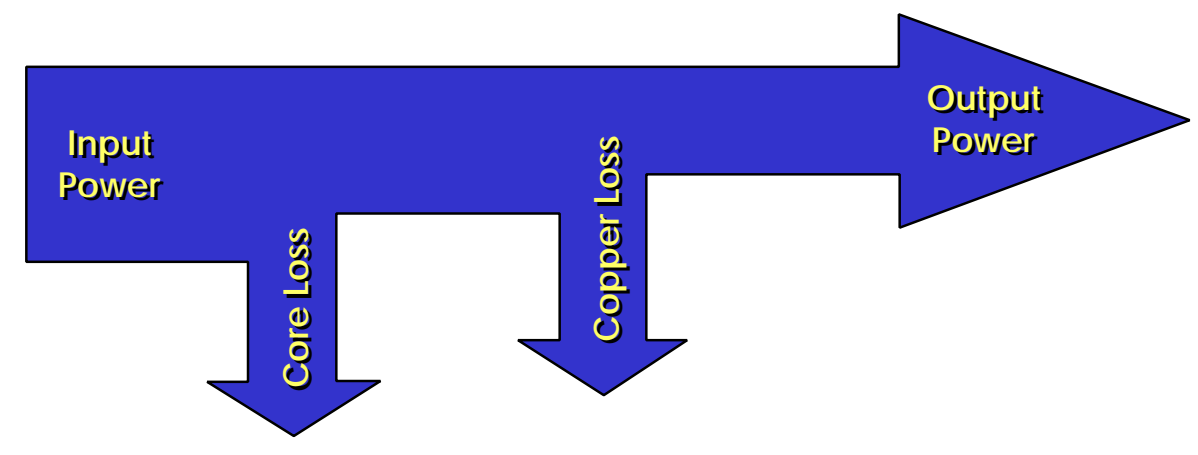

Figure 5.2.1-1: Linear Altemator Power Flow Diagram

excitation. Consequently, the core loss at an arbitrary frequency, $f_{a}$, can be found by determining the core loss at $60 \mathrm{~Hz}$ at the simulated level of induction from the supplied data and applying the correction as shown in equation 5.2.1-2.

$$
\text { Coreloss }=\text { Coreloss }_{60 \mathrm{~Hz}}\left(\frac{f_{a}}{60 \mathrm{~Hz}}\right)
$$

The volume of the machine is also to be considered as part of the optimization. The term of the objective function for minimizing the volume is not as easily found as that of the efficiency. The efficiency is always between zero and one, so this term is naturally normalized. The volume, on the other hand, is free to take on a large range of values which are not limited. To incorporate these two terms into a single objective function, the volume term must be normalized.

To accomplish this normalization, the machine is first optimized such that the volume is minimized and the output criteria are satisfied without regard to the system efficiency, using the objective function shown in equation 5.2.1-3. 
The minimum volume found from this optimization is then used as the normalization factor for the volume. The final objective function, which combined the minimization of the volume with the maximization of the efficiency is given as shown in equation 5.2.1-4. The coefficient of the efficiency term, $C_{e}$, is set to $90 \%$ to reflect the increased importance of the efficiency over the volume in the optimization.

$$
\text { OBJECTIVE FUNCTION }=C_{e}\left(\frac{1}{\text { efficiency }}\right)+\left(1-C_{e}\right) \frac{\text { Volume }_{\text {Volume }_{\text {MIN }}}}{(}
$$

The optimization routine takes a set of user supplied optimization variables as an initial guess at the optimum design and passes these parameters along with an optimization function and the parameter bounds to the MATLAB command CONSTR which performs the constrained minimization.

The goal of this work is to select the best alternator for a particular linear engine. The engine to be used in this part of the research is a new engine being constructed at the Engine Research Center at West Virginia University. The pertinent parameters of the engine are given in Table 5.2.1-1. 
Table 5.2.1-1: Parameters for New Engine

\begin{tabular}{|l|l|l|}
\hline Bore & 76 & $\mathrm{~mm}$ \\
\hline Maximum Stroke & 70 & $\mathrm{~mm}$ \\
\hline Compression Ratio & 28 & \\
\hline Expected Output Power & 5.9 & $\mathrm{~kW}$ \\
\hline
\end{tabular}

With this particular engine selected, the optimization can be performed to find the alternator which best suits the given engine. The alternator parameters that are used as optimization variables are shown in Table 5.2.1-2. Not all of the possible parameters of the system are used as optimization variables. In fact, the air gap length and the slot depth were not used as optimization variables.

TABLE 5.2.1-2: Optimization Parameters

\begin{tabular}{|l|}
\hline \multicolumn{1}{|c|}{$\begin{array}{c}\text { OPTIMIZATION } \\
\text { PARAMETERS }\end{array}$} \\
\hline Magnet Fraction \\
\hline Magnet Height \\
\hline Slot Fraction \\
\hline Backiron Height \\
\hline Number of Windings \\
\hline Wire Size \\
\hline Number of Parallel Paths \\
\hline
\end{tabular}

The air gap dimension will not be used as an optimization variable. In this case, the optimum design would have the air gap dimension at the prescribed lower bound since this would minimize the reluctance of the link path and result in higher fluxes for the same magnet configuration. So, the air gap dimension will simply be 
set to a constant value which allows for manufacturing capabilities as well as adequate clearance for vibration and shaft flex.

The slot depth is not used as an optimization variable because the resultant system would be over constrained. Since the desired output voltage and output power are specified constants, the optimization function must ensure that these requirements are met for every set of optimization variables passed to the function from the CONSTR routine. If the complete alternator is specified by the optimization variables, it is impossible to fulfill the desired power and voltage level requirements. Therefore, the slot depth of the alternator is not used as an optimization variable. Instead, the slot depth is calculated such that the number of windings necessary to provide the desired voltage and power will fit in the slot area.

A problem arises when finding the slot depth in that the number of windings is not known until the flux linkage is calculated. However, the flux linkage cannot accurately be determined until the slot depth is known due to the changes in reluctance as the slot depth varies. Figure 5.2.1-2 illustrates this problem.

To solve this problem, an iterative technique similar to that used in the simulation routine is necessary. The optimization function begins by providing a guess for the number of turns, $N$, equal to the number of turns found in the previous optimization step. In the case of the first optimization step, the guess is provided by the user as part of the initial machine parameters. The slot depth is then calculated so the turns will fit into the slot area, taking into account the packing fraction of the particular wire size selected. Then, the system is simulated to find the output for the 


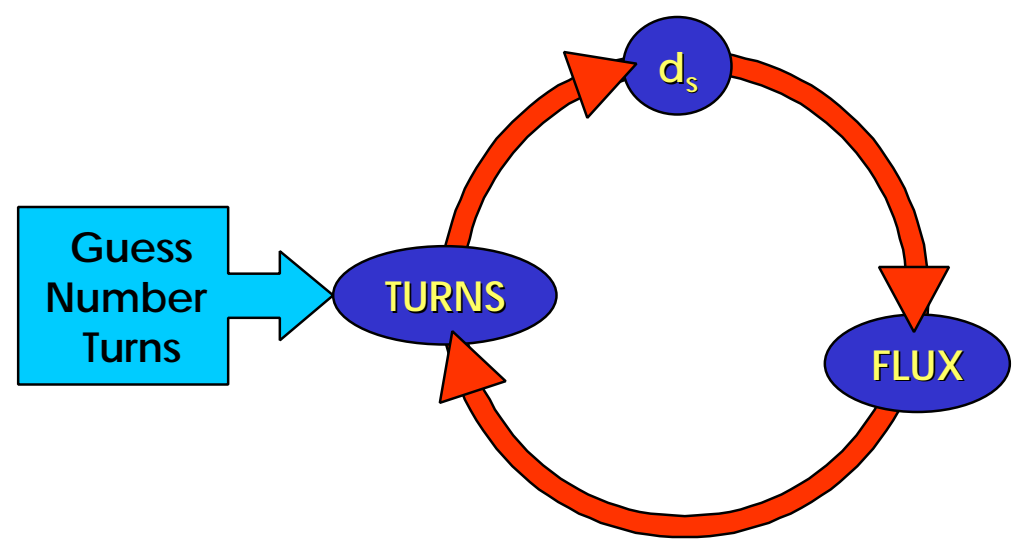

Figure 5.2.1-2: Illustration of the Problem Associated with Finding the Slot Depth and Number of Tums

system. If the number of turns produces the correct output, the optimization function returns the objective function and ends.

However, since it is highly unlikely that the initial number of turns is correct, an updated number of turns is found using equation 5.2.1-3 which accounts for the change in the voltage and the winding resistance due to the change in the number of turns. With the updated number of turns, the slot depth must be recalculated, and the machine must be simulated again to determine the effect of the change on the output.

$$
N_{\text {new }}=N_{\text {old }} \frac{V_{\text {desired }}}{V_{\text {enf }}-R_{\text {winding }} I_{\text {rated }}}
$$

where $V_{\text {emf }}$ is the internally generated voltage

$R_{\text {winding }}$ is the winding resistance

Once again, the differences between the new number of turns and the previous number of turns as well as the differences between the desired output voltage and power and the simulated output voltage and power are compared. If any of the 
differences exceeds a predefined threshold, the process is repeated until the differences fall below the desired threshold. Figure 5.2.1-3 illustrates the flow chart of the optimization function.

Once this iterative process is complete, the final system with the final number of turns is simulated. The output power and loss power are then calculated so the

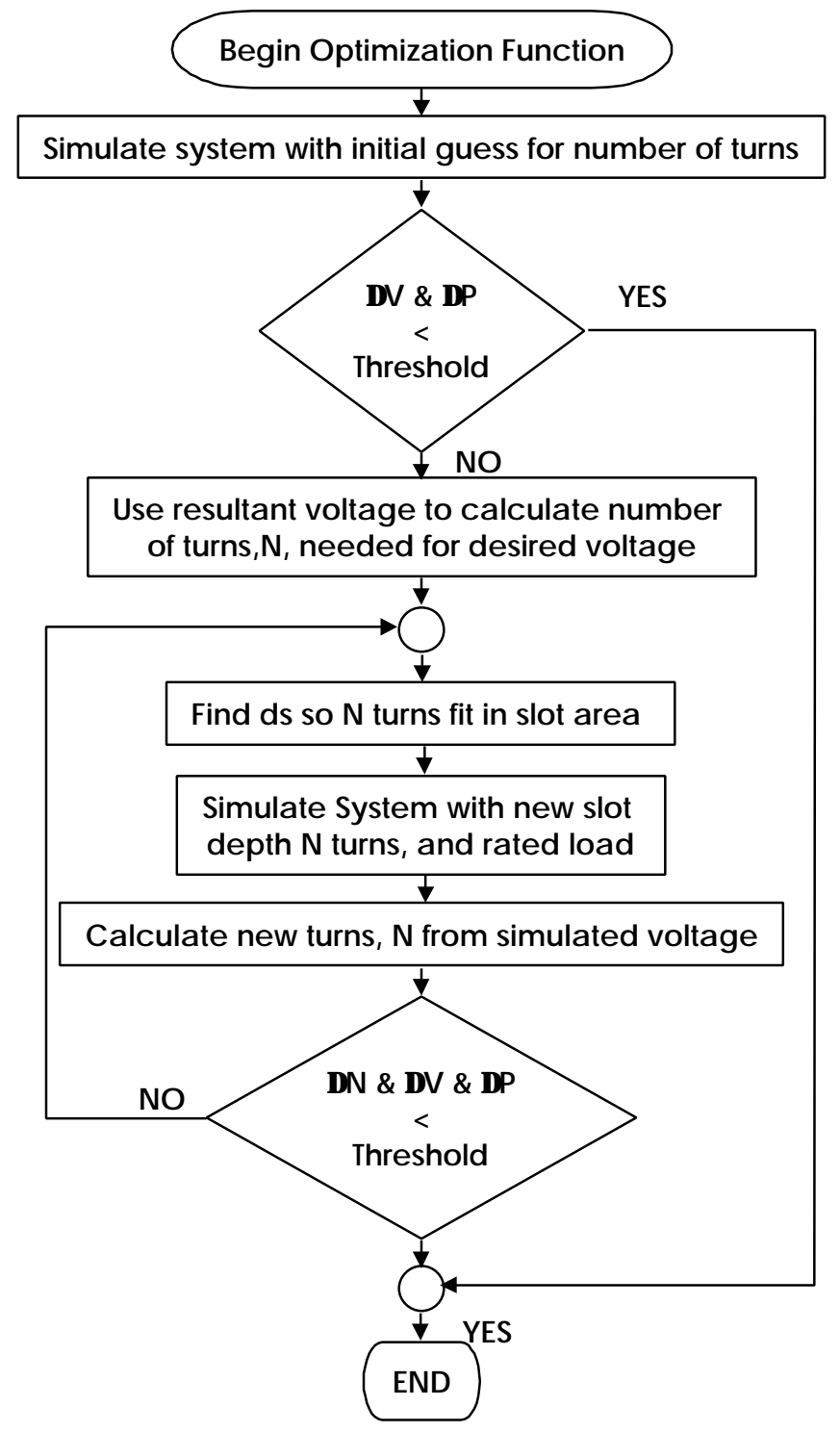

Figure 5.2.1-3: Flowchart for Optimization Function 
efficiency can be evaluated and returned to the CONSTR function.

For the optimization steps, the simplified finite element technique is used to determine the machine flux. Although this model does sacrifice some accuracy, the savings in computation time far outweighs the slightly reduced accuracy. However, since accuracy is an issue, the results of the optimization routine are confirmed using the full finite element simulation. Once the optimized model is found from the optimization routine, the model is then passed to the finite element based simulation routine. The results from the simplified simulation and the full finite element based simulation are then compared to insure the accuracy of the original simulation.

\section{$\underline{5.2 .2 \quad \text { Limit Selection }}$}

The optimization runs included in this work leave the bounds on the optimization parameters wide. This allows the optimization routines to select the best design over a wide range of possibilities. Since the goal is to provide the best design over a wide range of output voltages and powers, artificially selecting the optimization boundaries could result in a less than optimum design. Using a wide range of design possibilities, however, could result in designs that are not especially practical or feasible. In these instances, it is the responsibility of the designer to determine the feasibility of each solution and modify the optimization bounds if necessary to find a design which meets the feasibility requirement set forth. So, in this work the initial optimization bounds are selected to allow the optimization a wide range of possibilities. Then, if the resultant optimum system was deemed impractical or infeasible, the bounds were altered to find a feasible optimum solution. 
For example, the largest wire would provide the lowest copper losses. Since the largest wire size has the lowest resistivity, it would provide the lowest resistance per turn. Consequently, if left unbounded, the optimum design would utilize the largest wire size resulting in a large slot depth. By including both volume and efficiency in the optimization function, these problems can be eliminated. Although the maximization of the efficiency requires a large wire size and slot depth, the volume term forces the optimization routine to find a balance. Table 5.2.2-1 gives the upper and lower bounds placed on the alternator parameters for this optimization

\section{Table 5.2.2-1: Alternator Parameter Bounds}

\begin{tabular}{|l|c|c|l|}
\hline \multicolumn{1}{|c|}{ Parameter } & Upper Bound & Lower Bound & \multicolumn{1}{c|}{ Unit } \\
\hline Wire Size & 10 & 29 & AWG \\
\hline Parallel Paths & 1 & 10 & Paths \\
\hline Poles & 3 & 15 & Poles \\
\hline Magnet Thickness & 6.0 & 40 & $\mathrm{~mm}$ \\
\hline Magnet Fraction & 10 & 95 & $\%$ \\
\hline Slot Fraction & 10 & 95 & $\%$ \\
\hline Backiron Depth & 3.0 & 76.2 & $\mathrm{~mm}$ \\
\hline
\end{tabular}

\subsection{Optimization Results}

The optimization results provide the system parameters for a linear alternator and engine system such that the efficiency of the electrical generation is maximized and the volume minimized subject to a specified desired output power and output voltage. This section examines the results of the optimization routine by finding the alternator that best satisfies the previously developed objective function for the 
specified engine. Both an iron core and an air core machine will be examined. A discussion of the results is provided, and an examination of the ideal linear alternator is given.

The optimization results were obtained by running the developed MATLAB and ANSYS software on a Dell OptiPlex GXpro personal computer with a $233 \mathrm{MHz}$ Intel Pentium Pro processor and $64 \mathrm{MB}$ of RAM, running the Windows NT 4.0 Server operating system.

The optimization was first run to find the iron core alternator with the minimum volume that would satisfy the output criteria without regard for the efficiency of the machine. This volume was then used as the normalization factor for the volume in the combined objective function. Then, the optimization was run using the combined objective function. The resulting alternator parameters as well as the efficiency and volume for each of these optimization runs is shown in Table 5.3-1.

\section{Table 5.3-1: Optimization Results for the Iron Core Alternator}

\begin{tabular}{|l|c|c|l|}
\hline & $\begin{array}{c}\text { Minimum } \\
\text { Volume }\end{array}$ & $\begin{array}{c}\text { Efficiency } \\
\text { and Volume }\end{array}$ & \\
\hline AWG & 17 & 10 & \\
\hline Number of Poles & 3 & 3 & \\
\hline Parallel Paths & 4 & 1 & \\
\hline Slot Fraction & $60 \%$ & $62 \%$ & \\
\hline Magnet Fraction & $60 \%$ & $56 \%$ & \\
\hline Magnet Thickness & 18.7 & 19.0 & $\mathrm{~mm}$ \\
\hline Backiron Thickness & 22.8 & 21.5 & $\mathrm{~mm}$ \\
\hline Turns & 184 & 193 & \\
\hline Slot Depth & 29.6 & 34.5 & $\mathrm{~mm}$ \\
\hline Voltage & 215.7 & 225.8 & $\mathrm{~V}$ \\
\hline Power & 4806 & 5264 & $\mathrm{~W}$ \\
\hline Volume & 5.8 & 6.2 & $\mathrm{~L}$ \\
\hline Efficiency & $91.1 \%$ & $92.2 \%$ & \\
\hline
\end{tabular}


When the optimization was executed for only the minimum volume, the alternator efficiency was higher than originally expected. This can be explained by examining the wire size selected for the winding. It would seem for a minimum volume design, the choice would be to use the smallest wire size, since this would produce the minimum volume for a given number of turns. However, as the wire size gets smaller, two factors function to increase the volume. First, for smaller wire sizes, the current carrying capacity is lower, so more parallel coils are needed to carry the rated current. Second, the resistivity of smaller wire is larger, so more turns are required to overcome the additional voltage drop caused by the larger winding resistance. So, the optimization routine is forced to find a balance in the wire size. These results show that this balance is achieved in an area where the winding resistance is lower which results in a lower internal voltage drop and higher efficiencies.

Since the volume minimization produced a machine with a relatively high efficiency, the addition of the efficiency term to the objective function did not produce a significant improvement in the efficiency of the machine. As expected, the volume of the machine increased to provide an increase in the efficiency. The efficiency gain, however, required a larger percentage increase in the volume. Therefore, more highly efficient designs are possible, but these designs require a much larger volume. The selected design, then, represents a tradeoff between the efficiency and the volume of the alternator. 
The results show that in the iron core machine, there is little change in alternator geometry between the minimum volume case and the case where efficiency is considered. The only major change in the case when efficiency is considered is a change in the winding configuration, which reduces the winding resistance and increases efficiency.

The same two optimization runs were conducted for the air core machine. Table 5.3-2 shows the results for the air core machine. In the air core machine, the change in the winding configuration geometry from the minimum volume to the combined case is similar to the change in the iron core machine. However, there is a more significant change in the alternator geometry. With the addition of the efficiency term, the volume was allowed to grow to produce higher efficiencies. So, the magnet thickness and backiron thickness were increased and the slot depth decreased in an effort to increase the machine efficiency.

As with the iron core alternator, the minimum volume configuration already had a relatively high efficiency. Consequently, there was not a significant improvement in the efficiency between the runs. 
Table 5.3-2: Optimization Results for the Air Core Alternator

\begin{tabular}{|l|c|c|l|}
\hline & $\begin{array}{c}\text { Minimum } \\
\text { Volume }\end{array}$ & $\begin{array}{c}\text { Efficiency } \\
\text { and Volume }\end{array}$ & \\
\hline AWG & 17 & 11 & \\
\hline Number of Poles & 7 & 7 & \\
\hline Parallel Paths & 4 & 1 & \\
\hline Slot Fraction & $85 \%$ & $86 \%$ & \\
\hline Magnet Fraction & $57 \%$ & $80 \%$ & \\
\hline Magnet Thickness & 18.8 & 31.7 & $\mathrm{~mm}$ \\
\hline Backiron Thickness & 15.4 & 24.7 & $\mathrm{~mm}$ \\
\hline Turns & 112 & 65 & \\
\hline Slot Depth & 12.3 & 6.4 & $\mathrm{~mm}$ \\
\hline Voltage & 220.4 & 220.5 & $\mathrm{~V}$ \\
\hline Power & 5016 & 5020 & $\mathrm{~W}$ \\
\hline Volume & 7.05 & 10.6 & $\mathrm{~L}$ \\
\hline Efficiency & $89.5 \%$ & $92.4 \%$ & \\
\hline
\end{tabular}

The primary difference between the air core alternator and the iron core alternator is that the air core machine uses seven poles to the three poles in the iron core design. In the iron core machine, there is little penalty for a large slot depth since the flux is directed by the steel teeth. In the air core machine, however, the flux is significantly reduced as the slot depth increases. To keep the slot depth small and still accommodate the required number of turns, the optimization routine had to increase the number of poles. The increased number of poles accounts for the larger volumes in the air core design. 


\section{CHAPTER}

\section{SIX}

\section{CONCLUSION}

The primary goal of this research was to provide a design methodology for the selection of an engine and alternator combination. To accomplish this goal, several tasks were completed. First, models for the engine and the alternator were developed and integrated into a comprehensive model of the combined system. Next, a simulation was written to determine the output of the system for variable system parameters. An optimization method was subsequently developed for selection of the design that would fulfill the output voltage and power requirements and would maximize the efficiency and minimize the volume of the system.

\subsection{Model Development and Simulation}

One of the objectives of this work was the development of an integrated model of the linear engine and linear alternator system. Individual models of the engine and alternator were developed in Chapter 2 and Chapter 3. Then, the models were integrated in the simulation in Chapter 4.

The engine model development began by examinin $\mathrm{g}$ a simplified cross section of the linear engine. The pressure volume diagram of the idealized Otto cycle was 
then examined, and its significance to the linear engine was discussed. Next, the Otto cycle PV diagram was used to formulate a force balance equation which describes the operation of the linear engine. Finally, a simplified version of the engine describing equation was found for frictionless, no load operation. This special case model was the engine model used in the remainder of the research.

Once the engine model was found, a representation of the linear alternator was needed. Chapter 3 presented the development of a linear alternator representation using the ANSYS finite element analysis package. First, the structure of the ANSYS program was examined, and the application of the ANSYS package to the representation of the linear alternator was presented.

With the models for the engine and the alternator complete, the simulation was examined. First, the engine was simulated as a stand alone component with the translator mass equal to that of the alternator translator, thus representing the engine and alternator operating at no load. The results of this engine simulation were then compared with experimental data from the existing system operating at no load. The results indicated that the engine simulation accurately represented the operation of the linear engine.

Next, the engine and alternator models were integrated into a single simulation representing the combined system. The simulation operation was then discussed in detail, and the results of the simulation were presented. Finally, the models and simulations were validated by comparing the results of the simulation with experimental data taken on the existing machine. 


\subsection{Optimization}

The primary goal of this work was to provide a design methodology for selection of the engine and alternator parameters. A strategy was necessary to select one design over another. To make the selection, an optimization routine was developed to find the most efficient engine and alternator combination. In Chapter 5, an overview of the optimization routine was presented, and some of the problems encountered were discussed. The results of the optimization for the linear alternator and engine system were then presented and discussed.

Overall the optimizations produced reasonable results. With the complex interactions between all of the system parameters, it was difficult to predict the results of the optimizations. However, as shown in Chapter 5, the results do show that both an iron core and an air core machine can be designed to function with the new engine being constructed. The efficiency values presented in Chapter 5 are only the generation efficiencies. The overall system efficiency, with the engine included, is not considered.

\subsection{Future Work}

A secondary objective of the work was to provide a basis for future exploration of the linear alternator and engine system. Several avenues exist for further investigation into the best design for a linear alternator and engine system. 
Some possibilities include an improved engine simulation, other alternator configurations, and full finite element optimizations.

One possible step to further this research would be the integration of an improved engine simulation. The model used for the linear engine in this work is a simplified model which provides only the natural frequency of the system and the speed profile under ideal, no load conditions as discussed in Chapter 2. Although this simplified model functioned for this work, an improved engine model would increase the accuracy of the simulations and optimizations. In particular, an improved engine model would provide a representation of the speed profile at various loading levels and would also examine the efficiency of the engine.

In addition to an improved engine model, another step to further this work would be the investigation of other alternator configurations. This work examines an axial flux, permanent magnet, iron core alternator. Future work could examine radial flux machines, or the use of shoes on the stator teeth could be examined. This research could also be expanded to examine a three phase alternator. Additionally, this research provides a framework for the examination of induction, reluctance, or other types of alternators.

Finally, due to the computational time required for the finite element solutions, this research used a simplified finite element approach for the optimizations. Although the simplified approach matches the full finite element results with some degree of accuracy, performing the optimizations using the full finite element based simulations certainly would prove more accurate. However, the full finite element optimization was impractical due to the extraordinarily long time 
necessary to complete the optimization. With more powerful processors, it may be possible in the future to implement the entire optimization routine with the full finite element based simulations, rather than having to rely on simplified simulations. 


\section{REFERENCES}

\section{Chapter 1:}

[1] Richard L. Browder, "Increasing The Availability Of Emergency Diesel Generators," American Society of Mechanical Engineers, Proceedings of the Joint ASME/IEEE Power Generation Conference, Oct. 17-22 1993.

[2] Bishu Chatterjee, "Use Of Diesel Generators For Coping With Loss Of Offsite Power," Proceedings of the 1994 Industrial Power Conference Proceedings of the 1994 Industrial Power Conference, Mar. 27-30, 1994.

[3] William M. Chase, Jr. "Emergency Power Design For High-Rise Buildings," Consulting-Specifying Engineer, Vol. 3, No. 2, p 35-38, Feb. 1988.

[4] Chandrabhan Sharma, Fazil Bacchus, and Albert Gordon, "Computer Aided Solution For Loading A Standby Generator," West Indian Journal of Engineering, Vol. 13, No. 1, p 65-81, Jan. 1988.

[5] Ed Palko, "Selecting And Applying Standby Generators," Plant Engineering, Vol. 41, No. 8, p 36-42, Apr. 23, 1987.

[6] C.N. Nightingale, “ A.C. Standby Power Systems For Satellite Communications Earth Stations," International Telecommunications Energy Conference Proceedings, p 17-23, 1986.

[7] Alan T. Krawczak, and Brian K.Wilson, "Analysis Of Emergency Diesel Generators For Improved Reliability," Proceedings of the 55th Annual Meeting of the American Power Conference, Vol. 55, No. PT 2, Apr. 1993.

[8] Umberto Grasselli, "Reliability Survey Of Standby Generator By Evaluation Of Maintenance Service Data," IEEE Conference Record of Industrial and Commercial Power Systems Technical Conference Proceedings of the 1994 IEEE Industrial and Commercial Power Systems.

[9] I. Boldea, and S. A. Nasar, "Permanent-Magnet Linear Alternators--Part I: Fundamental Equations," IEEE Transactions on Aerospace Electronic Systems, Vol. AES-23, No. 1, p 73-78, Jan. 1987.

[10] I. Boldea, and S. A. Nasar, "Permanent-Magnet Linear Alternators--Part II: Design Guidelines," IEEE Transactions on Aerospace Electronic Systems, Vol. AES-23, No. 1, p 79-82, Jan. 1987. 
[11] S. A. Nasar, and C. Chen, "Optimal Design Of A Tubular Permanent Magnet Linear Alternator," Electric Machines and Power Systems, Vol. 14, No. 3, p 249-259, 1988.

[12] J.C. Holliday, S.G. Howell, M. Richter, "Free-Piston Linear Alternator Solar Stirling Engine Concept," Proceedings of the $21^{\text {st }}$ Intersociety Energy Conversion Engineering Conference, p 468-473, 1986.

[13] George R. Dochat, "Development Of A Small Free-Piston Stirling Engine, Linear-Alternator System For Solar Thermal Electric Power Applications," SAE Preprints, Feb. 23-27, 1981.

[14] George Dochat, Thomas Moynihan, and Nanmohan Dahr, "1-kW Free-Piston Stirling Engine/Linear Alternator Test Program," Proceedings of the Intersociety Energy Conversion Engineering Conference, Vol. 3, Aug. 128-22, p 1976-1981, 1980.

[15] Richard K. Shaltens and Jeffery G. Schreiber, "Preliminary Designs For A 25 Kw Advanced Stirling Conversion System For Dish Electric Applications," Proceedings of the $25^{\text {th }}$ Intersociety Energy Conversion Engineering Conference, Vol. 6, p 310-316, Aug. 12-17, 1990.

[16] G. Benvenuto, and F. de Monte, "Analysis Of Free-Piston Engine/Alternator Systems Part 1: Theory," Journal of Propulsion and Power, Vol. 11, no. 5, p 1036-1046, Sept.-Oct. 1995.

[17] Necati Ulusoy, and Frances McCaughan, "Nonlinear Analysis Of Free Piston Stirling Engine/Alternator System," Proceedings of the $29^{\text {th }}$ Intersociety Energy Conversion Engineering Conference, Vol. 4, p 1847-1852, Aug. 7-11, 1994.

[18] David M. Kankam, Jeffery S. Rauch, Walter Santiago, "Dynamic Analysis Of Free-Piston Stirling Engine/Alternator-Load System - Experimentally Validated," Proceedings of the $27^{\text {th }}$ Intersociety Energy Conversion Engineering Conference, Vol. 5, p 315-323, Aug. 3-7, 1992.

[19] David M. Kankam, Jeffery S. Rauch, "Transient And Steady-State Performance Of Space Power Research Engine With Resistive/Motor Loads," Proceedings of the $31^{\text {st }}$ Intersociety Energy Conversion Engineering Conference, Vol. 2, p 1277-1280, Aug.11-16, 1996.

[20] Z. X. Fu, S. A. Nasar, and Mark Rosswurm, "Stability Analysis Of Free Piston Stirling Engine Power Generation System," Proceedings of the $27^{\text {th }}$ Intersociety Energy Conversion Engineering Conference, Vol. 5, p 13 -21, Aug. 3-7, 1992. 
[21] Parviz Famouri, William R. Cawthorne, Nigel Clark, Subhash Nandkumar, Christopher Atkinson, Richard Atkinson, Thomas McDaniel, Sorin Petreanu. "Design And Testing Of A Novel Linear Alternator And Engine System For Remote Electrical Power Generation," Proceedings of the IEEE Power Engineering Society Winter Meeting 1999, p 108-112, New York, Feb. 1999.

\section{Chapter 2:}

[1] Subhash Nandkumar, "Two Stroke Linear Engine," Thesis Collection, West Virginia University.

[2] Nigel Clark, Subhash Nandkumar, Christopher Atkinson, Richard Atkinson, Thomas McDaniel, Sorin Petreanu, Parviz Famouri, William R. Cawthorne. "Operation of a Small Bore Two-Stroke Linear Engine," Proceedings of the 1998 Fall Technical Conference of the ASME Internal Combustion Engine Division, Vol. ICE 31-1, p 33-40, 1998.

\section{Chapter 3:}

[1] P. P. Silvester, and R. L. Ferrari, Finite Elements For Electrical Engineers, Cambridge University Press, Cambridge, 1983.

[2] Peter Kohnke, ANSYS Theory Reference, Ansys Inc. Cannonsburg, PA, 1998.

[3] David K. Cheng, Field and Wave Electromagnetics, Addison-Wesley, Reading, MA, 1990.

[4] P. Silvester, "Finite Element Solution of Saturable Magnetic Field Problems," IEEE Transactions on Power Apparatus and Systems, Vol. PAS-89, No. 7, Sept./Oct. 1979.

\section{Chapter 4:}

[1] Nigel Clark, Subhash Nandkumar, Christopher Atkinson, Richard Atkinson, Thomas McDaniel, Sorin Petreanu, Parviz Famouri, William R. Cawthorne. "Operation of a Small Bore Two-Stroke Linear Engine," Proceedings of the 1998 Fall Technical Conference of the ASME Internal Combustion Engine Division, Vol. ICE 31-1, p 33-40, 1998. 


\section{Chapter 5:}

[1] Andrew Grace, Optimization Toolbox For Use with MATLAB, The MathWorks, Natick, Massachusetts, 1990.

[2] C.G. Broyden, "The Convergence of a Class of Double-rank Minimization Algorithms," J. Inst. Mathematics. Applications, Vol. 6, p 76-90, 1970.

[3] R. Fletcher, "A New Approach to Variable Metric Algorithms, " Computer Journal, Vol. 13, p 317-322, 1970.

[4] D. Golfarb, "A Family of Variable Metric Updates Derived by Variational Means," Mathematics of Computing, Vol. 24, p 23-26, 1970.

[5] D.F. Shanno, "Conditioning of Quasi-Newton Methods for Function Minimization," Mathematics of Computing, Vol. 24, p 647-656, 1970.

[6] Duane C. Hanselman, Brushless Permanent-Magnet Motor Design, McGraw Hill, New York, 1994. 


\section{APPENDIX}

\section{A Program Code}

\section{alist.m}

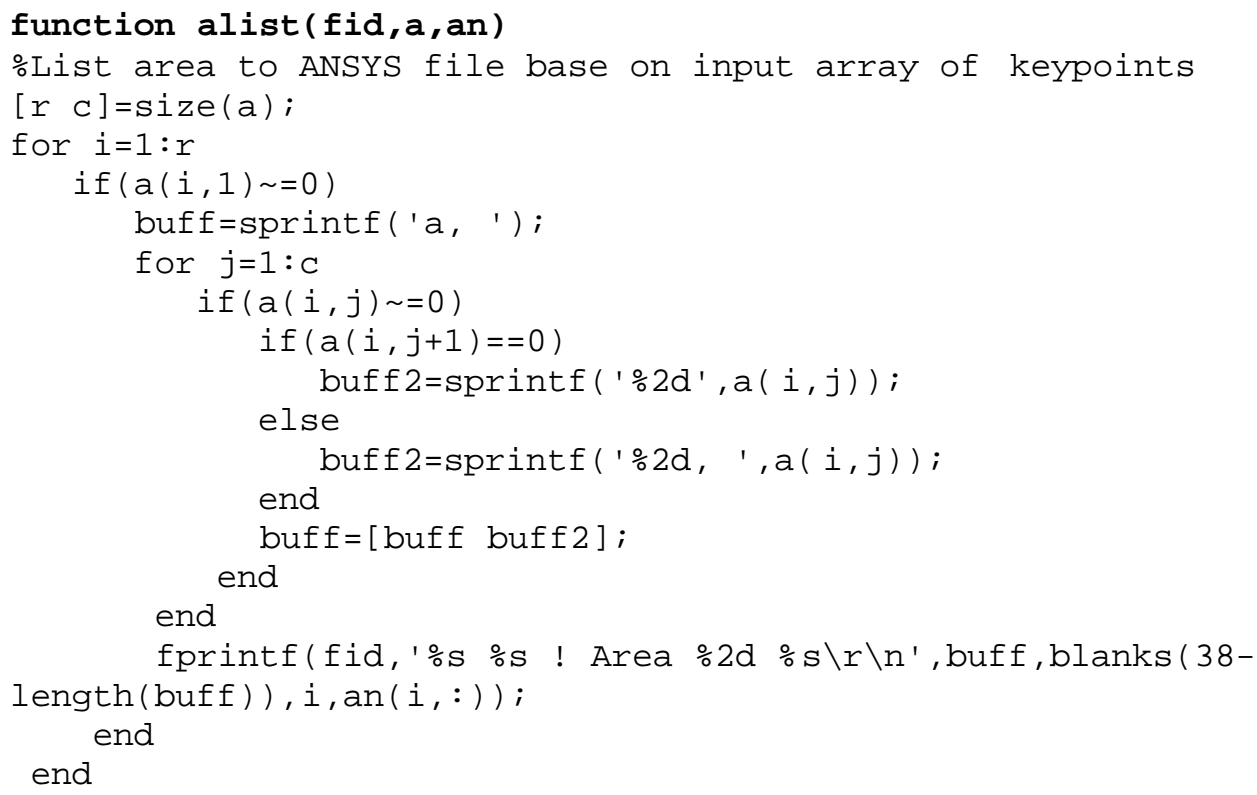

\section{axial.m}

function $[A, 1]=\operatorname{axial}(I R, t, h)$

This function returns the cross sectional area

\% and length for reluctance calculations for

\% a cylinder with flux flowing axially

o through the cylinder. 


\section{bhcurve.m}

function $[\mathrm{B}, \mathrm{H}]=$ bhcurve;

\% Supplies BH curve data for Armco M-6 silicon steel

- Data derived from Armco data sheets

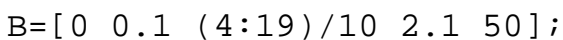

$\mathrm{ur}=\left[\begin{array}{lllllllllllll}152.05 & 181.97 & 330 & 400 & 470 & 530 & 600 & 650 & 700 & 710 & 720 & \ldots\end{array}\right.$

$7006305003301809020 \quad 21 / 100 \quad 2 / 100] * 100$;

uo $=4 e^{-7 *}$ pi;

$\mathrm{H}=\mathrm{B}$. / ( ur*uo);

Hoe $=\mathrm{H} * 0.01257$; $\%$ Convert or oe

\section{calc b.m}

function [B_bi, B_teeth] =

calc_B (tau, dshaft, dm, dg, ds,dsbi, as, flux_max)

o Calculate flux density based on flux and area for teeth and backiron

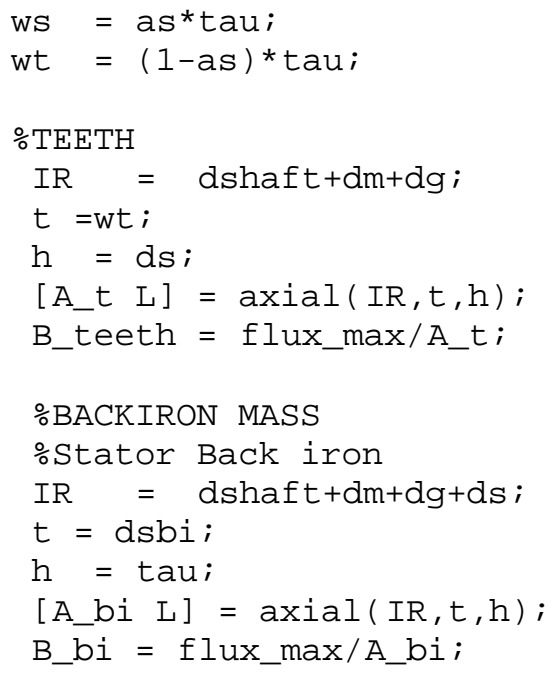




\section{calc mass.m}

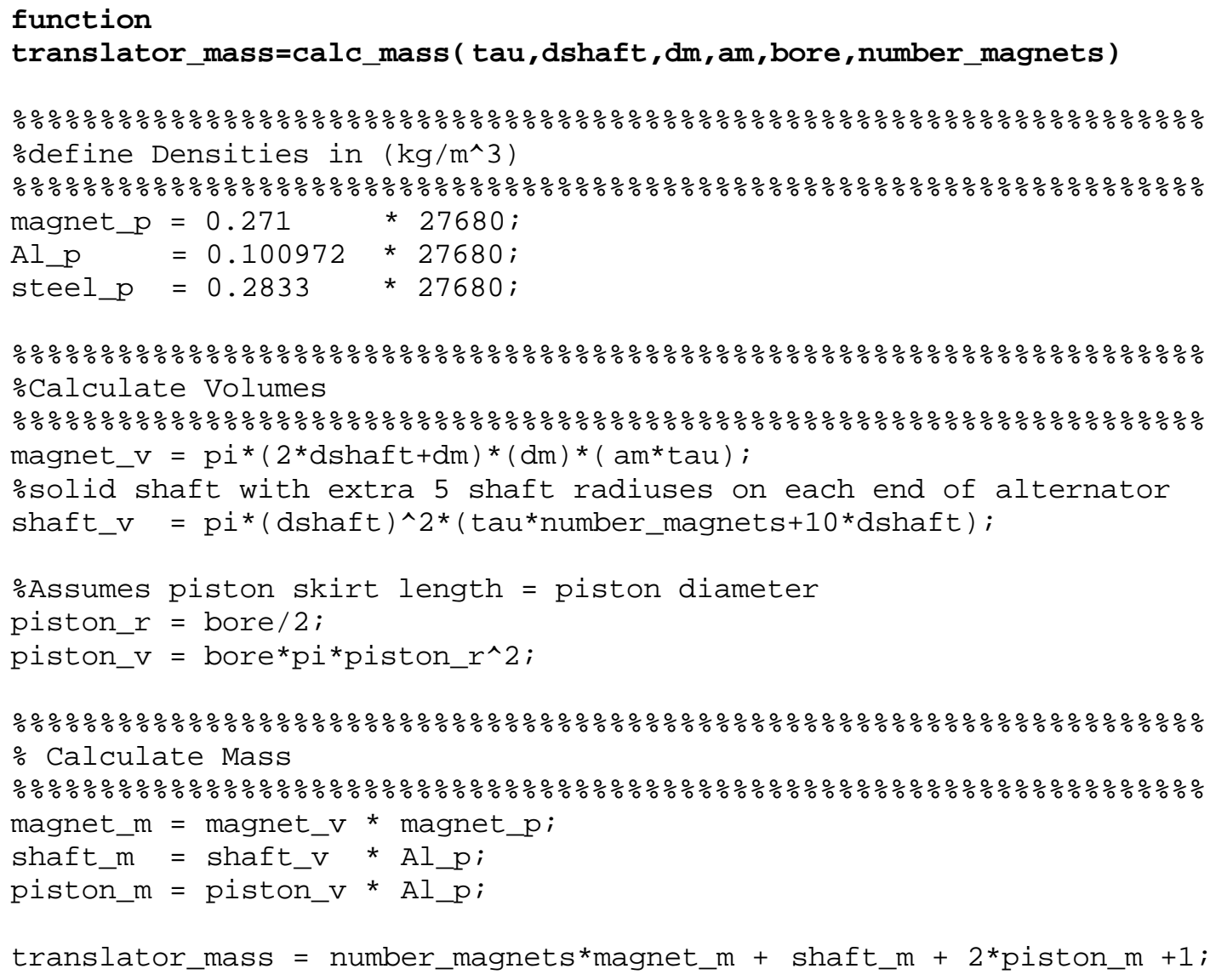




\section{calc_stator_mass.m}

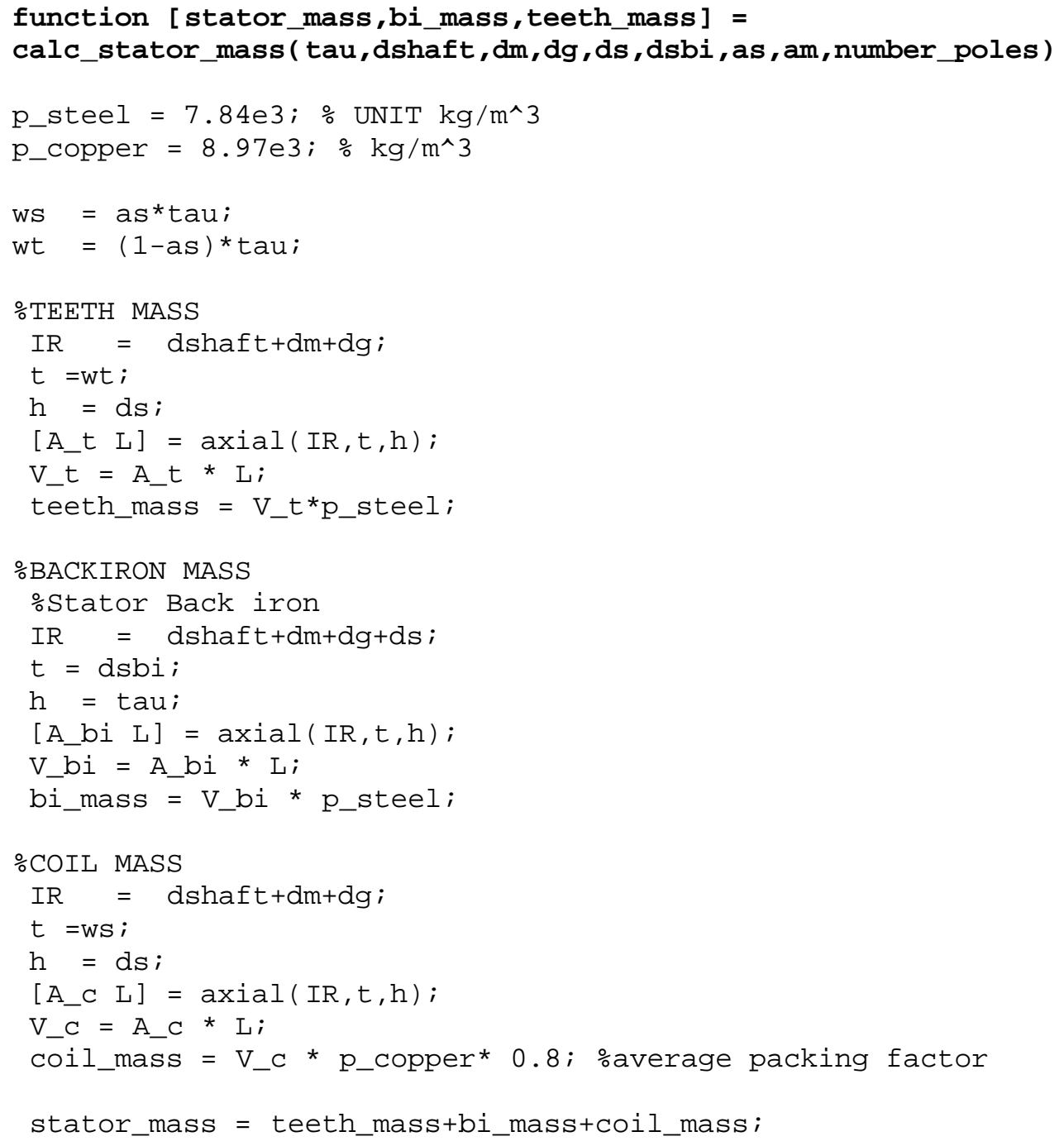

\section{Coreloss.m}

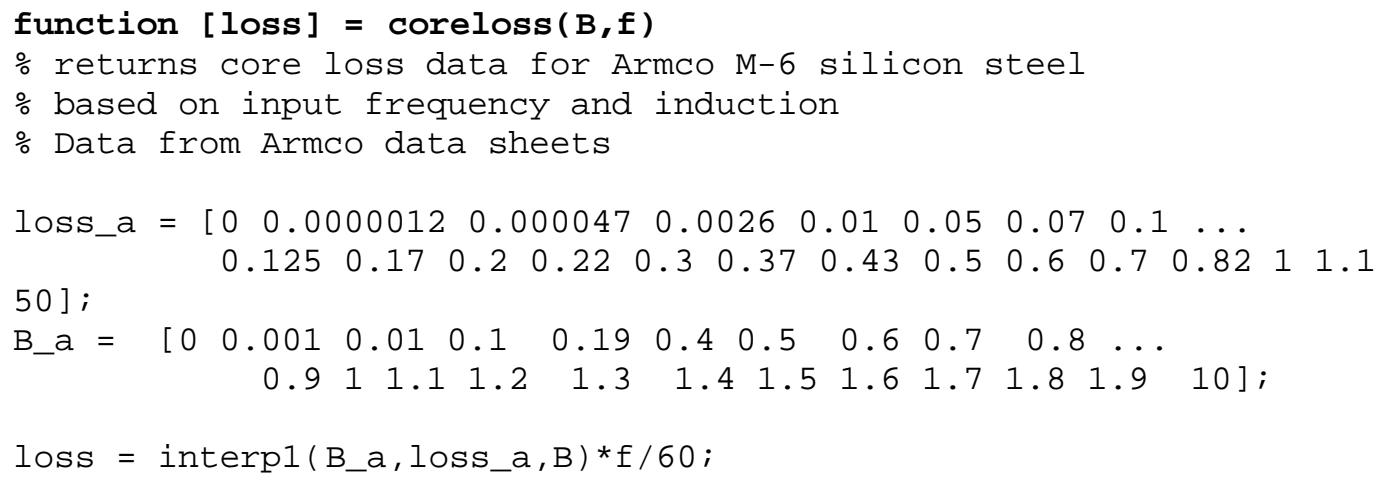




\section{engfunc.m}

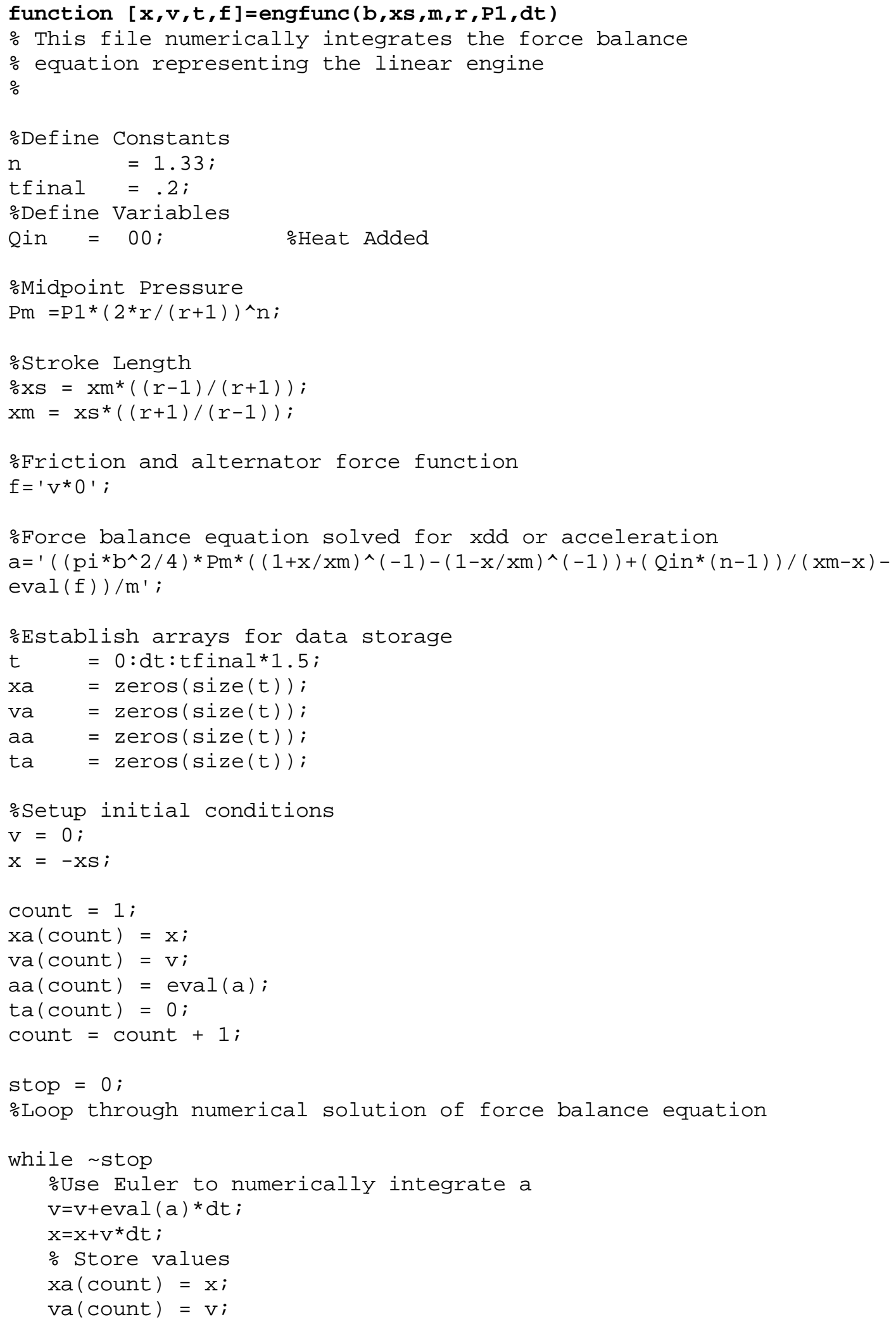




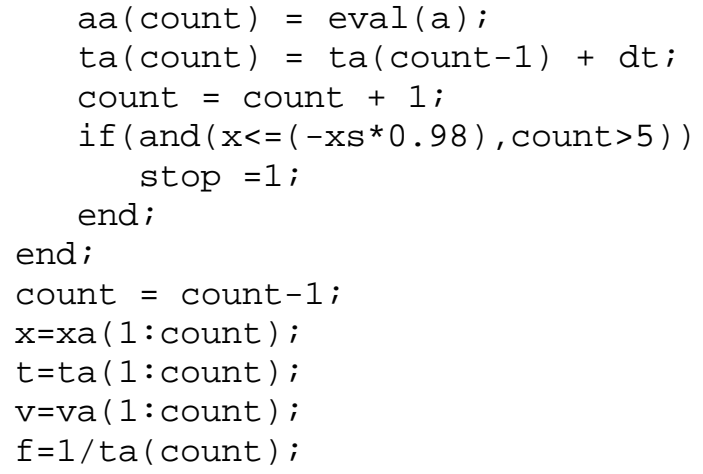

\section{findawg.m}

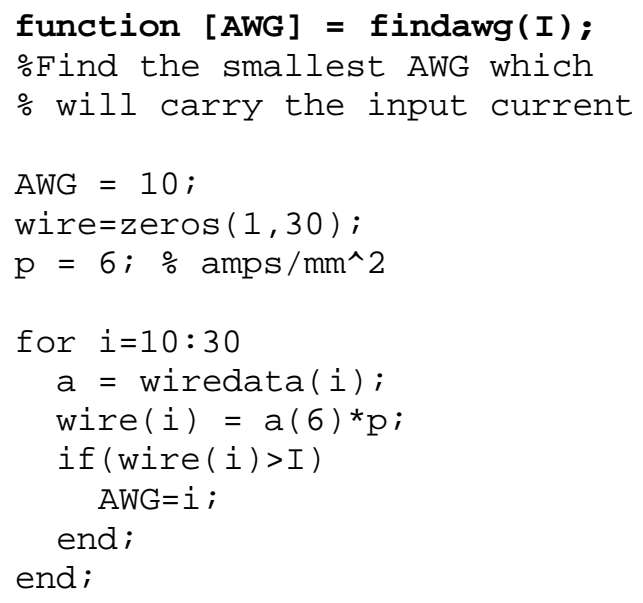

\section{find_delta.m}

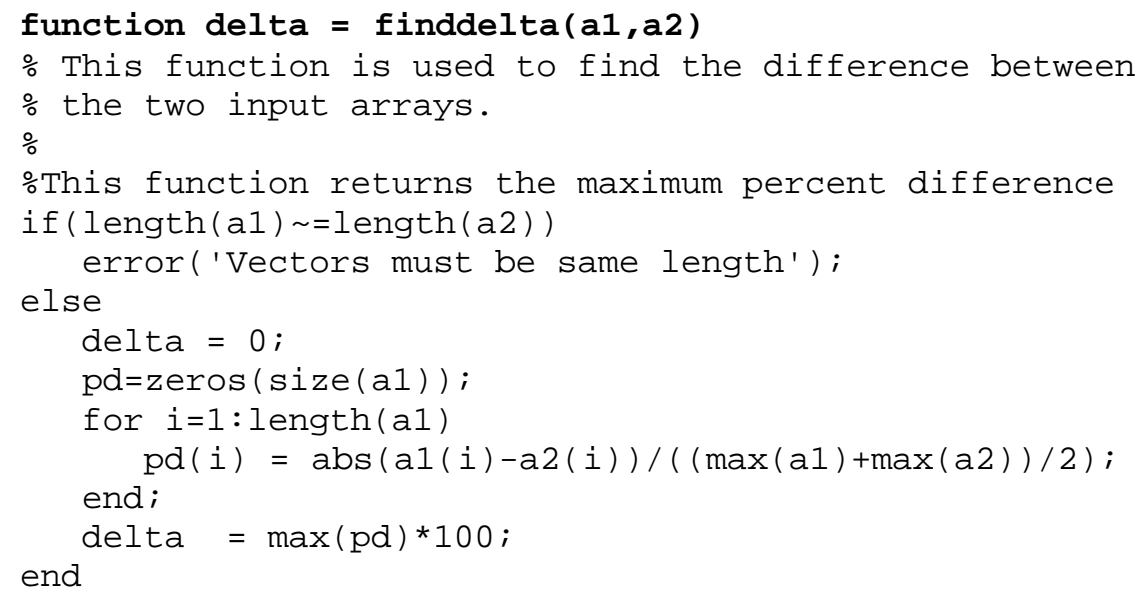




\section{find_fft.m}

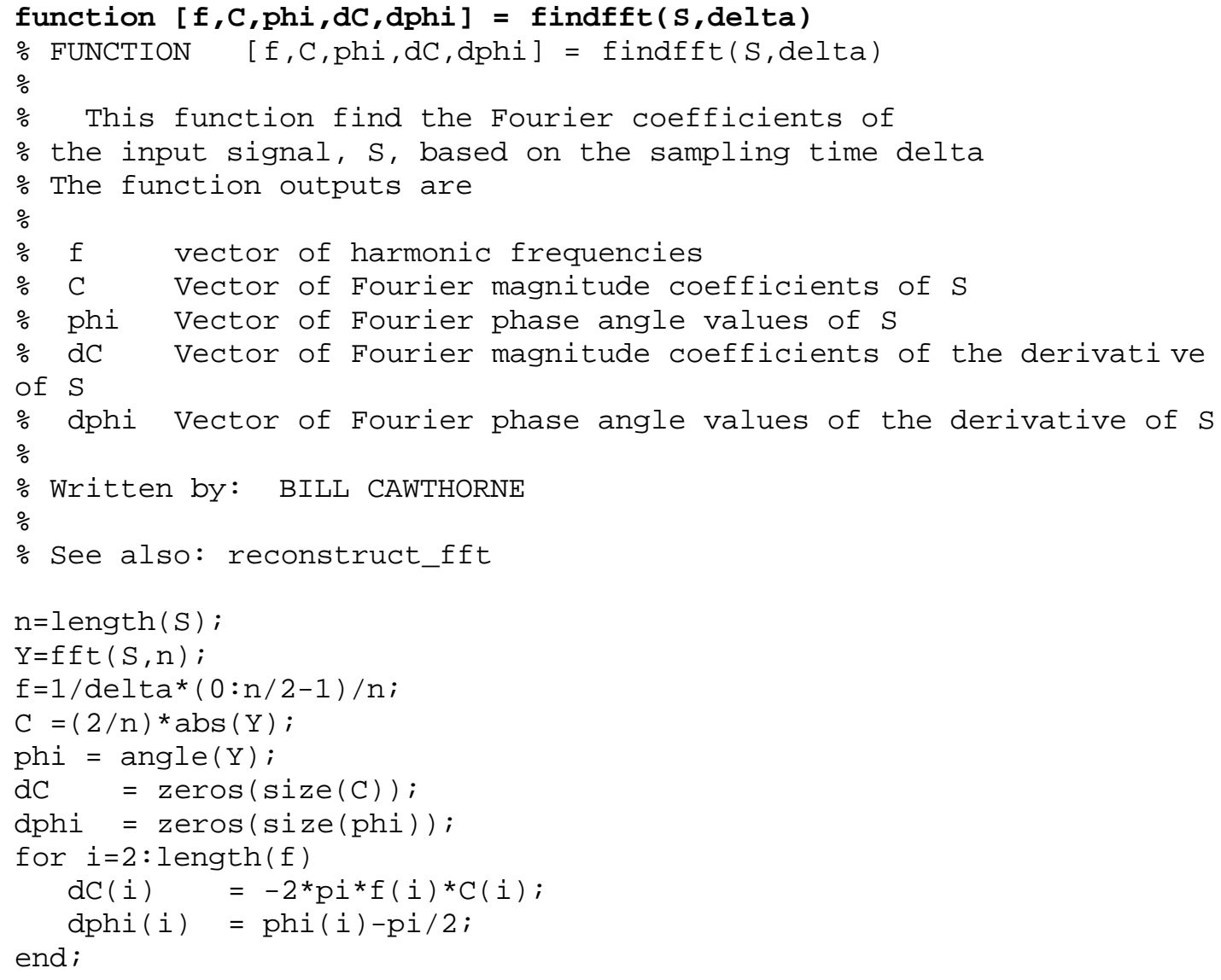




\section{generate_ansys_file.m}

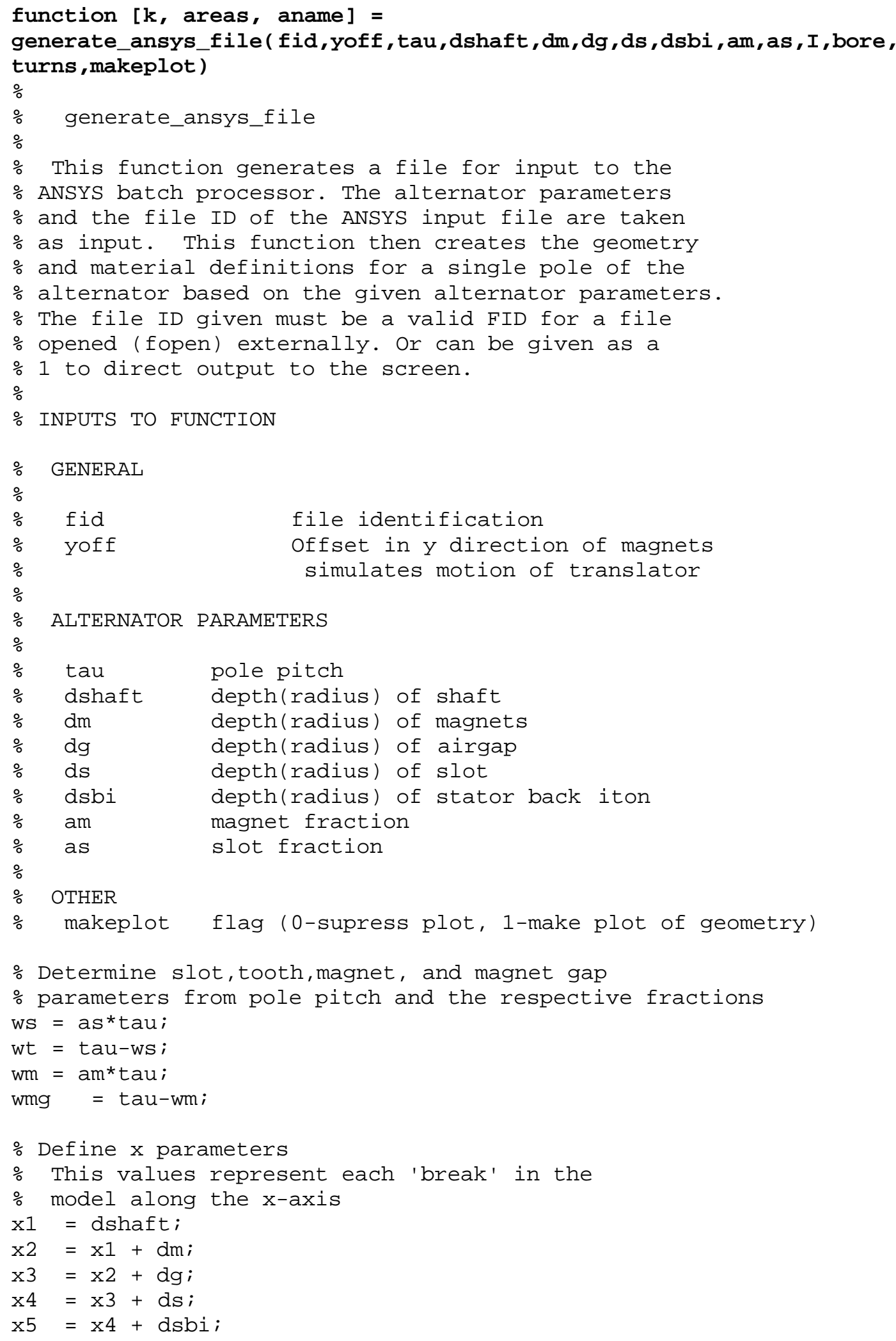




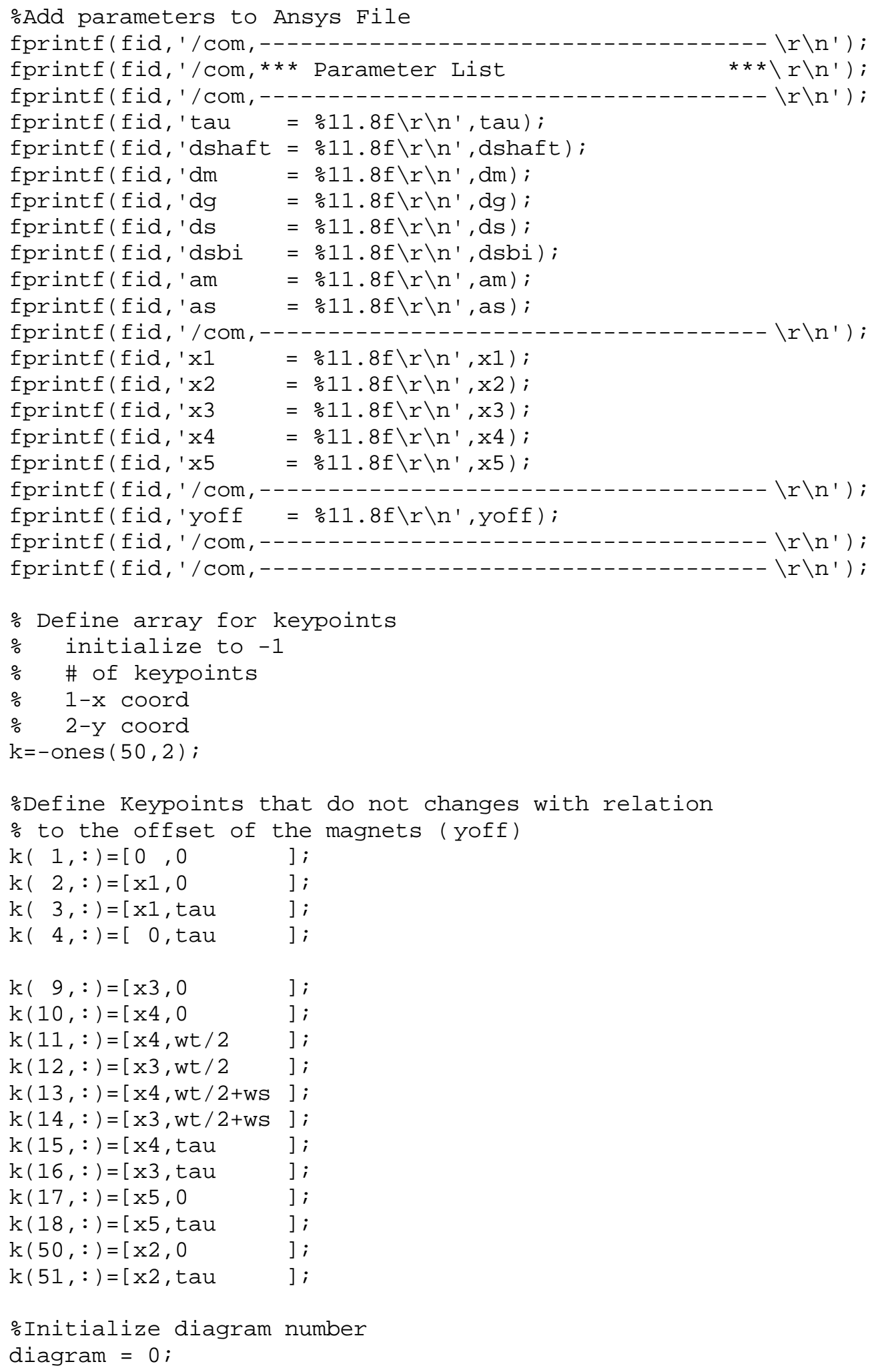




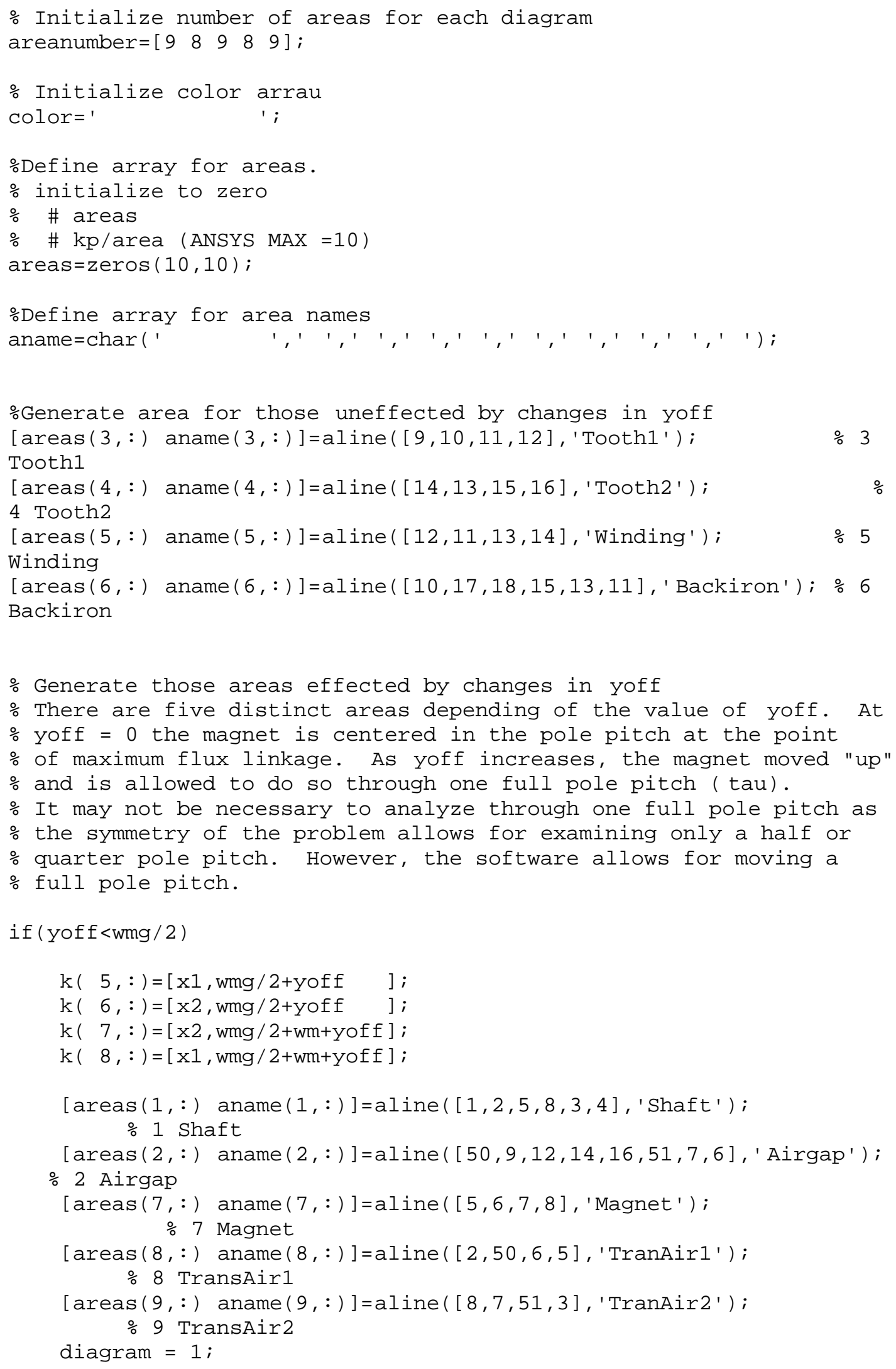




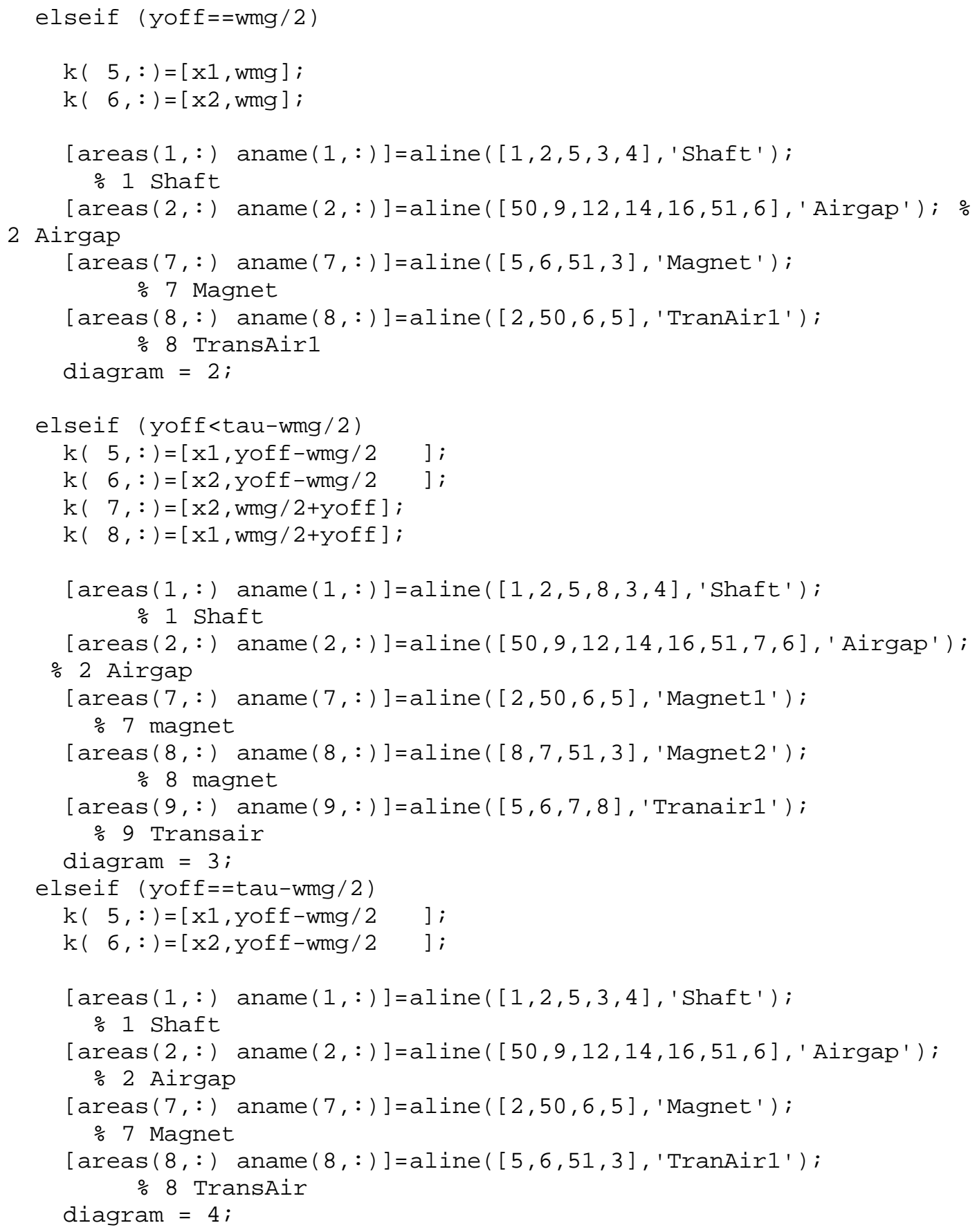




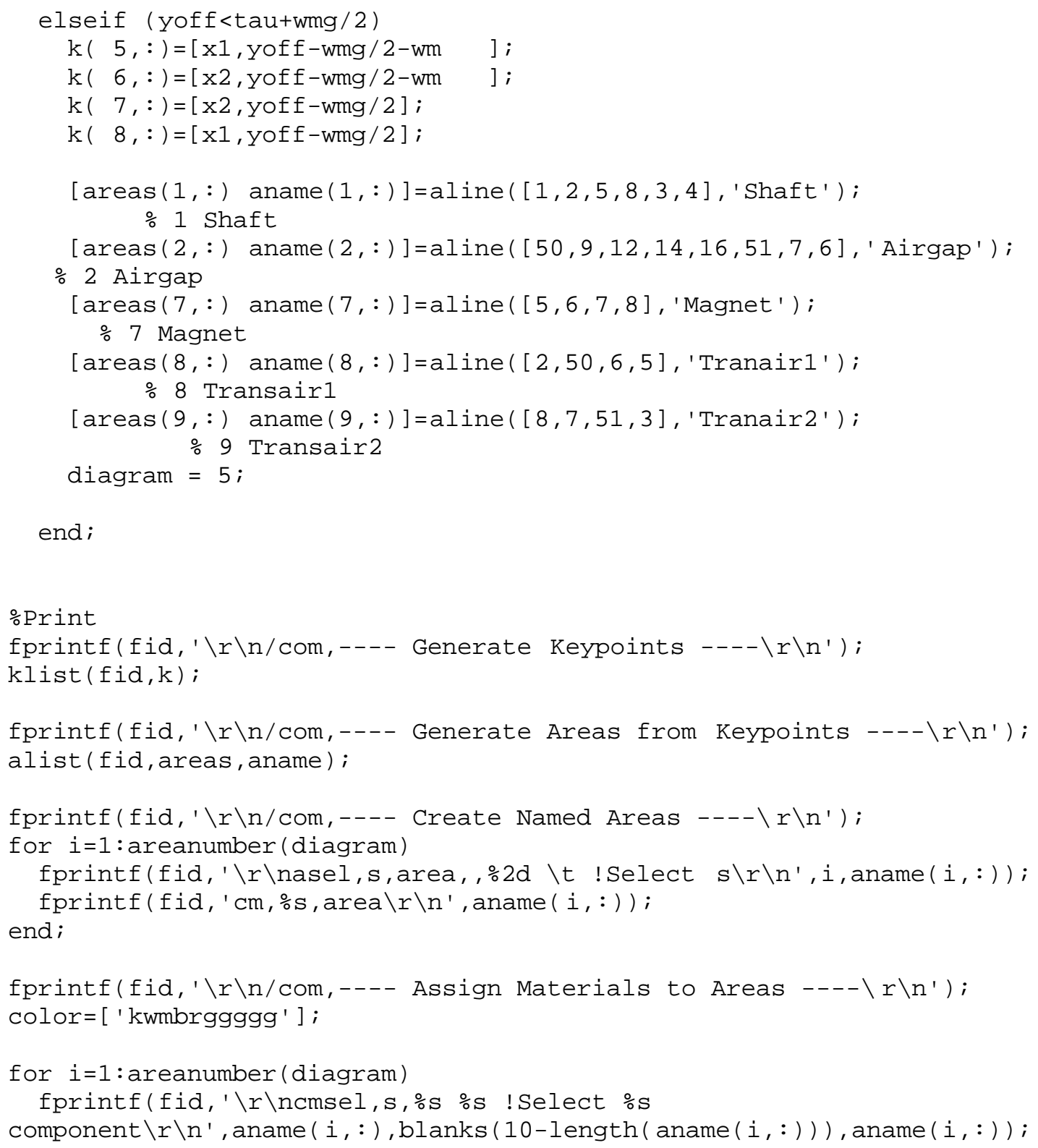




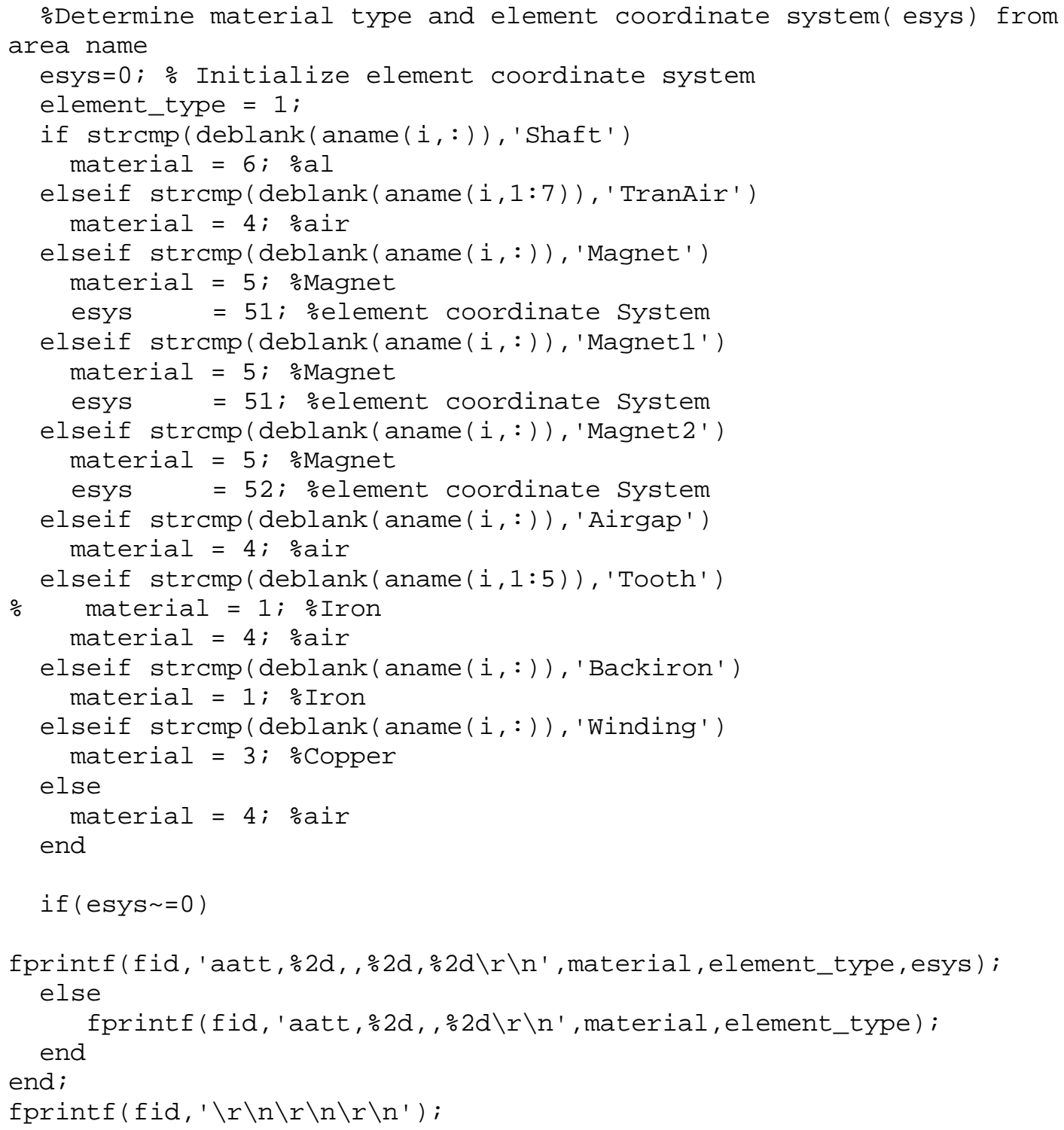




\section{get_ansys_data.m}

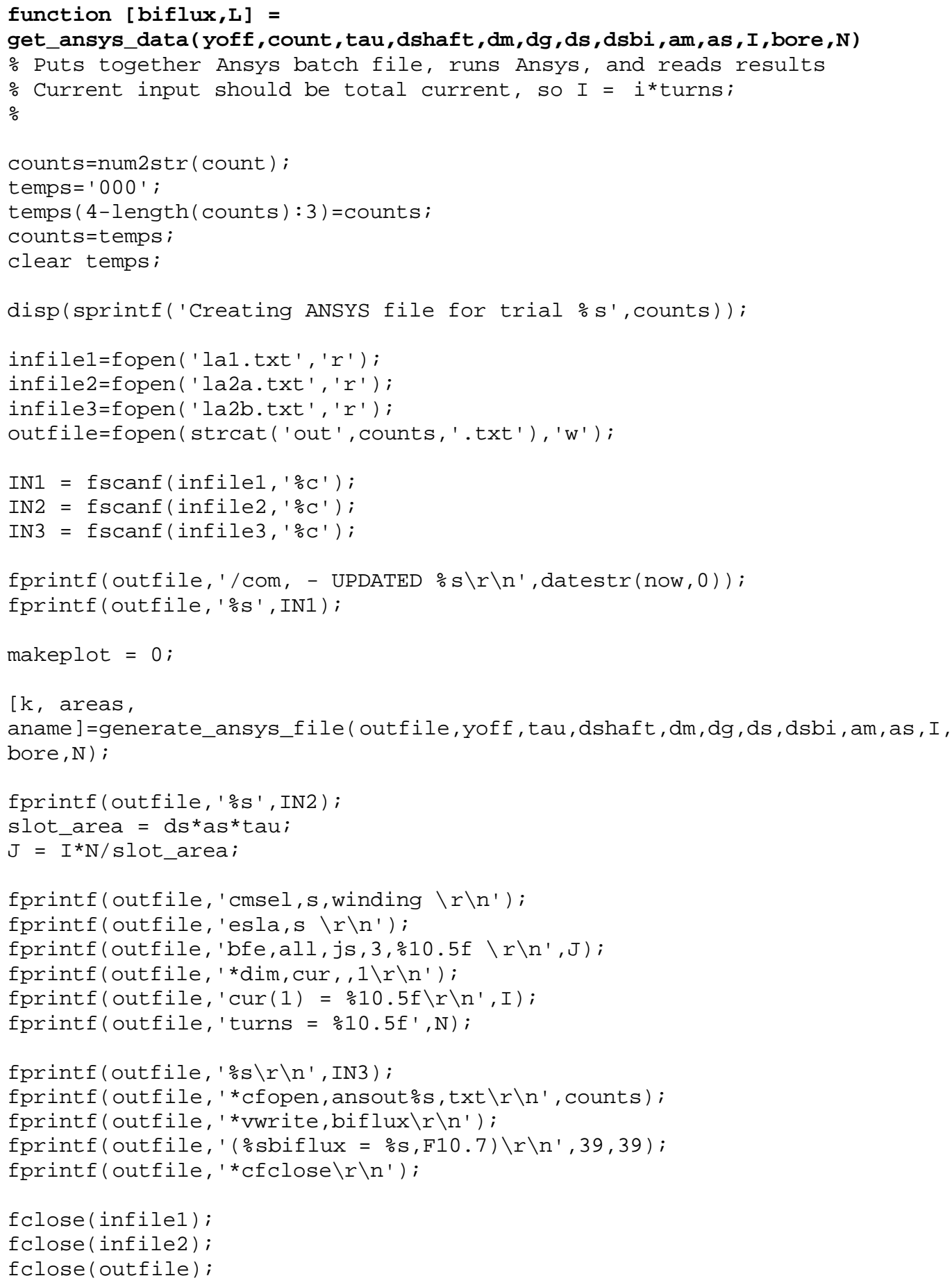




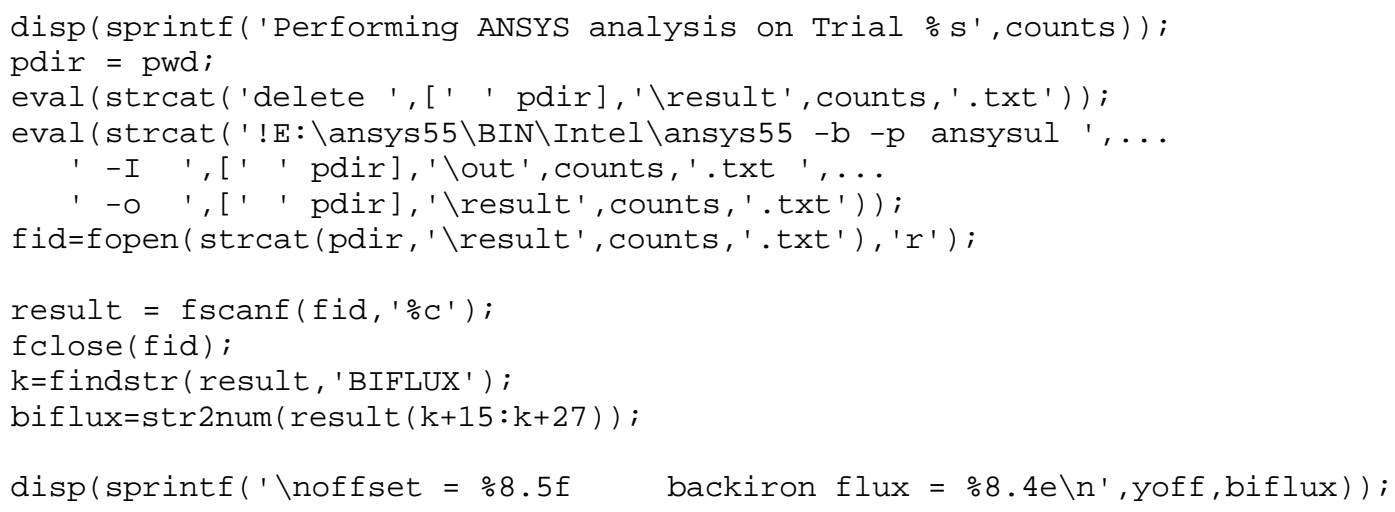

\section{klist.m}

\section{function klist (fid, k)}

oList keypoints to ANSYS file based on input array of keypoints for $i=1$ : length $(k)$

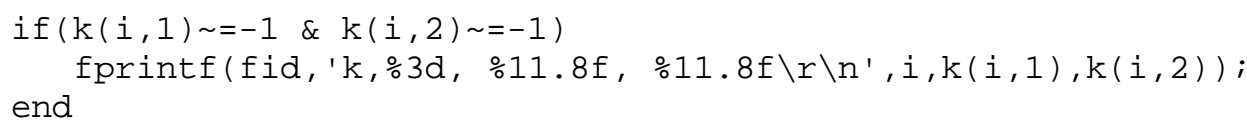




\section{optimize_la.m}

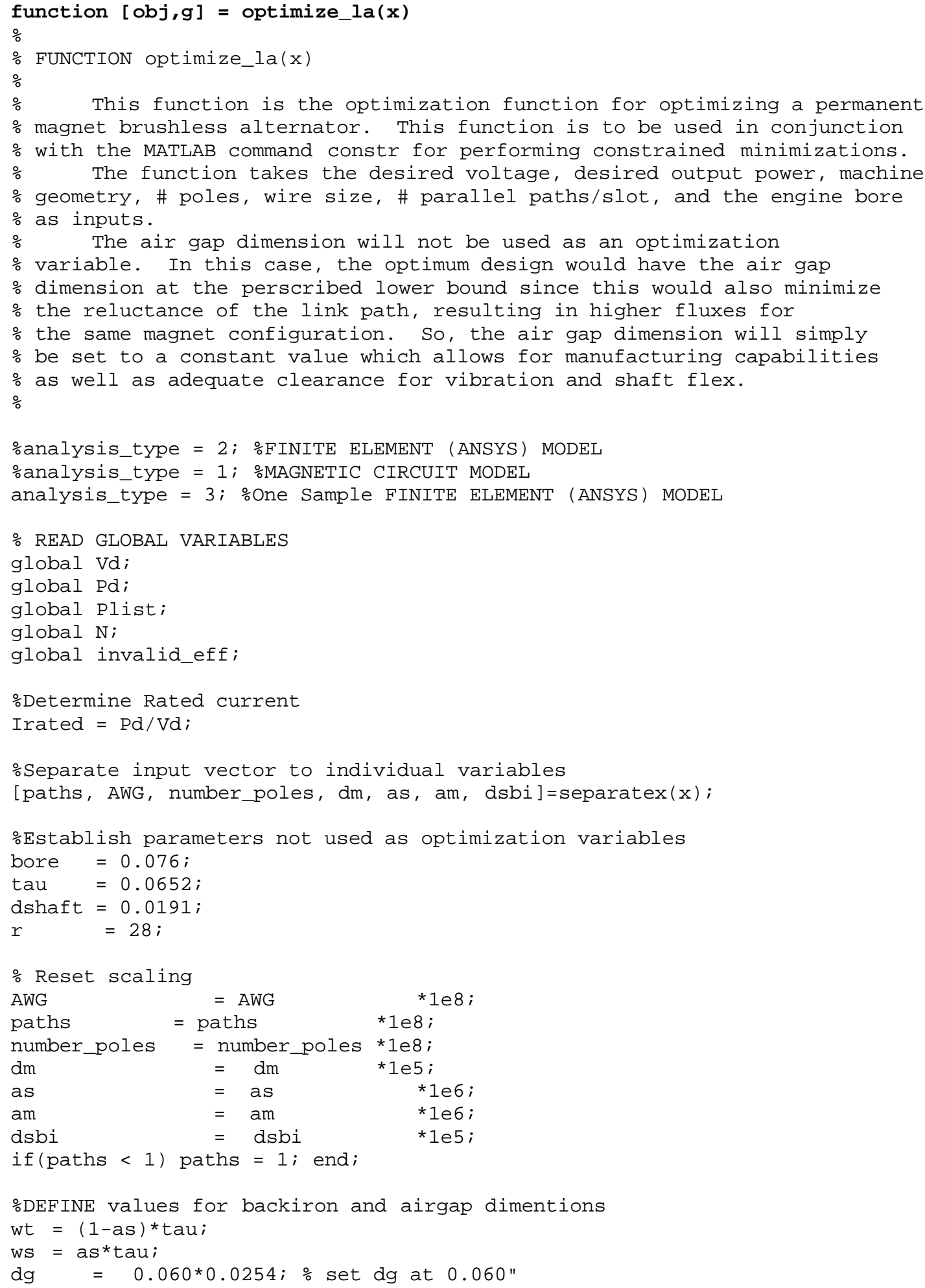




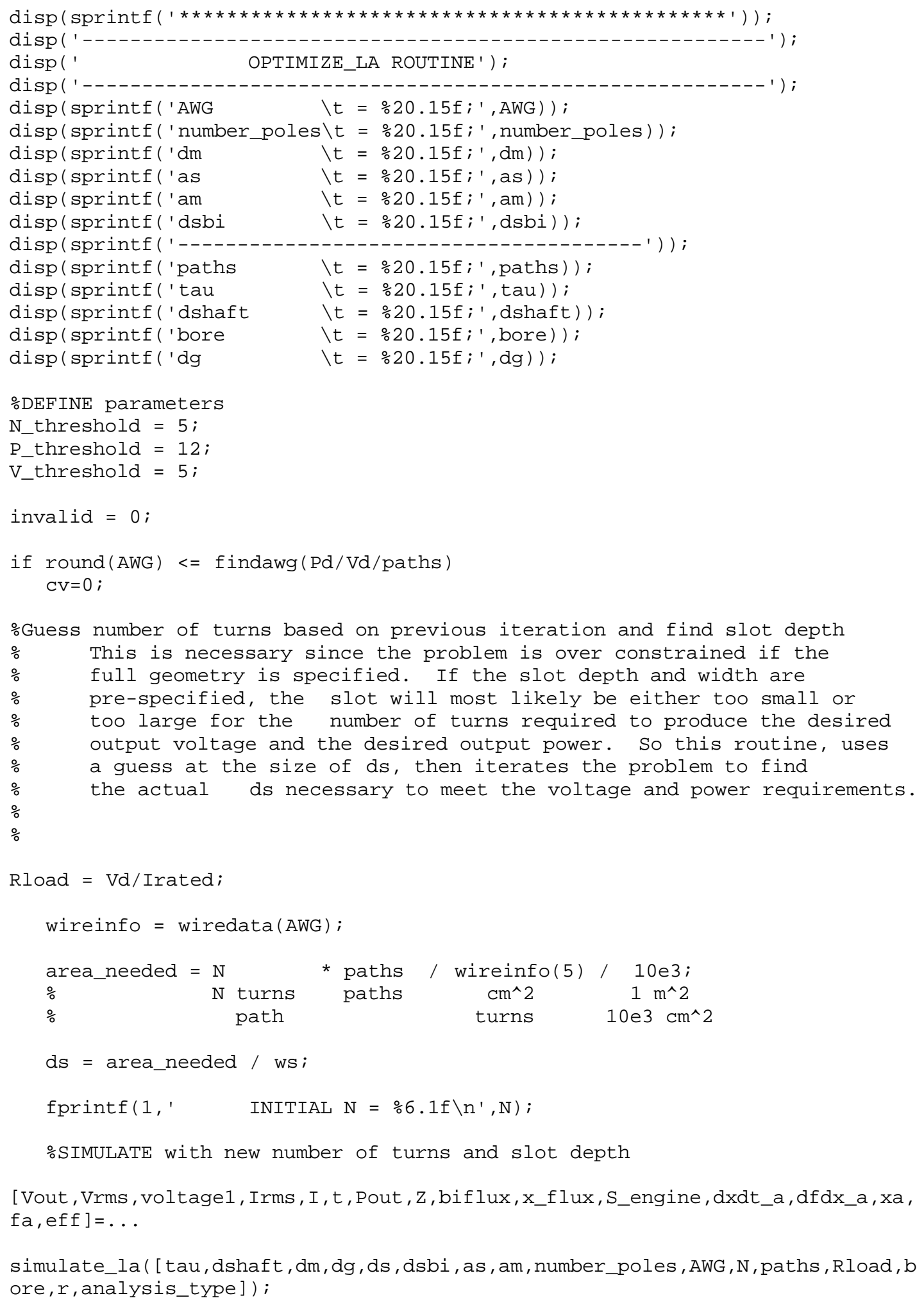




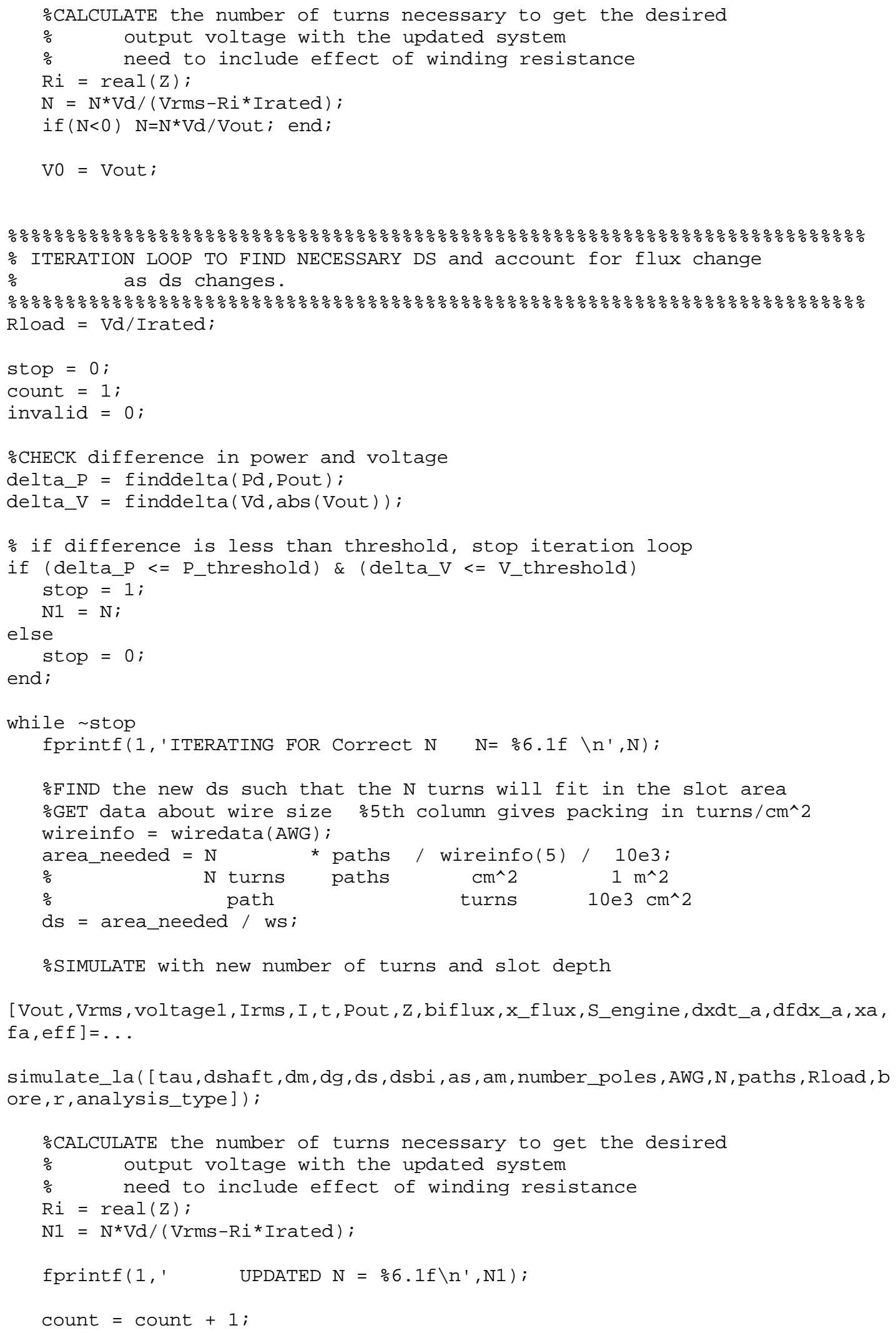




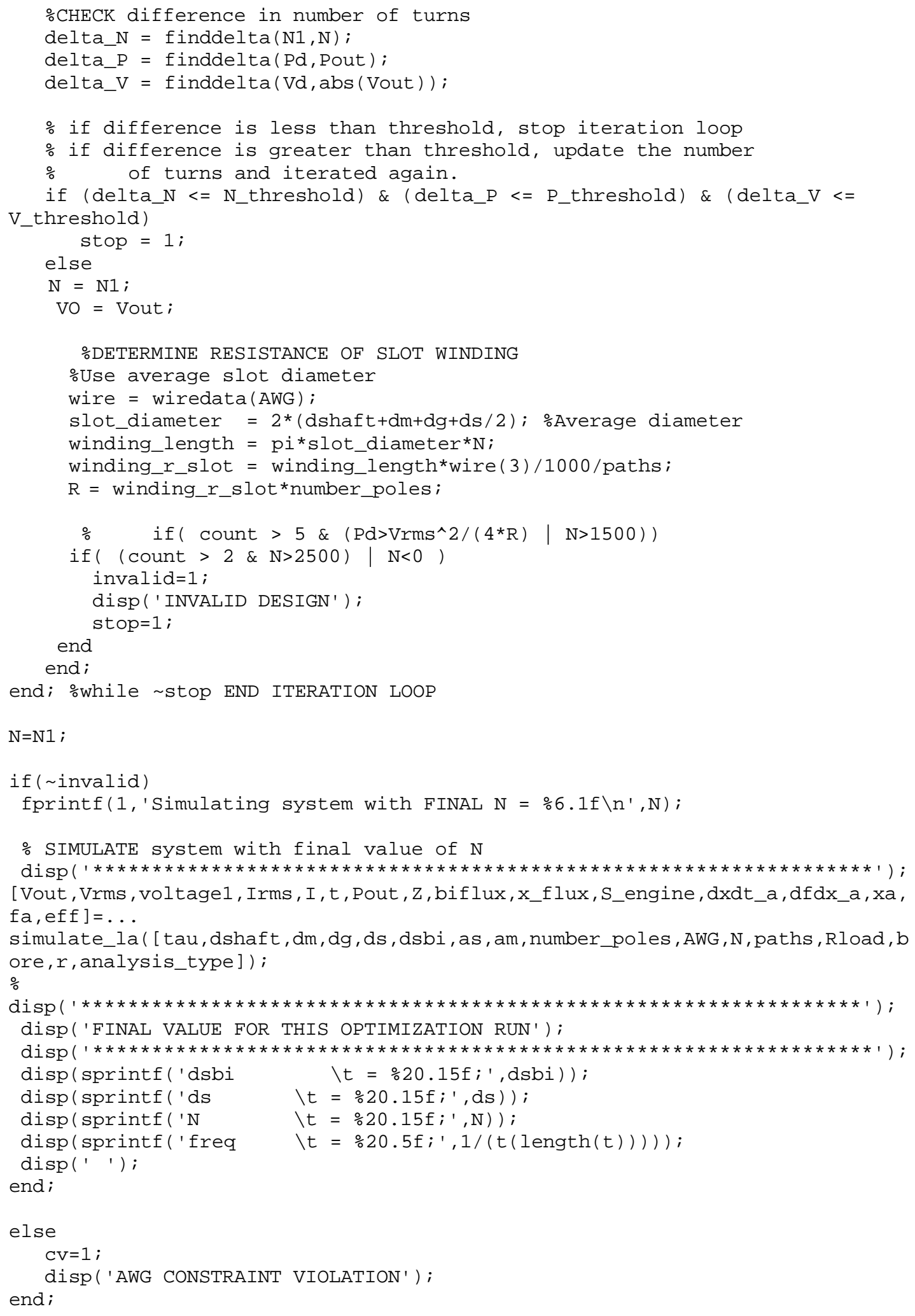




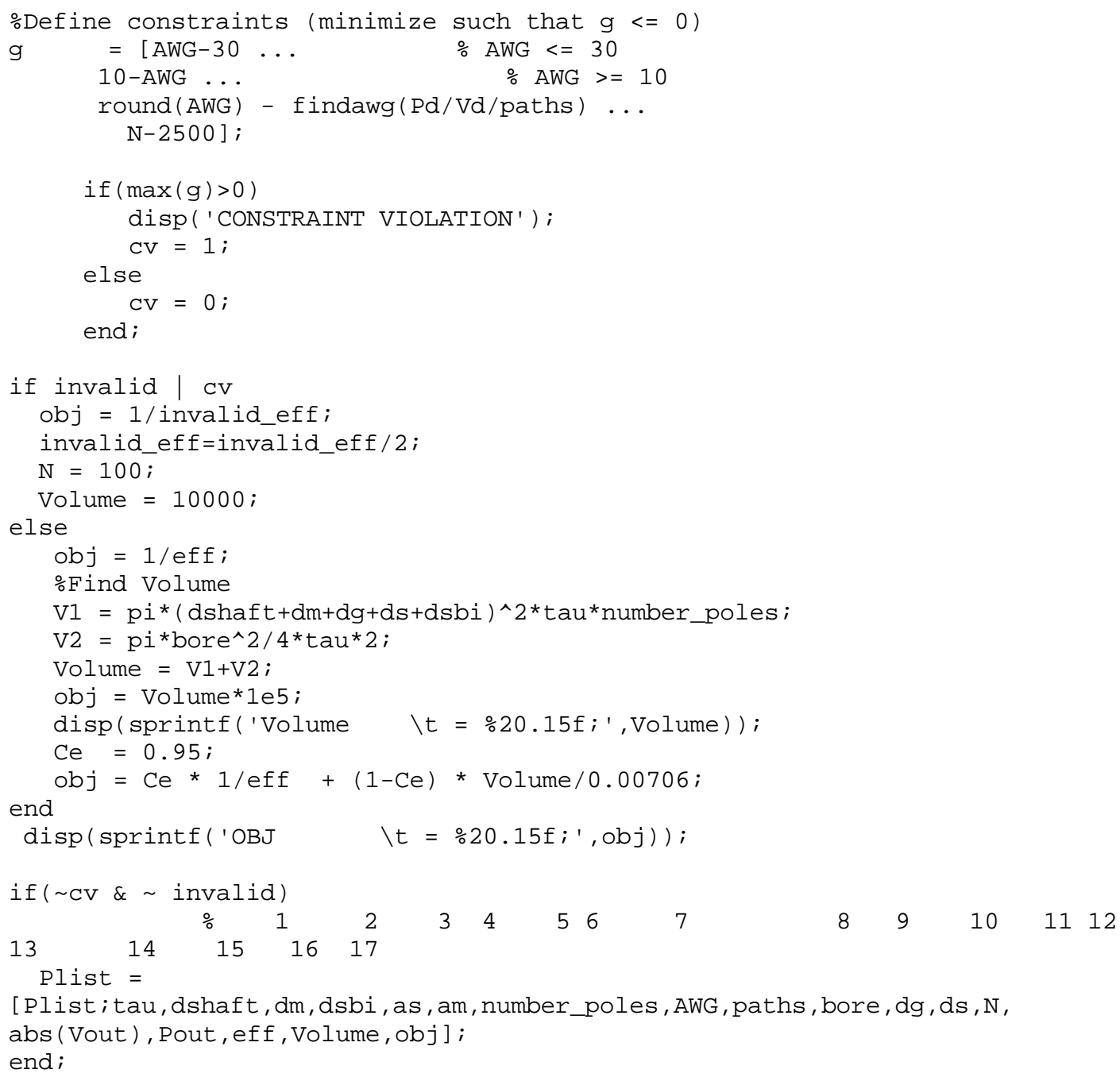

\section{Pdiff.m}

function $[\mathrm{p}]=\operatorname{pdiff}(\mathrm{A}, \mathrm{B})$

finds percent difference between inputs

$\mathrm{p}=\max (\operatorname{abs}((\mathrm{A}-\mathrm{B}) . /(\mathrm{A}+\mathrm{B}) * 2)) * 100$;

\section{radial.m}

\section{function $[A, 1]=\operatorname{radial}(I R, t, h)$}

$\div$ This function returns the cross sectional area

ㅇ and length for reluctance calculations for

o a cylinder with flux flowing radially

\% through the cylinder.

\% INPUTS: Inner radius, wall thickness, height $\mathrm{A}=\mathrm{pi} * \mathrm{~h} *(2 * I R+\mathrm{t})$;

$l=\mathrm{t}$; 


\section{reconstruct fft.m}

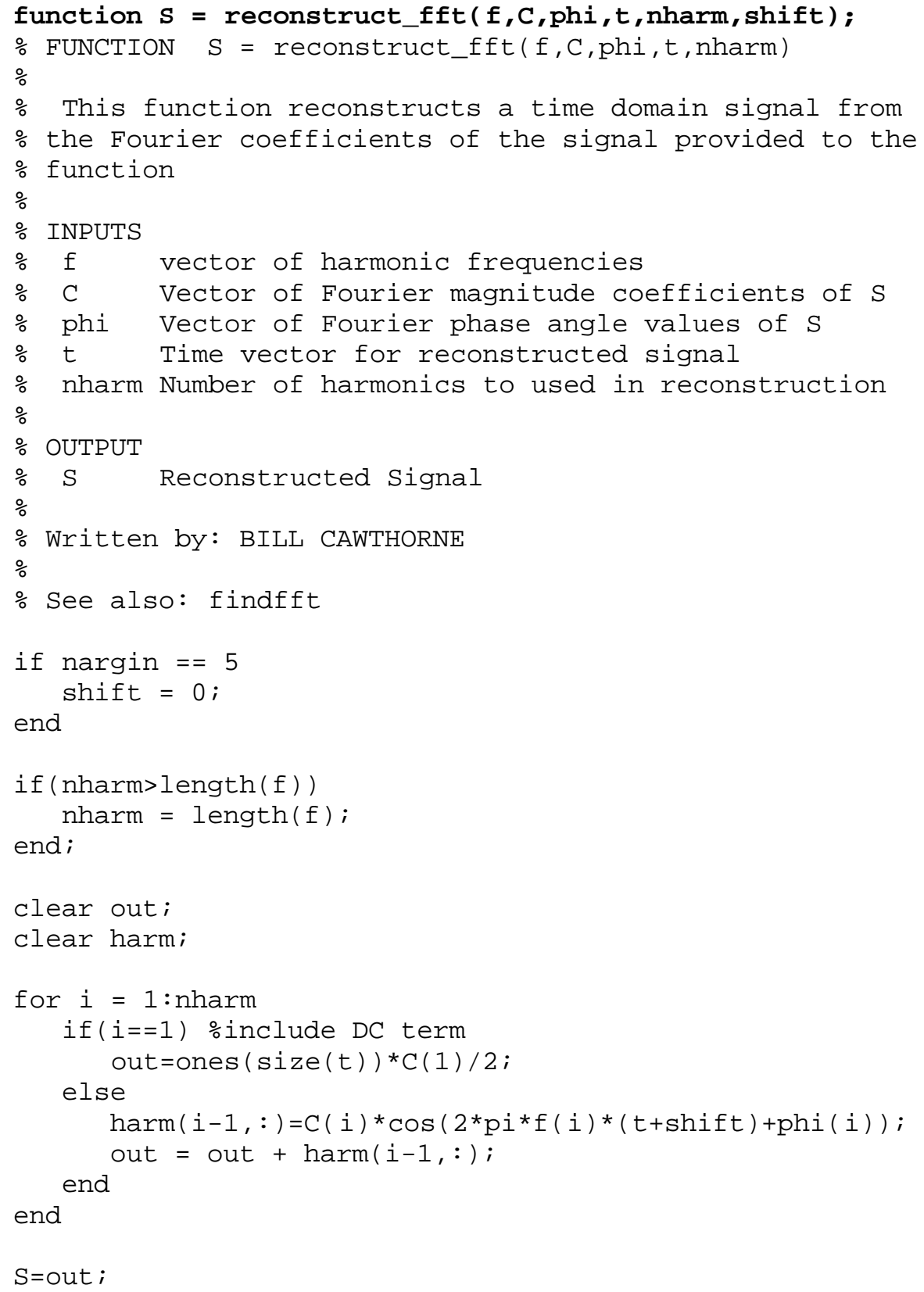




\section{rms.m}

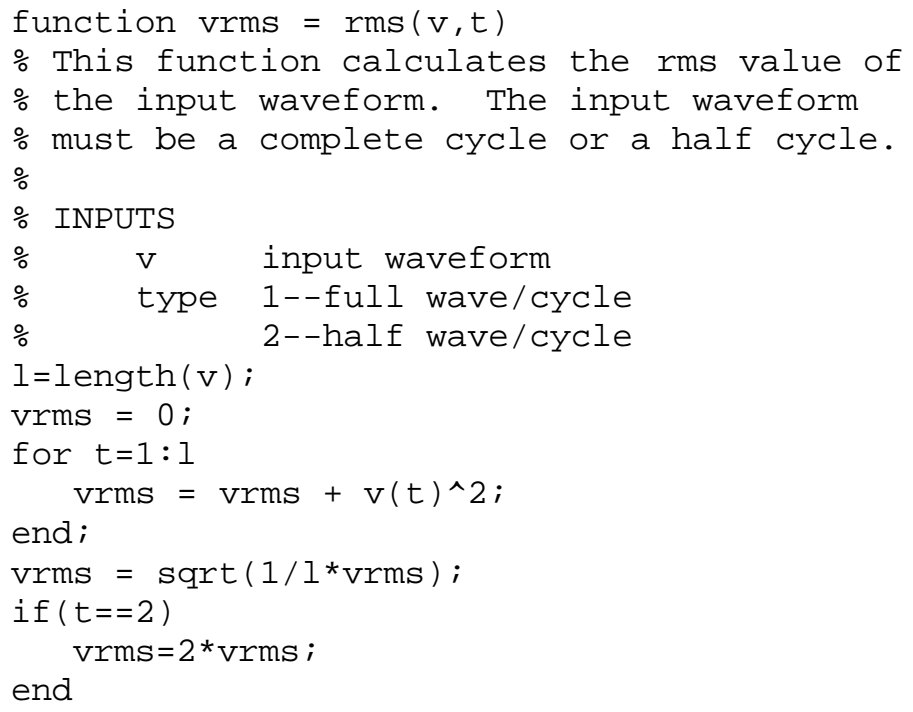

\section{run optim.m}

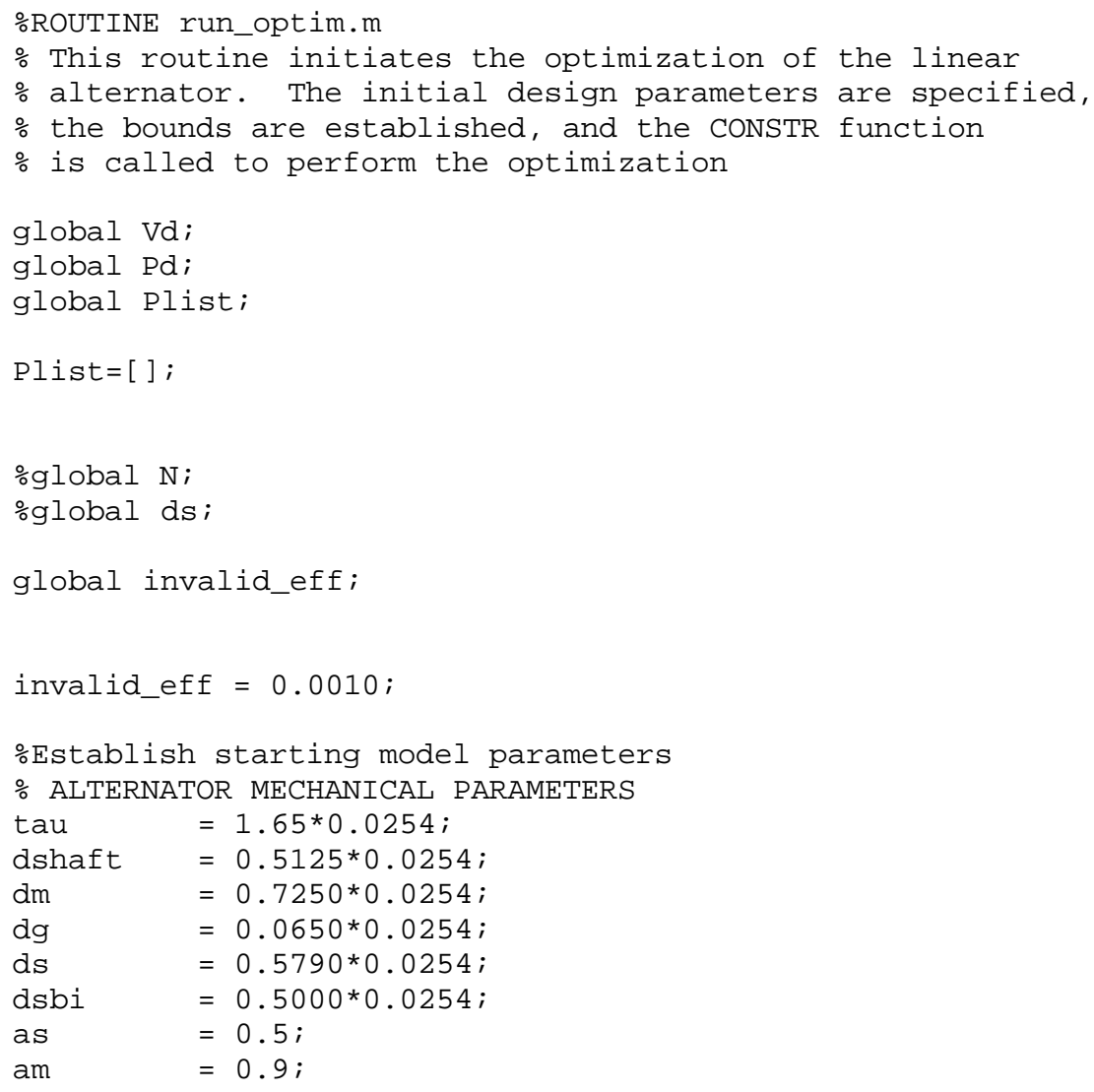




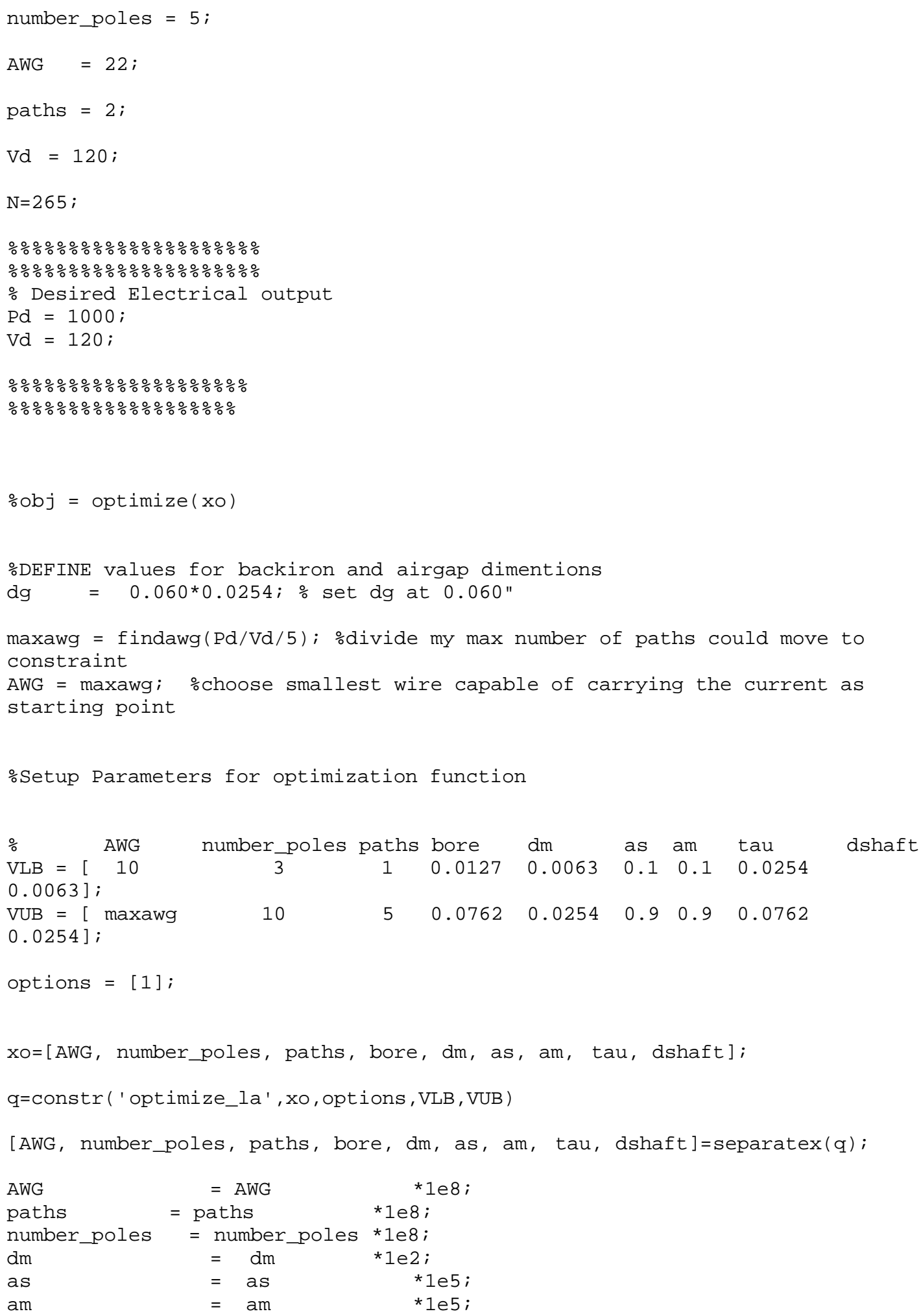




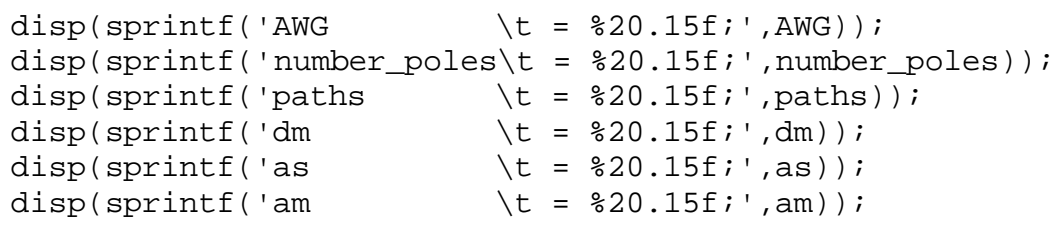

\section{separatex.m}

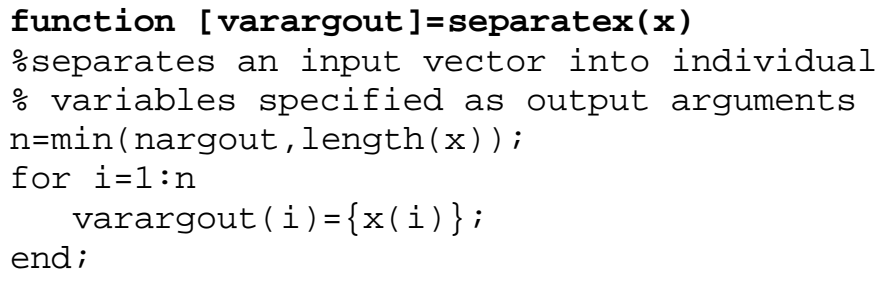

\section{Simulate la.m}

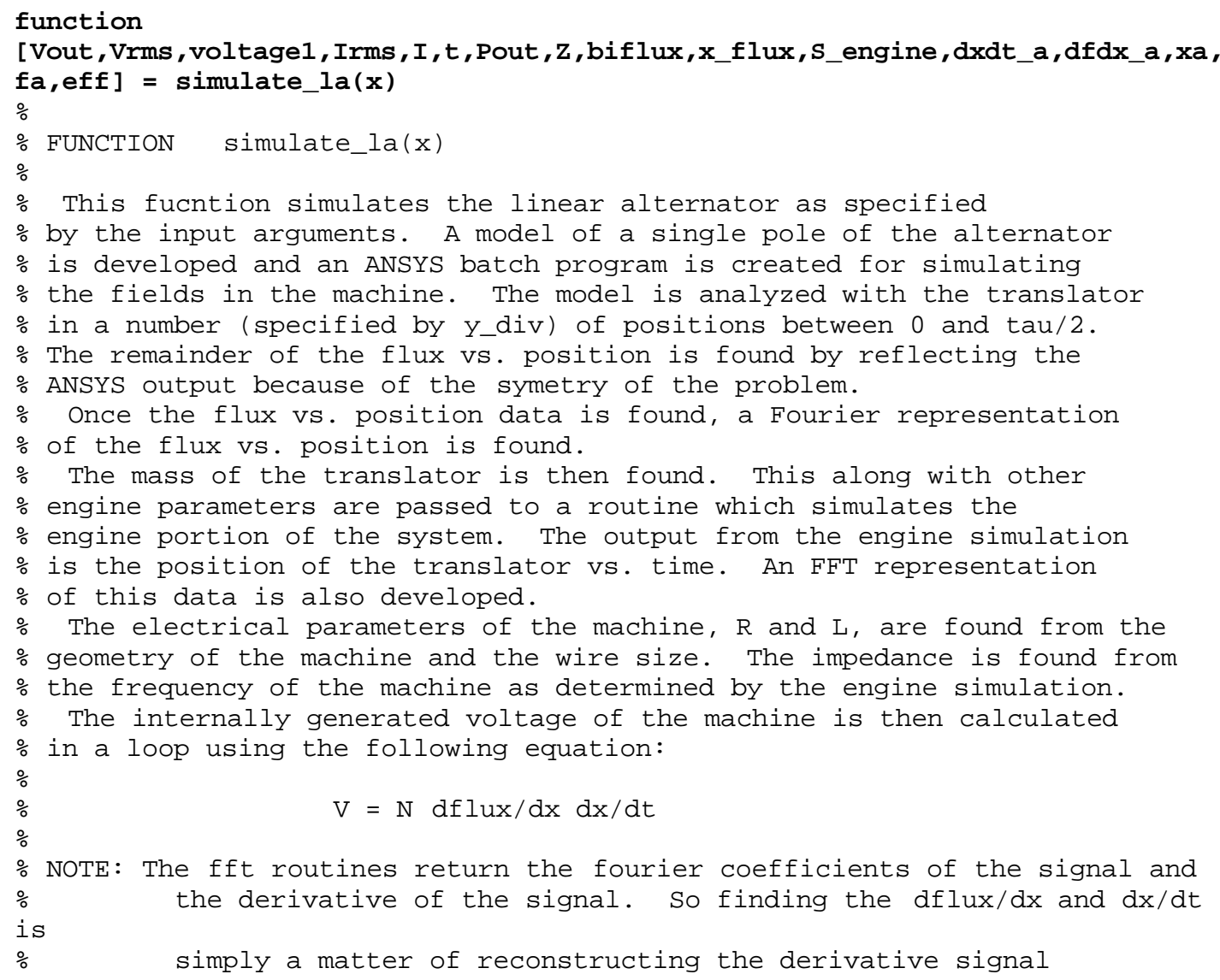




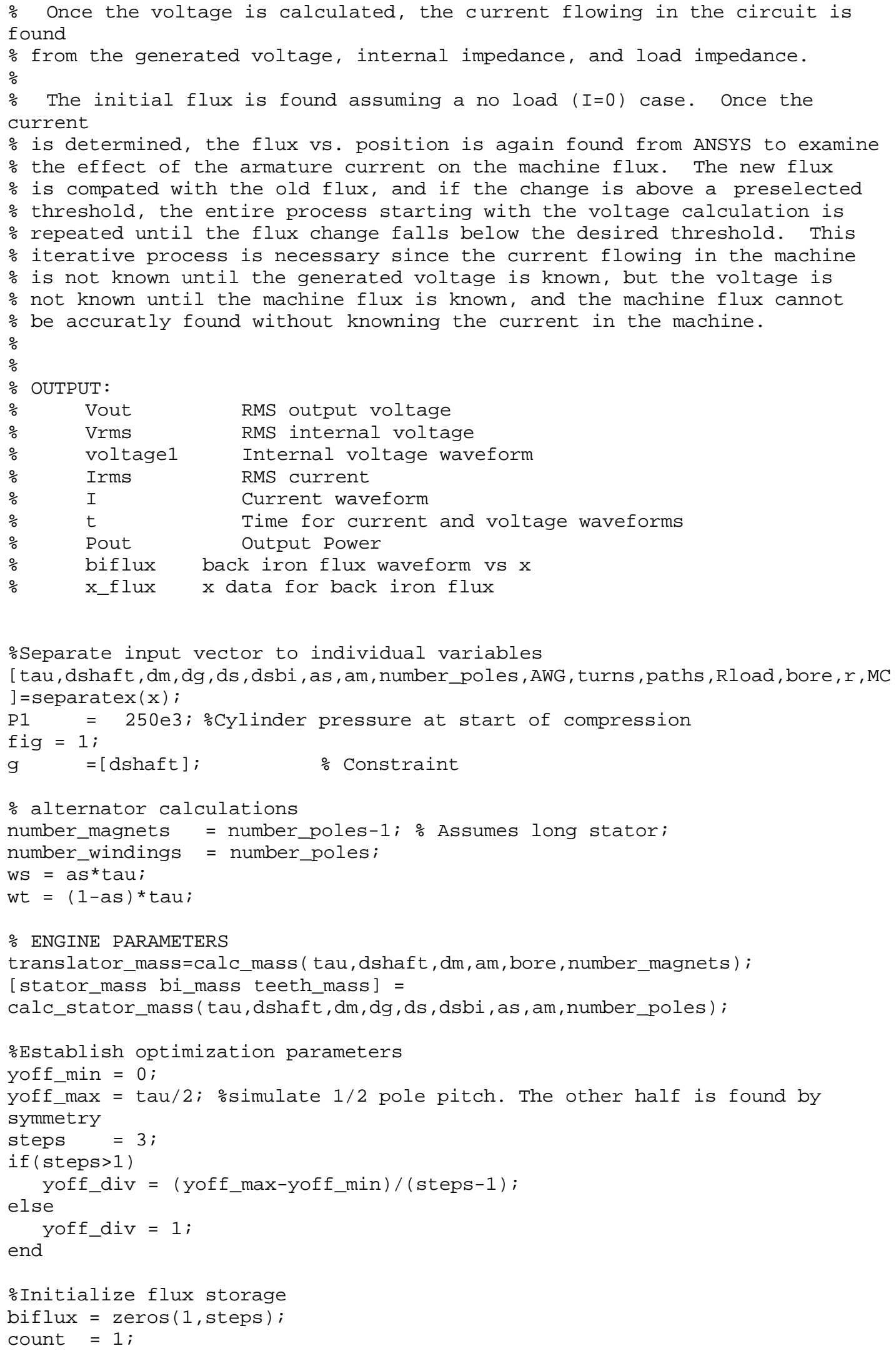




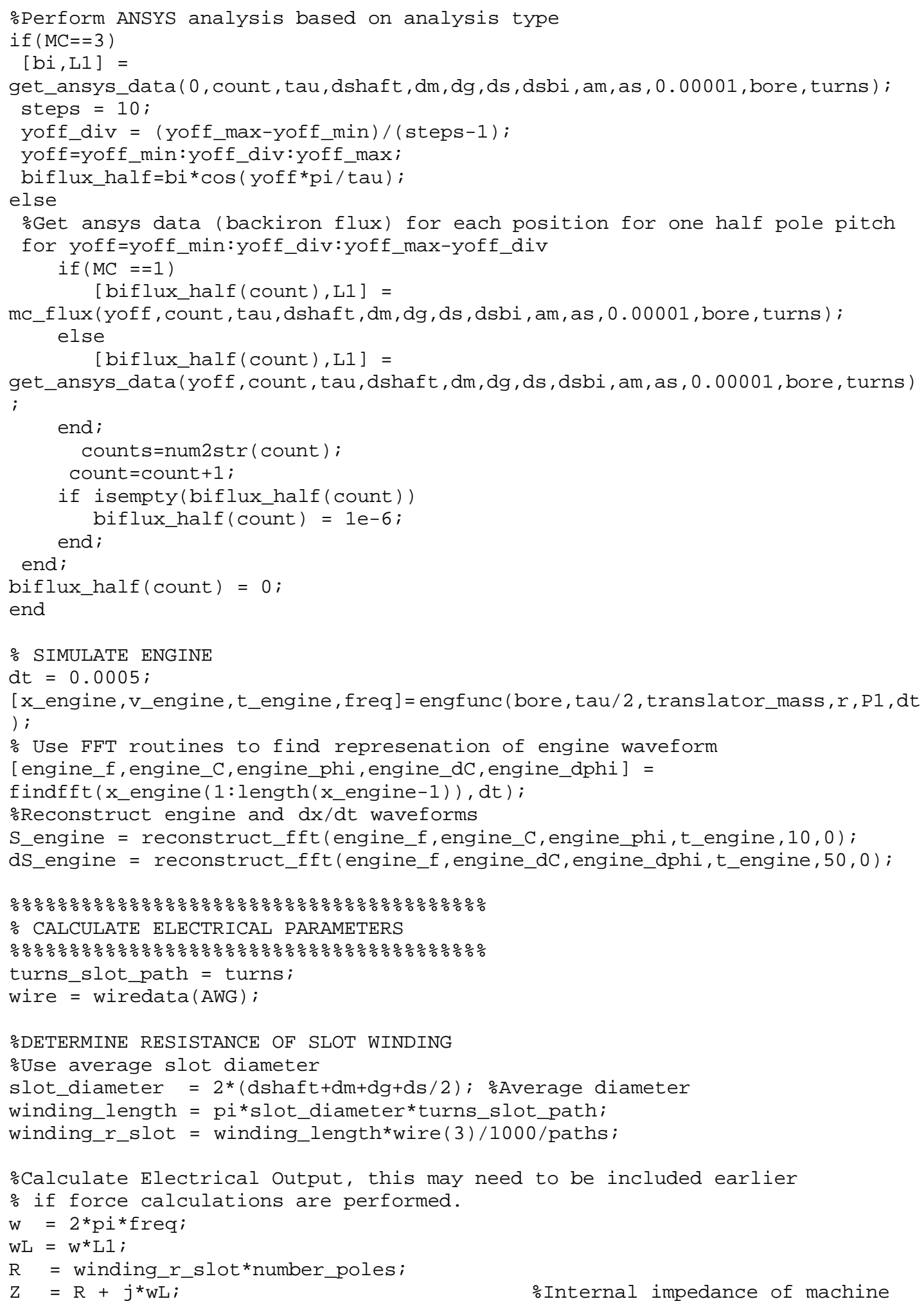




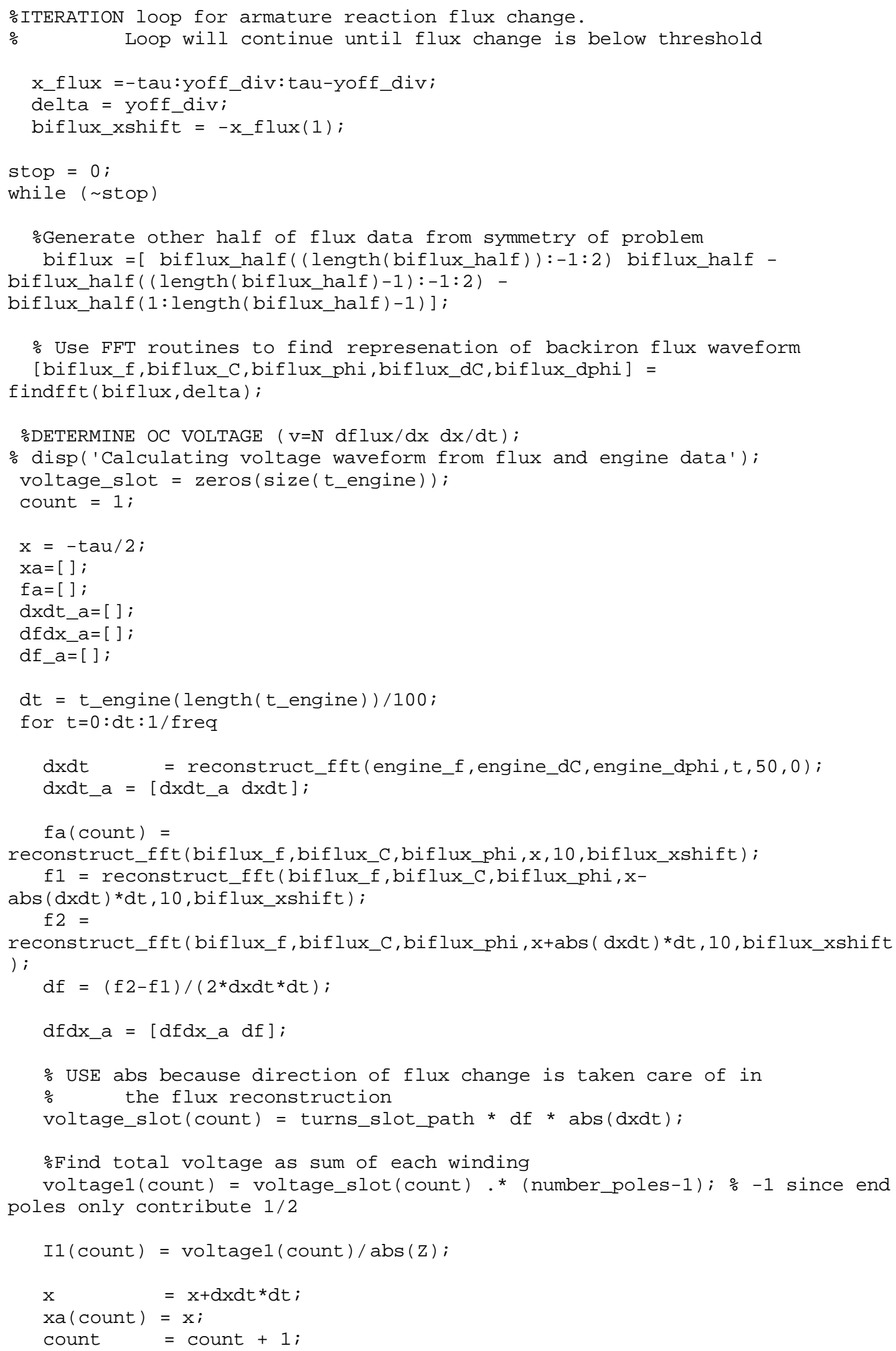




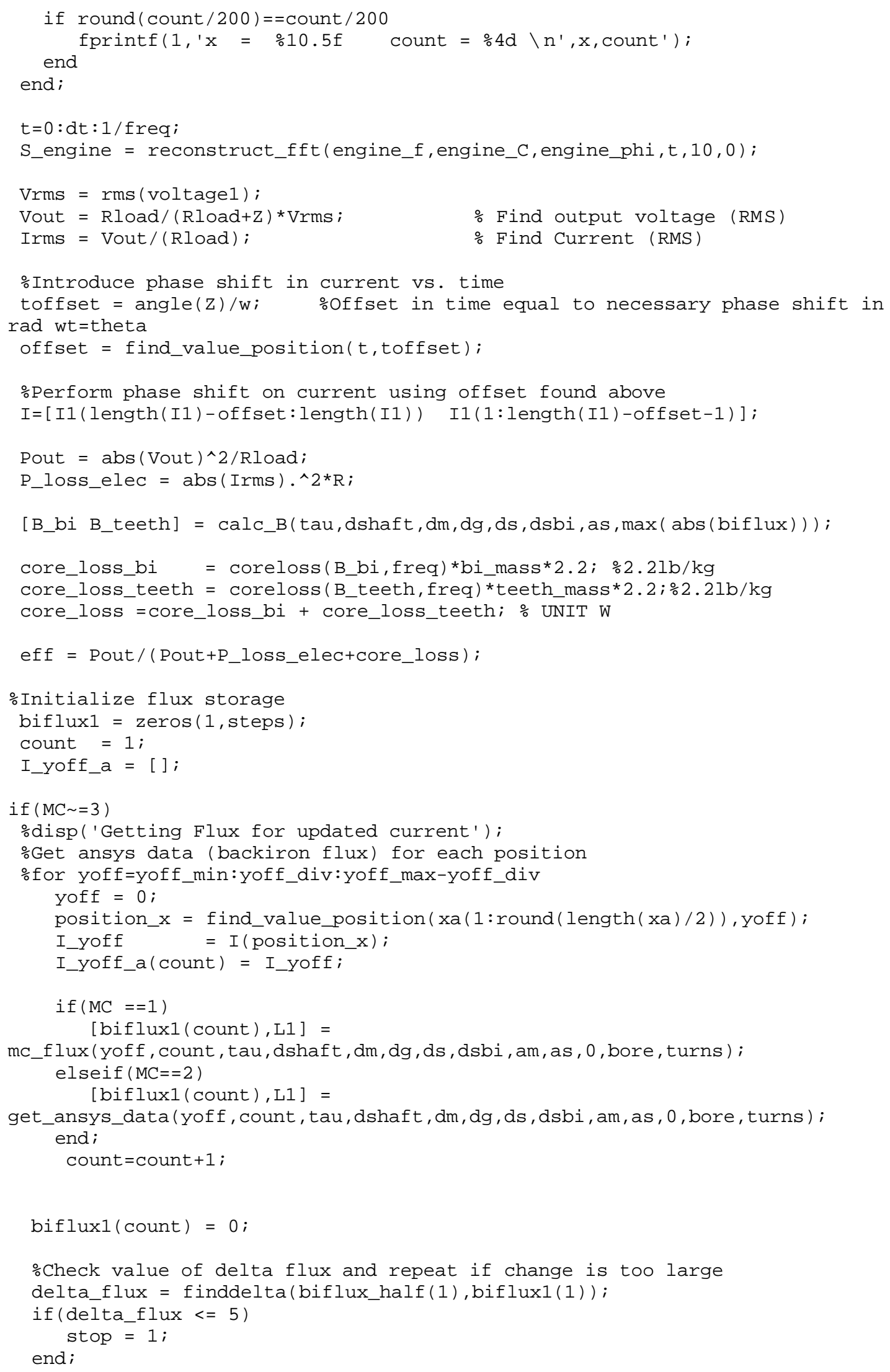




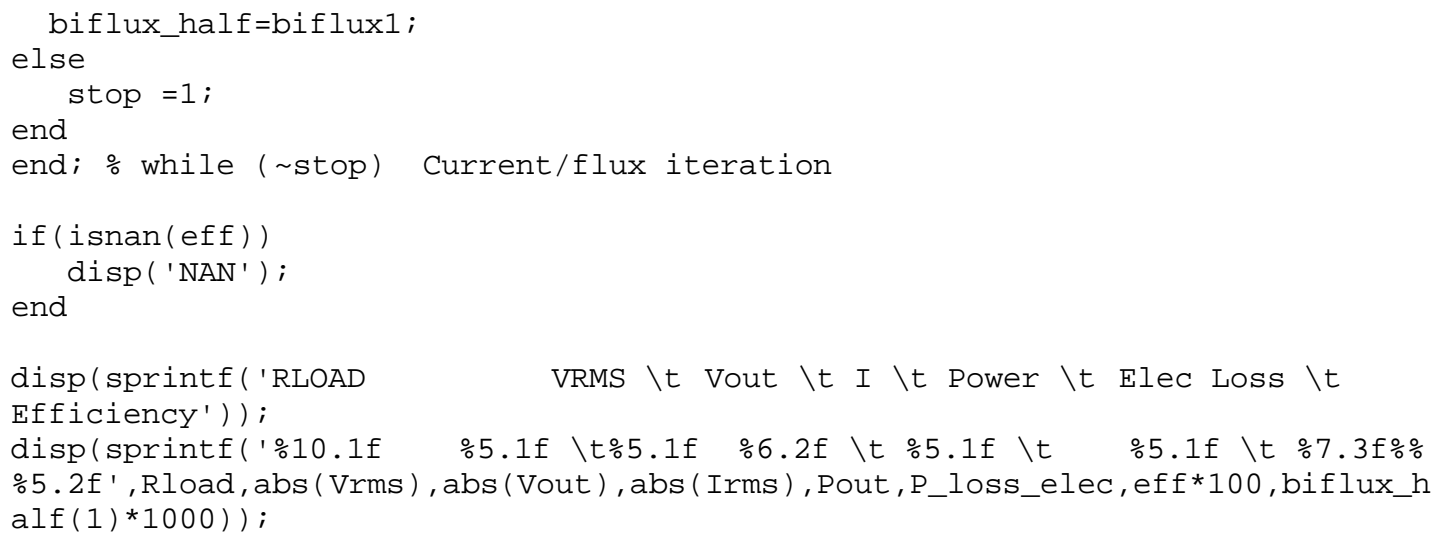

\section{wiredata.m}

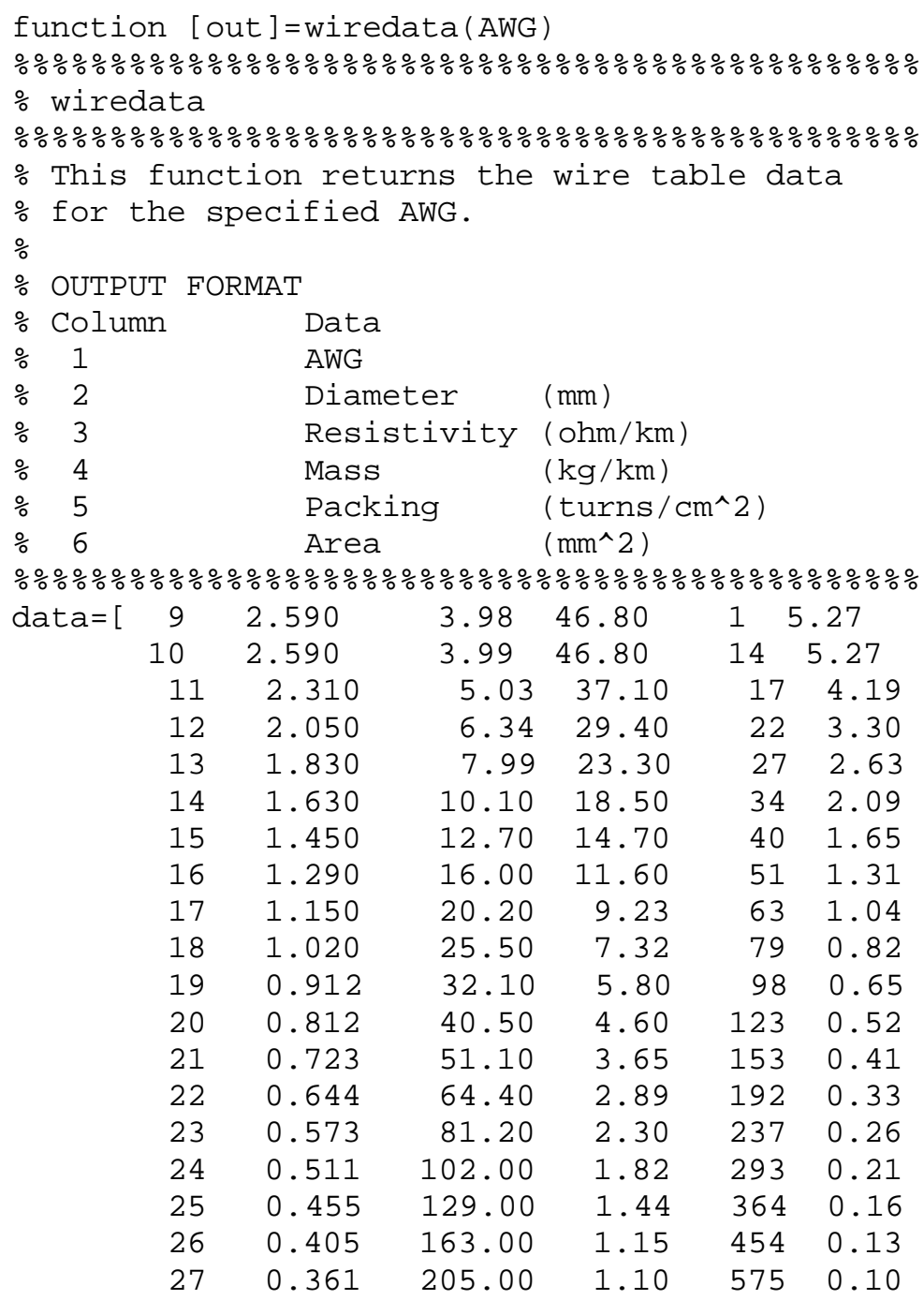




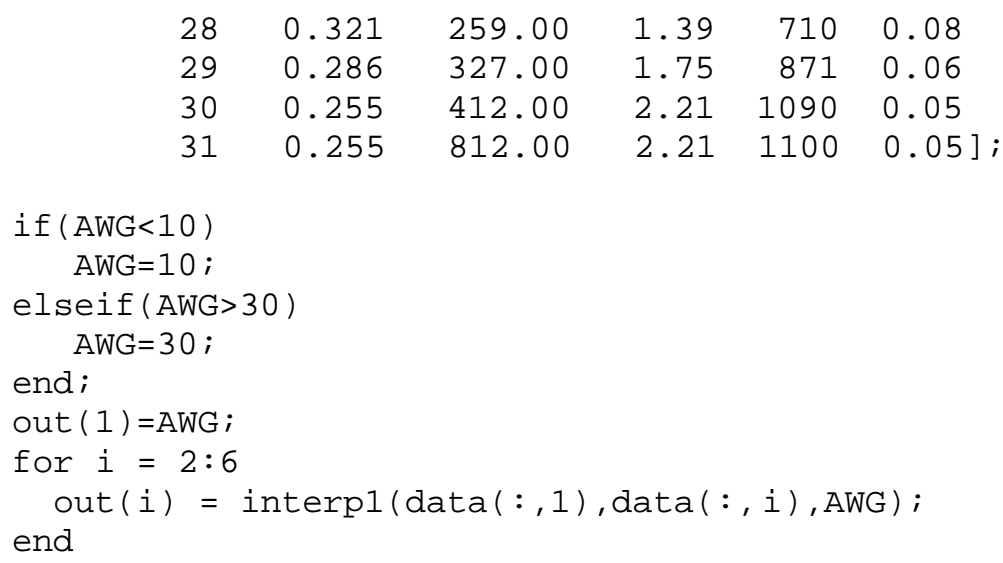




\section{William R. Cawthorne}

EDUCATION WEST VIRGINIA UNIVERSITY, Morgantown WV 26506 Doctor of Philosophy in Engineering Master of Science in Electrical Engineering Aug 1999 GPA: 4.0/4.0

GPA: $4.0 / 4.0$

Bachelor of Science in Electrical Engineering Bachelor of Science in Computer Engineering

May $1994 \quad$ GPA: 3.9/4.0

Registered Engineering Intern -- West Virginia: EI 6502

Dissertation Title “Optimization of a Permanent Magnet Linear Alternator for Use With a Linear Internal Combustion Engine"

Thesis Title

"Design, Modeling, and Simulation of an Automotive 12 Volt Electrical Generating System Utilizing a Permanent Magnet Rotary Alternator"

Senior Design: “Orbital Research Unit Automated Docking System” funded by NASA

SPECIAL SKILLS

\section{Electric Vehicle and Racing Background}

For the past five years, I have led a student team working on a full sized, high performance, electric powered race vehicle. Responsibilities include managing and leading the team as well as electric motor selection and design, suspension setup, vehicle simulation, battery selection, battery exchange design, component installation, wiring, transmission selection, gear ratio selection, public relations, web page development, and fund raising.

Worked on a series HEV for the HEV Challenge and consulted with the WVU Future Car Team in the design of a series hybrid for a Chevy Lumina conversion.

\section{Computer Background}

Proficient programming in C, C++, MATLAB, Ada, Pascal, FORTRAN, BASIC, Motorola 68000 Assembly, Intel 80x86 Assembly, AutoCAD, Ansys

Fluent with DOS, UNIX, Windows 3.11, Windows 95, and Windows NT 4.0, as well as numerous software packages including finite element analysis, circuit and logic simulation, mathematical packages, spreadsheets, word processing and database applications.

Able to quickly learn and utilize new software and operating systems

Have experience interfacing with both Intel 80x86 and Motorola microprocessor based systems

\section{Graduate Control System Courses}

Fundamentals of Control Systems

Linear Control Systems

Optimal Control

Applied Nonlinear Control

Stochastic Systems Theory

Advanced Topics in Control Theory

Graduate Computer Courses

Neural Computers

Advanced Study of Fuzzy Logic
Graduate Power System Courses

Introduction to Power Electronics

Advanced Power Electronics and Drives

Advanced Electrical Machinery

Application of Digital Computers to Power System Analysis

Advanced Independent Study of Power System Harmonics

\section{Other Important Graduate Courses}

Internal Combustion Engines Statics

Sensors and Displays Dynamics

RF Systems 


\section{CAREER \\ RELATED EXPERIENCE}

\section{SCHOLARSHIPS}

\section{HONORS AND \\ ACTIVITIES}

\section{West Virginia University}

Research Assistant in the ElectroMechanical Systems Laboratory 1996 to present Worked on various research projects including a linear alternator/internal combustion engine combination for hybrid electric vehicle application and a brushless permanent magnet alternator system for automotive applications .

\section{West Virginia University}

Teaching Assistant 1994 to 1996

Taught second semester undergraduate circuits course as well as labs in circuits, signals, and systems. Assisted in teaching an electric vehicle course. Developed new design exercises and laboratory experiments

\section{Wheeling Pittsburgh Steel Corporation, Wheeling, WV 26003}

Electrical Engineering Summer Intern Summer 1992 and 1993

Worked as a project engineer in a steel mill environment on projects including rebuilding a fire damaged distribution substation, and installing secondary containment for acid and oil tanks and served on a modernization task force in a hot strip mill. Supervised projects including asbestos encapsulation, cable-pulling, and lighting system installation. Participated in digital and analog motor drive installation, cable scheduling, cable tray system design, and lighting system design.

West Virginia University Foundation Scholarship Bell Atlantic Scholarship
Eta Kappa Nu Electrical and Computer
President
Engineering Honor Society
Electrical and Computer Engineering Student
Advisory Board
President, Founding
Institute of Electrical and Computer Engineers (IEEE)
Member
Student Chairman,
Treasurer

Tau Beta Pi Engineering Honorary

The Honor Society of Phi Kappa Phi

Golden Key National Honor Society

Phi Mu Epsilon Math Honorary

Chimes Junior Honorary

Mountaineer Council

Alpha Phi Omega National Service Fraternity

West Virginia University Honors Program

Ohio Valley Youth Track League

Arnold Hall Council

Undergraduate President's List

Undergraduate Dean's List

The National Dean's List

Phi Kappa Phi Outstanding Freshman Award

\author{
Volunteer Coach \\ Treasurer \\ 8/10 Semesters \\ 10/10 Semesters
}


RECENT

PUBLICATIONS

HOBBIES AND INTERESTS

REFERENCES

William R. Cawthorne, Roy S. Nutter, Parviz Famouri, "Development of a High Performance Electric Race Vehicle Drive System." Proceedings of the Electrical Manufacturing and Coil Winding Association Hybrid and Electric Vehicle Racing Symposium 2, Cincinnati, Ohio, pp. 1-6, October 5, 1998.

William R. Cawthorne, Roy S. Nutter, Parviz Famouri, "Electric Race Vehicle Drive System Evolution," submitted to IEEE Transactions on Vehicular Technology, 1998

Nigel Clark, Subhash Nandkumar, Christopher Atkinson, Richard Atkinson, Thomas McDaniel, Sorin Petreanu, Parviz Famouri, William R. Cawthorne. "Operation of a Small Bore Two-Stroke Linear Engine," Proceedings of the 1998 Fall Technical Conference of the ASME Internal Combustion Engine Division, Vol. ICE 31-1, p 33-40, 1998.

Parviz Famouri, William R. Cawthorne, Nigel Clark, Christopher Atkinson, Richard Atkinson, Thomas McDaniel, Subhash Nandkumar, Sorin Petreanu, "Design and Testing of a Novel Linear Alternator and Engine System for Remote Electrical Power Generation," Proceeding of the IEEE Power Engineering Society Winter Meeting 1999, p 108-112, Jan. 31-Feb. 4, 1999.

William R. Cawthorne, Parviz. Famouri, J. Chen, Nigel Clark, Christopher Atkinson, Richard Atkinson, Thomas McDaniel, Subhash Nandkumar, Sorin Petreanu "Development of a Linear Alternator-Engine for Hybrid Vehicle Applications", accepted for publication in IEEE Transactions on Vehicular Technology, 1999.

Parviz Famouri, William R. Cawthorne, "Power System Harmonics." Encyclopedia of Electrical and Electronics Engineering, John Wiley and Sons, New York, NY, 1998.

Sports, water-skiing, maintaining and repairing my personal automobiles, camping, racing, reading, home repair and improvement, Amateur Radio (KB8VVS)

Dr. Roy S. Nutter

Professor, CSEE

West Virginia University

925 Engineering Sciences Building

P.O. Box 6109

Morgantown, WV 26506-6109

(304) 293-6371 Ext. 2510

Mark S. Lesonick

Whemco

P.O. Box 438

West $7^{\text {th }}$ Avenue

Homestead, PA 15120

(412) 464-4400
Dr. Parviz Famouri

Professor, CSEE

West Virginia University

Engineering Sciences Building

P.O. Box 6109

Morgantown, WV 26506-6109

(304) 293-6371 Ext. 2530

John Albaugh

Wheeling Pittsburgh Steel

Corporation

Steubenville South Plant

Mingo Junction, Ohio 43938

(740) 283-5193 